\title{
فلسفة التربمة الفلسفية وشروط الإبداع الحضاري
}

\section{1 أبو يعرب المرزوقي}

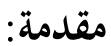

يمكن الافتراض بداية، أن إشكالية الترجمة تمثل ما يمكن اعتباره التجربة الحاسمة في علاج قضية

طبيعة التعبير عامة والتعبير المبدع خاصة. فهذا العلاج يمكن أن يبين أن التعبير اللساني ليس مميزا للإنسان، إلا بوصفه قمة جبل الثلج الرمزي المميز للإنسان. وأن الإبداعات غير اللسانية، أو التي تتوسل إلى ضروب الترميز الأخرى، هي التي تسهم أكبر إسهام في المستوى الرمزي، من الإبداع الحضاري المحدد لدلالات المستوى الفعلي منه. ويشمل هذا القانون كل الحضارات؛ رغم أنه لم يصل إلى درجة الوعي الصريح إلا في حضارات الكتابة والكتاب. فبالنسبة إلى المسلمين، لا يمكن تصور المسلم قادرا على فهم الإبداع -فضلا عن الإسهام فيه- دون المرجعية الرمزية، التي يمثلها بدرجة أولى مستويا الإبداع القرآين: (إبداع القرآن المكي، وإبداع القرآن المدني)، ومستويا الإبداع الحديثي: (إبداع الحديث القدسي، وإبداع الحديث العادي) بدرجة ثانية. فهو لا يفهم الطبيعة والتاريخ وما بعدهما، ومن ثم لا يتصور لهما تفسيرا يساعد على إبداع نظرياتما دون آيات القرآن المكي، كما لا يفهم علاقته بالطبيعة والتاريخ دون آيات القرآن المدني. كما أنه لا يتصور عينة نموذجية من النفاذ إلى معاني القرآن المكي في غير الحديث القدسي، ولا عينة نموذجية من النفاذ إلى معاني القرآن المدني في غير الحديث العادي. وكل هذه الأبعاد تدور في وعيه الغائم أو الصافي، حول لحظة التاريخ الصدرية في إبداع التاريخ الفعلي، وحول القصص القرآني في إبداع التاريخ بالقص الرمزي استعادة واستيحاء. ولما كان عدد المسلمين الناطقين بالعبية دون عشر المسلمين، باتت الترجمة التي نحاول تحديد فلسفتها، السبيل الوحيدة لفهم هذا الإبداع الإسلامي في الماضي، والإسهام فيه في المستقبل. لكن إذا صحت نظريات الترجمة التي تقصرها على التناظر المستحيل بين الألسن، بات فهم الإبداع الإسلامي والإسهام فيه مقصورا على العرب.

وسيعجب الكثير من السطحيين مما سيجده من الإشارات الدينية الكثيرة -والإسلامية منها على

وجه الخصوص- في هذه المحاولة، فيظنها انحرافا عن غرض العلاج الفلسفي: وكأن فلسفة الدين لا تعدّ فلسفة لمجرد كون موضوعها دينيا. لكن من يتدبر الأمر بعمق سيدرك أن ذلك مما ليس منه بد؛ فنحن نتكلم

1 أستاذ الفلسفة اليونانية والعربية بجامعة تونس الأولى. يدرس حاليا على سبيل الإعارة فلسفة التاريخ والدين والفكر النقدي الإسلامي في الجامعة الإسلامية العالمية بماليزيا. abouyaareb@yahoo.com 
في الترجمة التي هي أداة التواصل الأساسية بين الثقافات، فضلا عن كوها شرط كل إبداع في صياغة قوانين

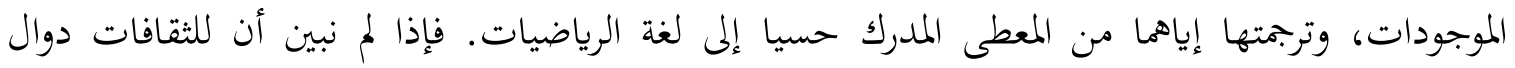

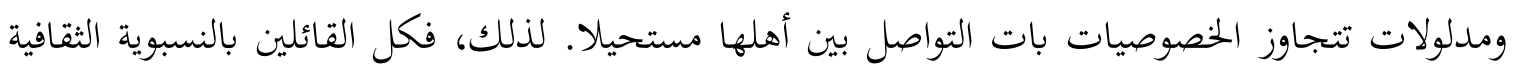

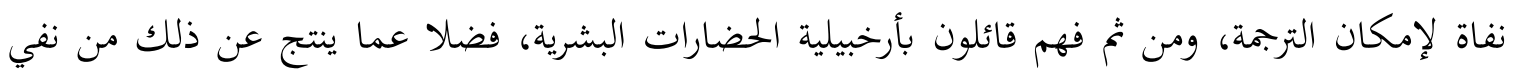

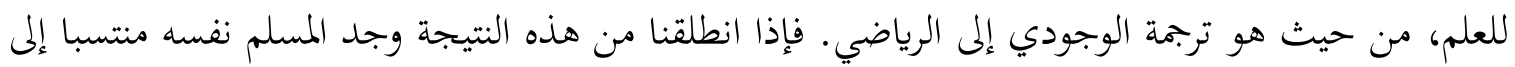

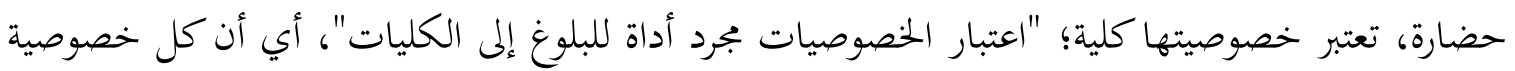
بمجرد إدراكها خصوصيتها تتجاوزها. لذلك فالإسلام يؤسس لنظرية التعارف بين الشعوب والقبائل غاية،

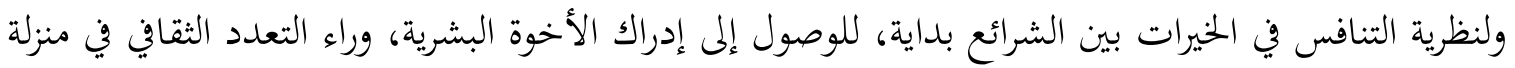
المستخلفين الذين يوحدهم سلبا الكفر بالطاغوت الثقافي، الكفر الذي يرمز إليه نقد القرآن لتقليد الآباء

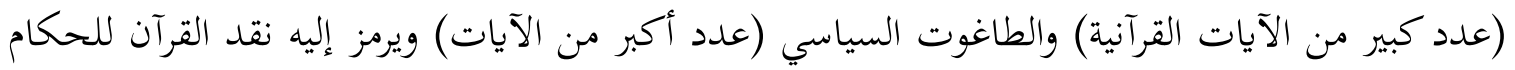

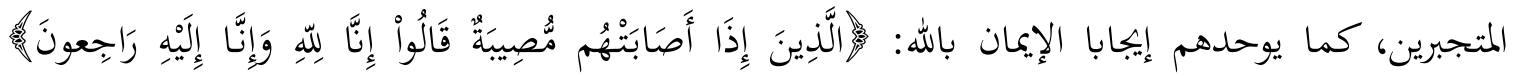
(البقرة: 156). ولعل آيتي الميثاق (الأعراف: 172-173) بحمع كل هذه المعاني نفيا للاحتجاج بتأثير التربية أو بالوراثة العضوية. فكيف لا يكون قول الرسول محمد لهُ

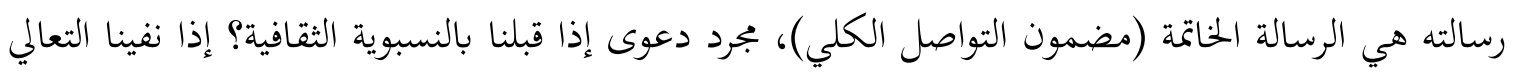
عن الثقافي نفيا مطلقا فاعتبرنا الترجمة ممتنعة بإطلاق، كيف يمكننا تصور القرآن قابلا لأن يكون كتاب إنهاب المسلمين جميعا وليس مقصورا على العرب منهم دون سواهم؟ تلك هي العلة في حصرنا النسبوية الثقافية، في مستوى الأدوات والغايات التدافعية، ورفضنا إطلاقها إلى مستوى الأدوات والغايات التعارفية.2 2

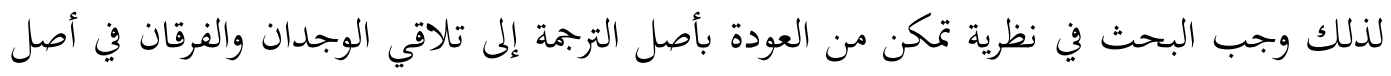

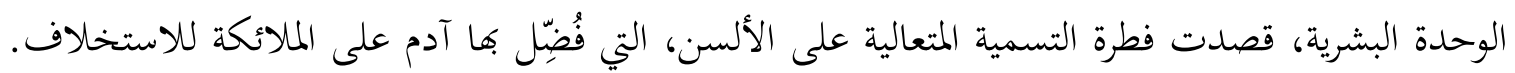

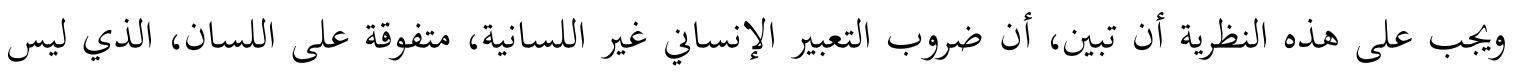
إلا ترجمتها إلى نظام رمزي خاص بمنظور حضارة معينة، لضروب التعبير العامة التي تشترك فيها كل الظاهرات

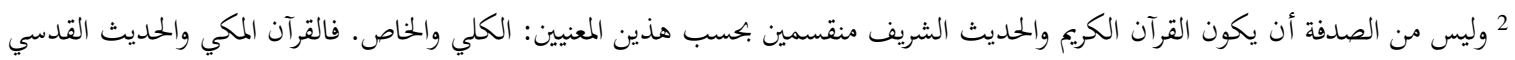

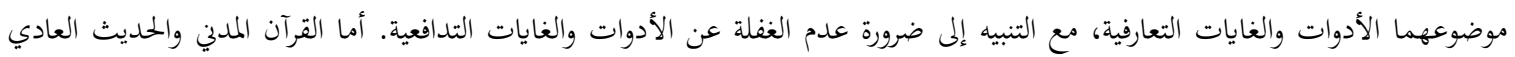

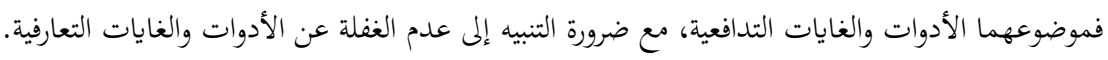

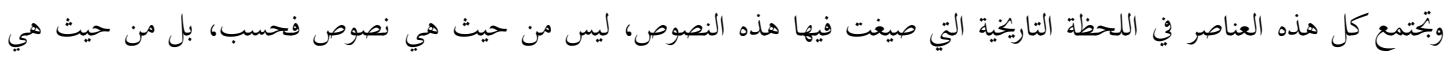

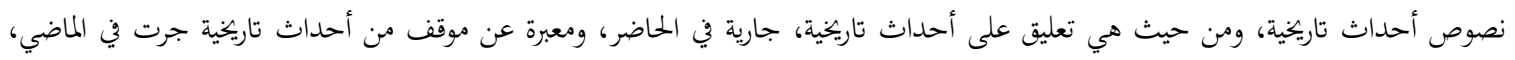

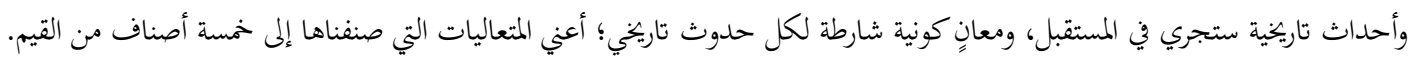


الحية، بل وكل الموجودات، فضلا عن الحضارات البشرية. وتتم هذه الترجمة المتعالية على الألسن، بآليتي

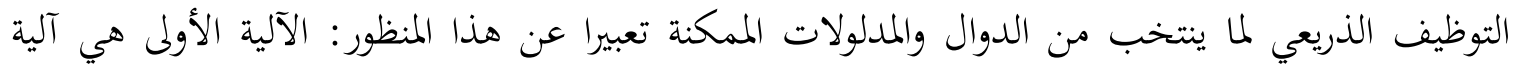
إدخال الانفصال الصريف على الاتصال الصوتي لحصر الوحدات الصوتية، كما يحصل في الحروف التي تعتمد

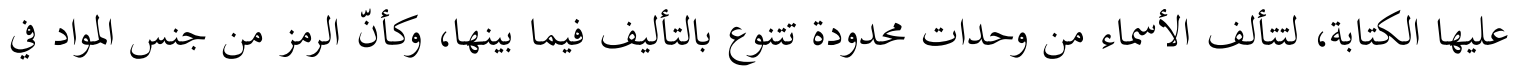

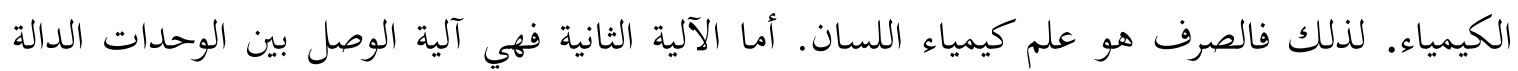
المؤلفة من تلك العناصر، لجعل المعاني بدورها مؤلفة من وحدات قابلة للحصر شكلا لا مضمونا، من خلال حصر قوانين التأليف. فيكون النحو بالقياس إلى اللسان كالفيزياء بالقياس إلى الطبيعة. وبذلك يكون اللسان الطبيعي مؤسسة اجتماعية، تفصل الإنسان من صلتيه بما يحيط به من الطبيعة وما وراء الطبيعة، ليحصر الترميز في الثقافي الحضاري الذي تَبْني عليه السوفسطائية المحدثة (ما بعد الحداثة) حصرها الإنسان في

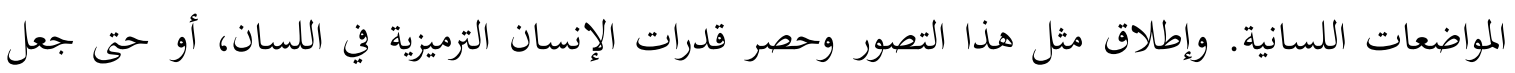

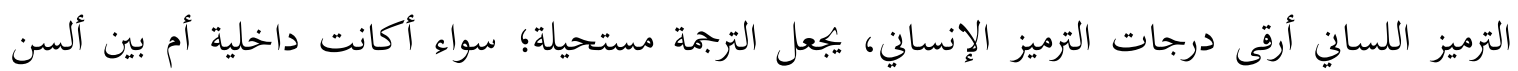
مختلفة.

وما دون الصرف يعيد إلينا اتصال الصوت المطلق، فيرجعنا -من ثم- إلى كل الأنظمة الصوتية التي يمكن أن تكون رموزا (الطبيعة). وما فوق النحو يعود بنا إلى التأليف المطلق، فيرجعنا -من ثم- إلى كل

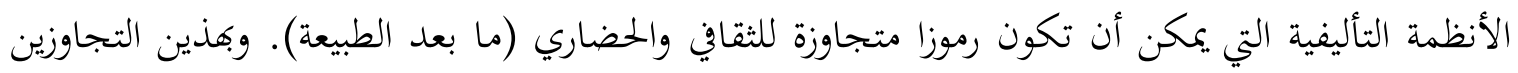

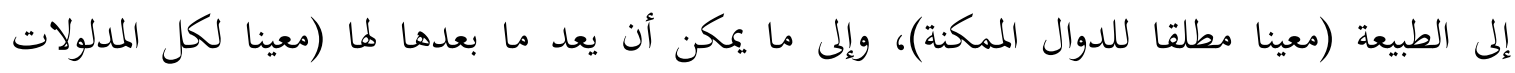

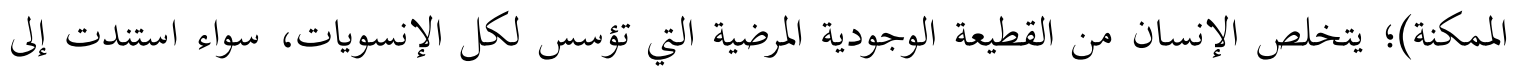

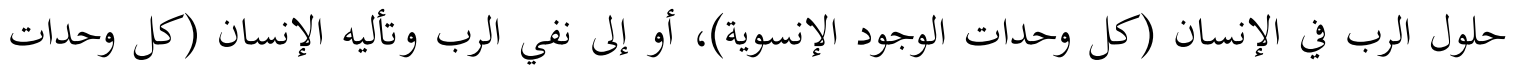
الوجود الطبعوية). فنجد التأليف اللامتناهي لمادة الدال، وراء المنفصلات الصرفية المنتجة للسان الطبيعي الخاص بشعب معين أو بحضارة معينة، ولنسمّهه موسيقى؛ وهذه التأليفات اللامتناهية أو الموسيقى قابلة لأن تكون أداة تواصل بين كل البشر، بل وبينهم وبين كل الموجودات الطبيعية. كما نجد التأليف اللامتناهي

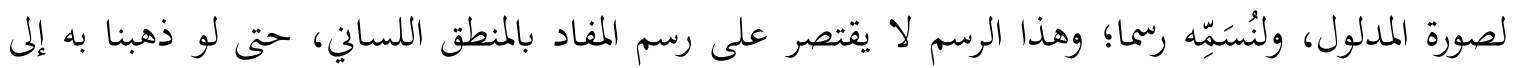
حد مدونة أرسطو (المصنفات الثمانية؛ كوفا جميعا تتعلق بالتأليفات المقصورة على اللساني)، بل يتعداه إلى إلى

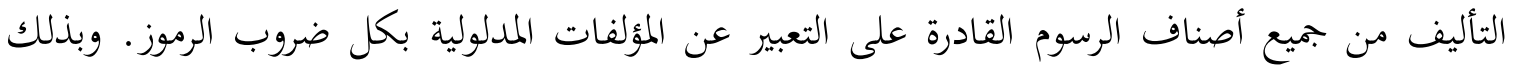
يجيط هذان التجاوزان -كل الطبيعة وكل ما بعدها- باللسان الإنساني، فيربطانه بما يتصوره الفلاسفة دون الرموز اللسانية وما فوقها، أعني يربطانه بكل الرموز ما كان منها طبيعيا، وما كان وضعيا، أي بالمفهوم الأعم الذي هو كون كل موجود رمزَ ذاته بذاته. فيربطه هذان التجاوزان بمفهوم الآية، التي تجعل كل موجود رمز كل 
الوجود بمنزلته فيه المنقوشة في ذاته. لذلك فهو يدرك بقيامه الذاتي وبمنزله في منظومة الموجودات، فيكون

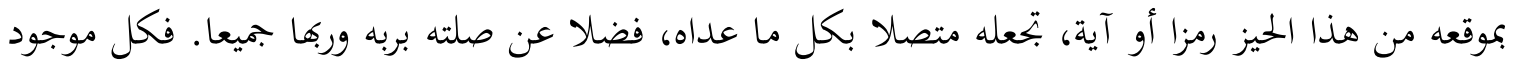
يمكن أن يكون رمزا لغيره ومرموزا إليه بغيره، في نظام رمزي كوين، هو شرط التواصل، ليس بين الناس فحسب؛ بل بين كل الموجودات في تبادها التأثير والتأثر، وفي علمها وعملها، فضلا عن كل ضروب التقويم التي يعود إليها إدراك الإنسان لهذه الأواصر بين الموجودات: (الذوقي، والرزقي، والنظري، والعملي، والوجودي).

لذلك فإن هذه الدراسة سوف تحاول فهم شروط الترجمة الفلسفية: تجريبيا؛ من خلال علاج بعض

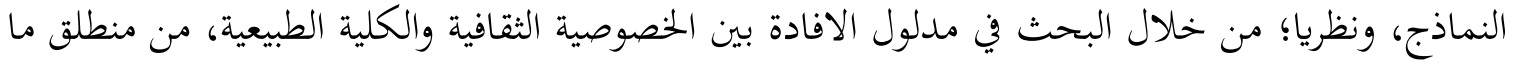

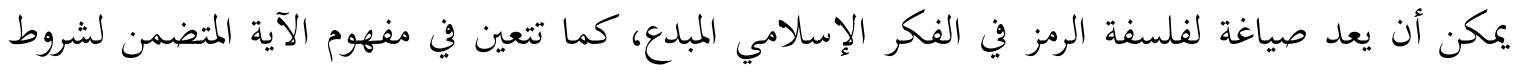

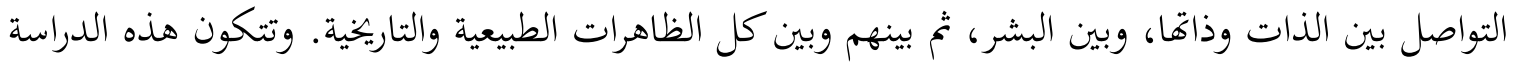
من ثلاث مسائل رئيسة: المسألة الأولى هي محاولة تطبيقية لتحديد العقبات الزائفة في الترجمة؛ من خلالئل

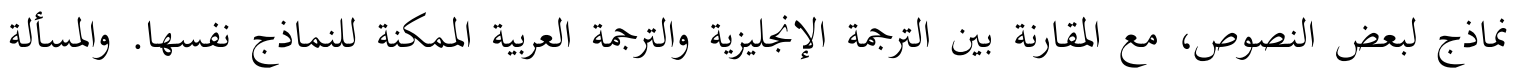
الثانية هي محاولة نعالج فيها طبيعة العقبات التي تعترض فعل الترجمة؛ من خلال العلاقة بين التعبير اللساني

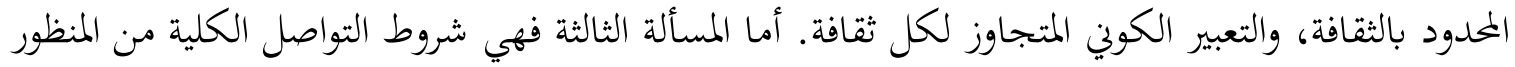
القرآي ومقوماته؛ من حيث هو أصل كل ابداع رمزي وفعلي في الحضارات البشرية. ونغتم المحاولات الثلاث

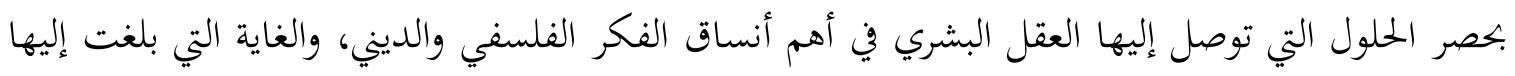
الرسالة الخاتمة، لتجاوز ما في الحلول من فصام يقضي على وحدة البشرية؛ وحدة الشخص بداية، ووحدة

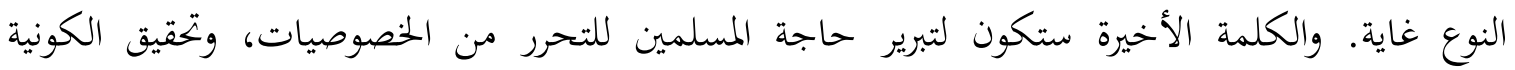
الإسلامية التي هي أساس الختم والتوجه للعالمين.

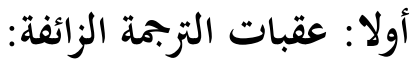

لن نقدم بعض الفرضيات حول محددات عملية الترجمة، قبل أن نضرب أمثلة تبين قابلية أي نص أصل

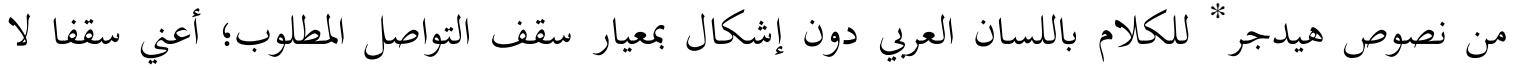
* لا أتصور أحدا من المثقعين المعاصرين يجهل هيدجر الفيلسوف الألماني الأخير من هو. وذلك لعلتلتين؛ فنظرياته اللسانية والتأويلية أولا

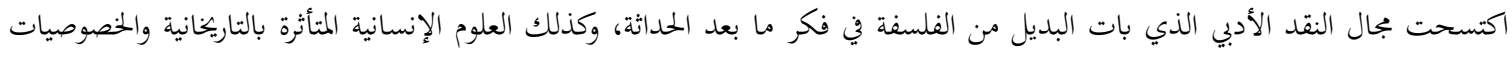

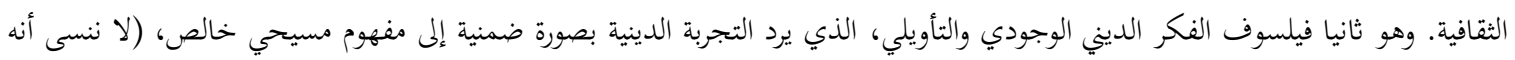

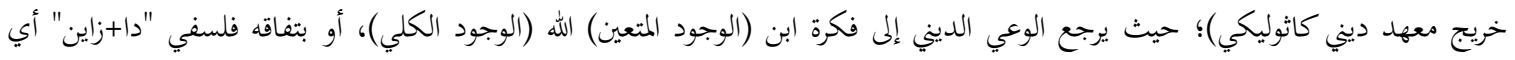

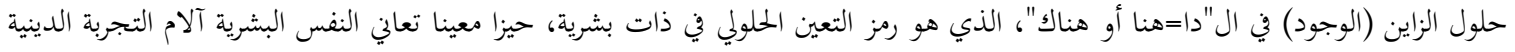


يتجاوز ما هو ممكن بترجمة النص إلى أي لغة أخرى؛ سواء أكانت من جنس اللسان الألماني أم من جنس

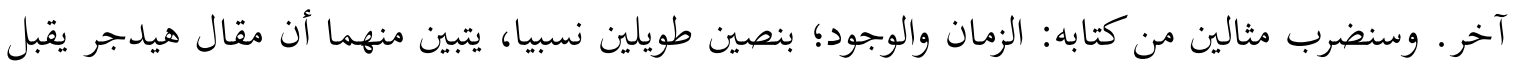

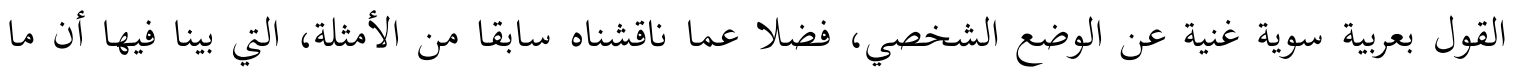
يتصوره المترجمون عقبات، لا وجود له إلا عند من يسعى إلى محاكاة خصائص الدال في اللغة المنقول عنها،

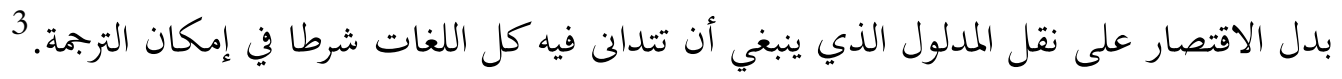

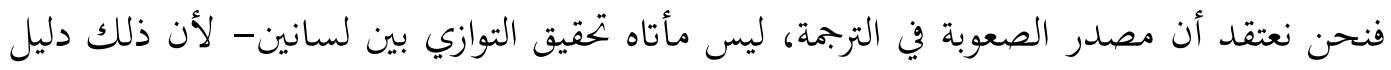

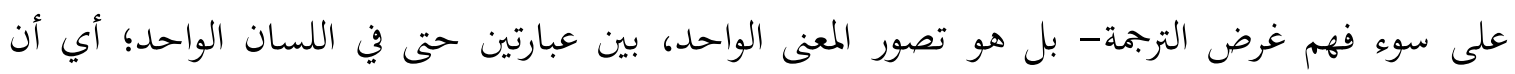

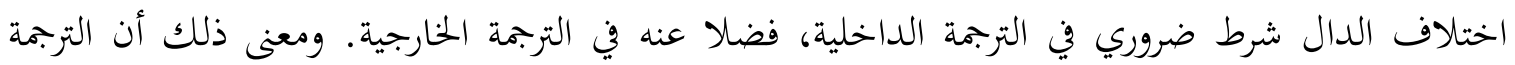

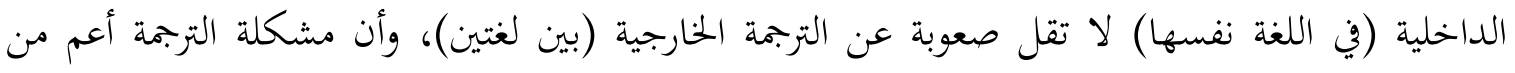

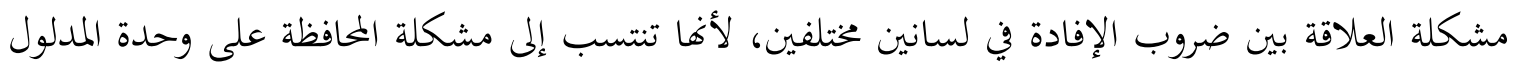

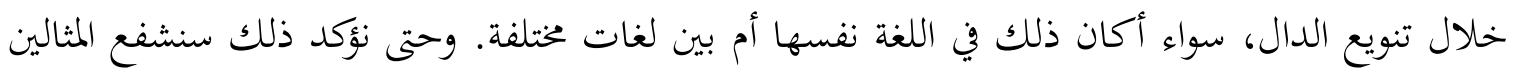

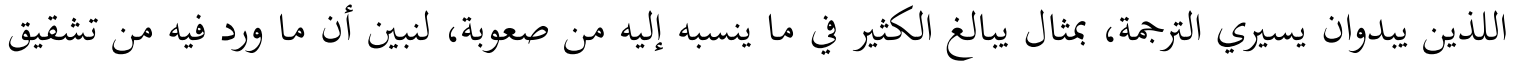

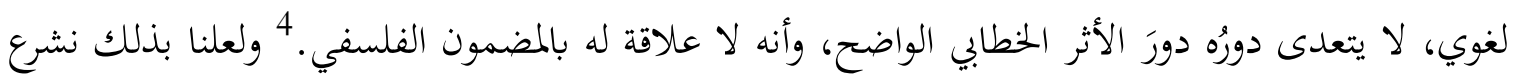

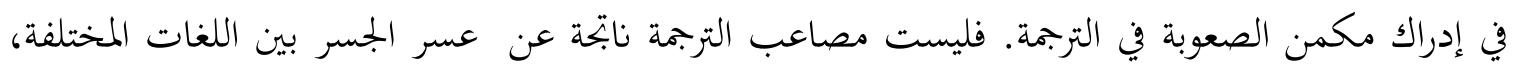

أو آلام المسيح. والمقصود بالآلام الوجود الدنيوي نفسه، لا إلى التعذيب الفعلي الحاصل على شخص النبي المسيح في الأرض المغصوبة. والمعلوم

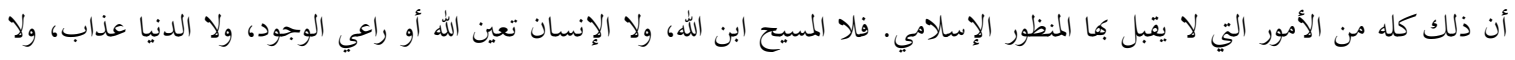

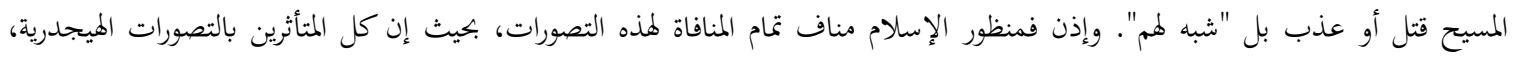

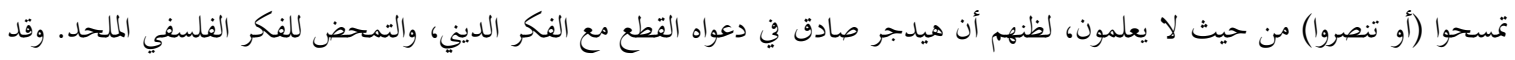

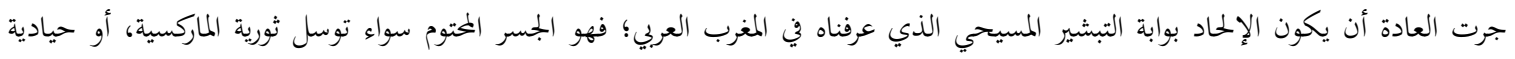

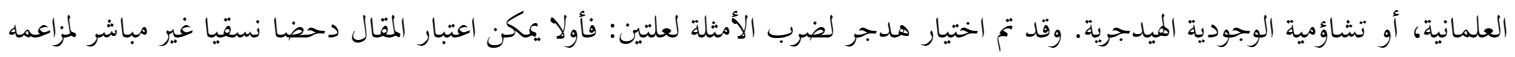

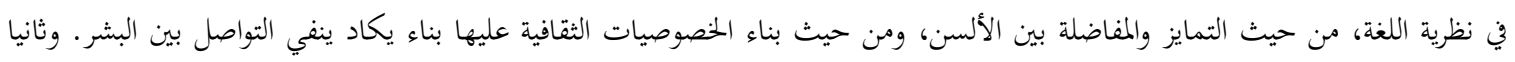

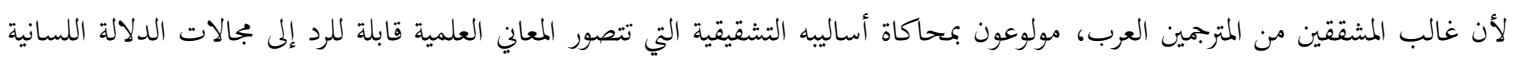
الغفلة. 3 انظر مقالا لنا بعنوان: "مفارقات الترجمة الفلسفية العربية: العقبات والحلول"، يصدر قريبا إن شاء الله في مجلة الفكر العربي المعاصر ببيروت يصدرها مركز الإنماء القومي، الأستاذ مطاع صفدي.

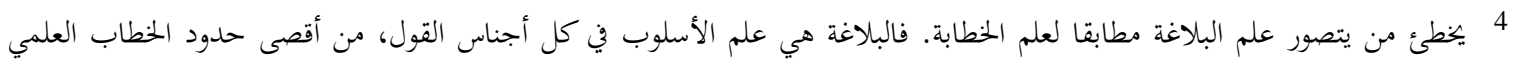

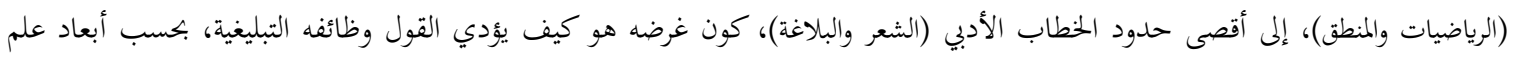

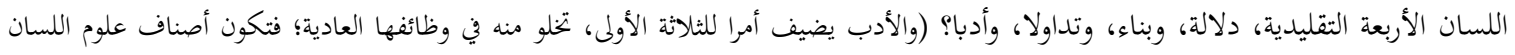

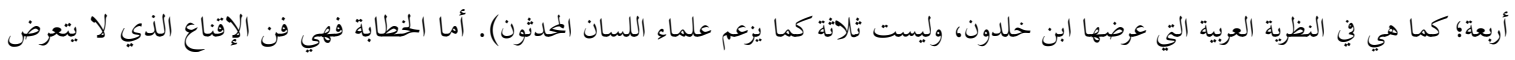

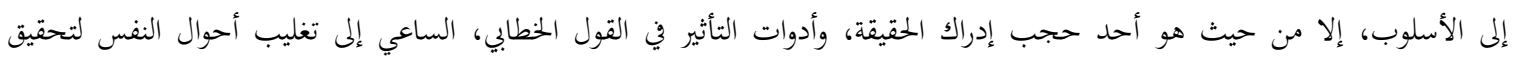

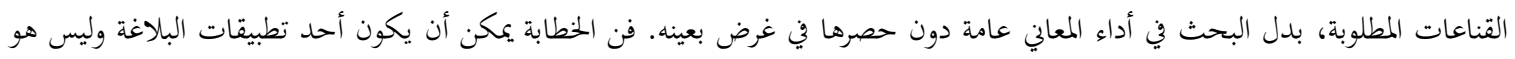
إياها - وليس البلاغة ذاتما. 


$$
\begin{aligned}
& \text { بل هي تصدر عن صعوبة المحافظة على وحدة المدلول عند تغيير الدال، وصعوبة المحافظة على وحدة الدال } \\
& \text { عند تغيير المدلول، سواء أكان ذلك في اللغة نفسها أم في لغتين مختلفتين. ومن ثم فعسر الترجمة هو عينه } \\
& \text { عسر التعبير الرمزي عامة، كيف نحقق التوازي بين التناهي الدالي واللاتناهي المدلولي، تحقيقا يخلصنا من } \\
& \text { المحاولة اللامتناهية لتحقيقه، المحاولة التي هي عاهة تنخر كل محاولة للتعبير الإنساني. فكيف نضمن وحدة } \\
& \text { الرامز عند تعديد المرموز، ووحدة المرموز عند تعديد الرامز، أو على الأقل؛ كيف نبقي على وحدة إدراكهما، } \\
& \text { إذا لم يكن ذلك مستندا إلى مواضعتين: أولاهما تتعلق بالحد الذي نعتبر فيه ما دونه من الفروق مقبولا، كونه } \\
& \text { لا يناقض الوحدة بل يبقي عليها، وثانيتهما تتعلق بالتبيت المتناوب للدال؛ لندرس تغير المدلول، أو } \\
& \text { للمدلول؛ لندرس تغير الدال. }
\end{aligned}
$$

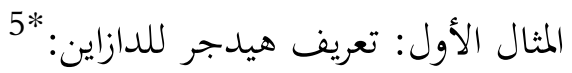

$$
\begin{aligned}
& \text { "يكمن جوهر هذا الموجود في استعداده إلى أن يكون. ف"ماهية" (إيسانسيا) هذا الموجود ينبغي - } \\
& \text { إذا صح أصلا لنا أن نتكلم عن ماهية ننسبها إليه- أن نتصورها من منطلق وجوده (الإنية: إكزيستنسيا). }
\end{aligned}
$$

* "دازاين" كلمة ألمانية مؤلفة من "دا" اسم إشارة في المكان بدلالتي هنا وهناك، و"زاين" بمعنى الوجود. وهي تعني العين الموجودة المشار، إليها

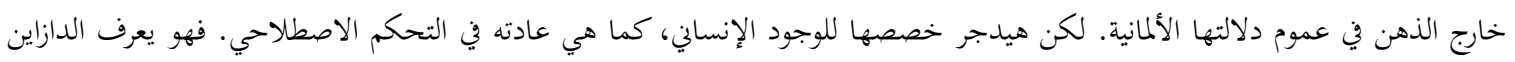

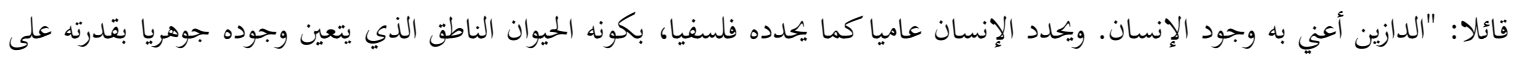

"Das Dasein, d.h. das Sein des Menschen ist in der vulgaeren ebenso wie in der philosophischen 'Definition' umgrenzt als 'xuon logon exon', das Lebende, dessen Sein wesenhaft durch das Redenkoennen bestimmt ist”'(S.u.Z. p.25)

5 'Das 'Wesen' dieses Seienden liegt in seinem Zu-sein. Das Was-sein( essentia) dieses Seienden muss, sofern ueberhaupt davon gesprochen wierden kann، aus seinem Sein ( existentia) begriffen werden. Dabei ist es gerade die ontologische Aufgabe zu zeigen, dass, wenn wir fuer das Sein dieses Seinden die Bezeichnung Existenz waehlen' dieser Title nicht die ontologische Bedeutung des ueberliferten Teminus existentia hat und haben kann; existentia besagt nach der Ueberliferung ontologish soviel wie Vorhandensein، eine Seinsart, die dem Seienden vom Charakter des Daseiens wesensmaessig nich zukommt. Eine Verwirrung wird daduch vermieden, dass wir fuer den Title existentia immer den interpretierenden AusdruckVorhandanheit gebrauchen und Existenz als Seinsbestimmung allein dem Dasein zuweisen. Das 'Wesen' des Daseins liegt in seiner Existenz. Die an disem Seienden herausstellbaren Charaktere sind daher nicht vorhandene 'Eignenschaften' eines so und so 'aussehenden' vorhandenen Seienden، sondern je ihm moegliche Weisen zu sein und nur das. Alles so-sein dieses Seienden ist primaer Sein. Daher drueckt der Titel 'Dasein', mit dem wir dieses Seiende bezeichnen، nicht sein Was aus, wie Tisch, Haus, Baum, Sondern das Sein." ( Heidegger، Sein und Zeit, Max Niemeyer Verlag، Tuebingen, 2001 s.42)

$$
\text { النص الانجليزي: }
$$

“The 'essence' [Wesen] of this entity lies in its 'to be' [Zu-sein]. Its Being -what-it-is [Was-sein] (essential) must, so far as we can speak of it at all, be conceived in terms of its Being (existentia). But here our ontological task is to show that when we choose to designate the Being of this entity as 'existence [Existenz], this term does not and cannot have the ontological signification to the traditioanal term 'existentia'; ontologically, existential is tantamount to entities of Dasein's character. To avoid getting bewildered, we shall always use the Interpretative expression 'presence-at-hand' for the term 'existentia', while the term 'existence', as a designation of Being, will be allotted solely to Dasein"( p.67 
والمهمة الأنطولوجية المباشرة هي أن نبين أننا عندما اخترنا أن نسمي وجود هذا الموجود ب"الوجود: إكسيستنتس" فإن مدلول هذا العنوان ليس الدلالة التي لمصطلح "الإنية: إكزيستنسيا" الوجودية في الموروث،

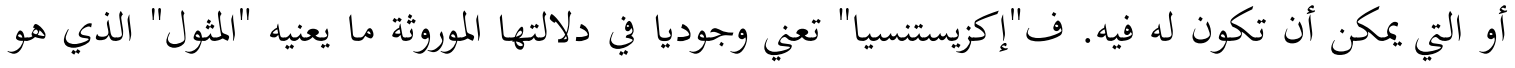
ضرب من التأنن لا يلائم جوهريا موجودا له خاصية الدازاين المميزة. ومن ثم فإننا نتجنب اللبس باستعمالنا

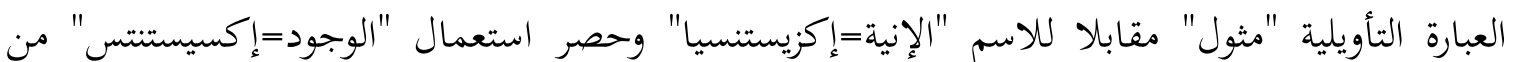
حيث هي حد وجودي للدلالة على الدازاين." إن جوهر الدازاين يكمن في وجوده. لذلك فإن ما يقبل التحرير من خاصيات هذا الموجود، ليس صفات قائمة الوجود لموجود يبدو على هذه الصورة أو تلك، بل هو دائما كيفيات استعداده لأن يكون ولا شيء غير ذلك. وكل وجود لهذا الموجود على هذه الصورة أو تلك هو بدءا وجود. ومن ثم فإن العنوان "دازاين" الذي نعرف به هذا الموجود لا يفيد "ماهية" (مثلما هو

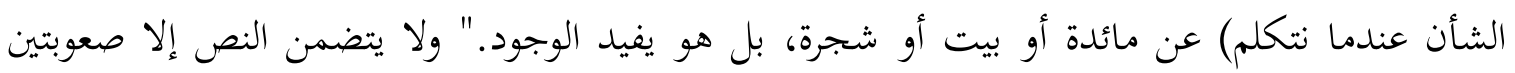

$$
\text { يسيرتي الحل دون مساس بالتقليد الفلسفي العربي: }
$$

أما الصعوبة الأولى: فهي المقابلة إكزيستنسيا وإكسيستنتز، والفرق في الدال هو نطق الأولى باللاتينية والثانية بالألمانية. وملا كنا لا نملك مثل هذه الإمكانية كون اللاتينية ليست أصلا للمقابل العربي، بات من الواجب أن نتواضع على مناظرة المقابلة بمقابلة مماثلة بين الإنية (التي نشتقها من إن العربية جزما

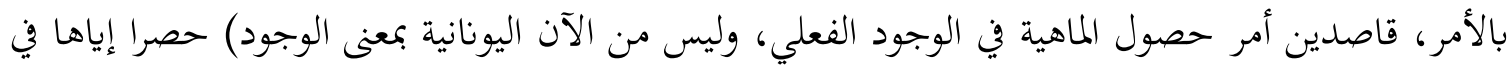
المدلول العام للوجود من حيث هو ما يقابل الماهية، والوجود بمعنى إكسيستنتس. ولسنا نفعل ذلك تحكما بل بقصد المحافظة على ما استقر من استعمال صارت تسمى به الفلسفة الوجودية. ولولا هذا الاستعمال

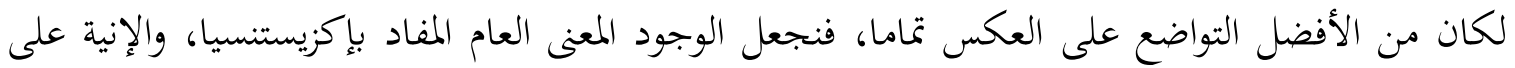
المعنى الخاص المفاد بإكسيستنتس. وأما الصعوبة الثانية: هو ترجمة "فورهندهايت". وقد فضلنا ترجمتها بالمثول، قاصدين المثول المجرد من كل توظيف بين يدي المدرك؛ بمعنى الحضور المتقدم على التوظيف الإنساني، كما في فورهندنزاين المقابلة

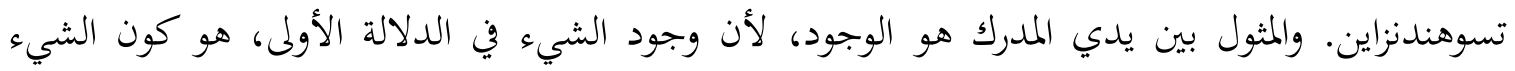

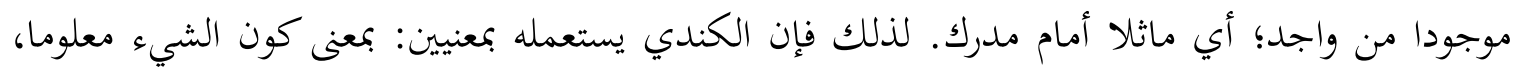

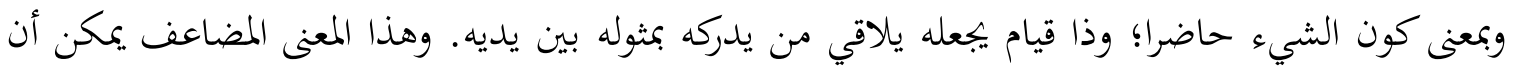

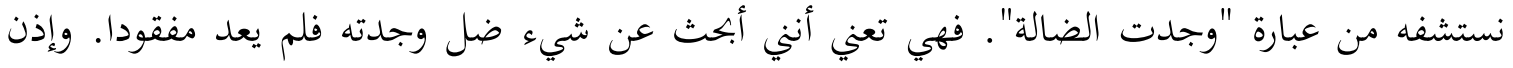

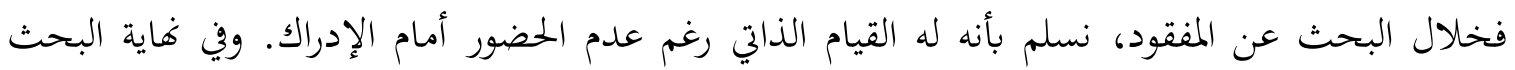
يصبح الموجود موجودا بالمعنيين: موجودا بذاته وموجودا عند الإدراك. 


$$
\begin{aligned}
& \text { أما المثال الثاني: فتعريف هيجدر للفلسفة:6 بأفها "نظرية الوجود والظاهراتية ليستا فنين مختلفين } \\
& \text { موجودين بجوار غيرهما من الفنون المنتسبة إلى الفلسفة، بل كلتا التسميتين تمثل خاصية الفلسفة ذاتما، من } \\
& \text { حيث موضوعها وطبيعة علاجها. فالفلسفة هي نظرية الوجود الظاهراتية التي تنطلق من تأويلية الدازاين؛ } \\
& \text { تأويليته التي تثبت فيها -من حيث هي تحليلية الكينونة- غاية الخيط الناظم لكل تساؤل فلسفي بوصفها } \\
& \text { مصدر التساؤل ومورده. ويقتضي تحصيل تصور الوجود الأساسي، ورسم ما يتطلبه من تصورية الوجودية } \\
& \text { وتغيراقما الضرورية نظاما هاديا متعينا. ذلك أن كلية تصور الوجود لا تناقض خصوصية البحث؛ أعني الولوج } \\
& \text { إليه عن طريق تأويل مخصوص لموجود معين، تأويل، الهنيس (من هنا + أيس لترجمة دا+زاين)، تأويله الذي } \\
& \text { ينبغي أن يستمد منه أفق الفهم والتأويل الممكن للوجود. لكن هذا الموجود هو ذاته موجود تاريخي؛ حيث إن } \\
& \text { الإنارة الوجودية الذاتية النافذة إلى أعماق هذا الموجود، لا بد أن تنقلب -ضرورة- إلى تأويل "تأريخي." } \\
& \text { أما النص الثاني، فإني لم أجد فيه صعوبة واحدة تذكر. ومن ثم فنقله لا يطرح قضايا اصطلاحية، بل } \\
& \text { فقط خيارات أسلوبية ليس من الصعب أداؤها بلسان عربي فصيح. ولعل هناك من يزعم أننا قد اخترنا نصين } \\
& \text { بسيطين وبتحبنا النصوص التي فيها قضايا مستعصية على الحل. لكننا في الحقيقة أخذنا النصين اللذين يعرفان } \\
& \text { المفهومين الرئيسين، اللذين يتضمنهما عمل هيدجر، وإليهما تعود كل الحبكات التي تنسب إلى المؤلف. أما } \\
& \text { المستعصي من الأساليب - كما في التعامق حول السؤال- فسنأخذه مثالا في حينه بعد أن حسمنا القضايا } \\
& \text { الوهمية المتعلقة بنوعي التركيب النحتي. }
\end{aligned}
$$

6 Ontologie und Phaenomenolgie sind nicht zwei verschiedene Disziplinen neben anderen zur Philosophie gehoerigen.Die beiden Titel charaketerisieren die Philosophie selbst nach Gegenstand und Behandlungsart. Philosophie ist universale phaenomenologische Ontologie, ausgehend von der Hermeneutik des Daseins, die als Analytik der Existenz das Ende des Leitfadens alles philosophischen Fragens dort festgemacht hat، woraus es entspringt und wohin es zuruckschlaeg (...) Die Gewinnung des Grundbrgriffes 'Sein' und die Vorzeichnung der von ihm geforderten ontologischen Begrifflichkeit und ihere notwendigen Abwandlungen beduerfen eines kondreten Leitfadens. Der Universalitaet des Begriffes von Sein widerstreitet nicht die 'Spezialitaet der Untersuchung-d.h.das vordringen zu ihm auf dem Wege einer speziellen Interpretation eines bestimmten Seienden, des Daseins, darin der Horizont fuer Verstaendnis und moegliche Auslegung von Sein gewonnen werden soll. Dieses Seiende selbst aber ist in sich 'geschchtlich', so dass die eigenste ontologische Durchleuchtung dieses Seienden notwendig zu einer 'historischen' Interpretation wird." S.und Z..s.38 and 439- s. 39.

$$
\text { النص الانجليزي: }
$$

"Ontology and phenomenology are not two distinct philosophical disciplines among others. These terms characterize philosophy itself with regard to its object and its way of treating that object. Philosophy is universal phenomenological ontology, and takes its departure from hermeneutic of Dasein, which, as an analytic of existence, has made fast the guiding-line for all philosophical inquiry at the point where it arises and to which it returns"( p.62) 
أما المثال الثالث: فبنية السؤال العامة:7 "ومن ثم فلا بد من شرح الأمور التي تنتسب إلى السؤال بصورة عامة، حتى نجعل مسألة الوجود مسألة بينة الحدود. فكل سؤال طلب، وكل طلب يهتدي بمطلوبه السابق. إن السؤال طلب "إن (ية)" الموجود، و "كيف (هو)" طلب على علم. وهذا الطلب يمكن أن يصبح "بحثا" يحرر فيه السائل حد مطلوبه الذي يتعلق به السؤال. فالسؤال من حيث هو طلب أمر... يكون ذا مطلوب. وكل "سؤال عن أمر" هو بنحو ما "مساءلة لأمر ما". فالطلب يقتضي -بالإضافة إلى الأمر المطلوب- أمرا يطلب منه المطلوب. وفي البحث أعني في السؤال ذي الطبيعة النظرية، ينبغي أن يحدد المطلوب تحديدا يرفعه إلى درجة التصور العقلي. وإذن ففي حصيلة الطلب يكمن بالذات مقصود الطلب، أو ما لأجله يكون السؤال. والسؤال ذاته له من حيث هو سلوك موجود -سلوك السائل- خاصية ميزة للوجود. ويمكن لمذا السلوك المميز أن يحصل في شكل سؤال غفل، أو في شكل مساءلة صريحة. وتتمثل خاصية الضرب الثاني في أنه يكون في المقام الأول بينا من حيث كل الخصائص المقومة للسؤال ذاته." هل في هذا النص صعوبة تذكر تعترض الترجمة نعم، إذا أراد المترجم أن يختار استراتيجية التعبير نفسها؛ فيفرض على لغته أن تقول المدلولات التي يفيدها النص، بمشتقات من دال واحد أو دالين اثنين لا، أكثر كما يماول هيجدر أن يفعل في نصه. لكن ذلك ليس ضروريا رغم أنه ليس مستحيلا، فضلا عن أن مفعوله لا يتجاوز الوقع الخطابي (rhetorical effect) الذي يمكن أن يثير الاعجاب بقدرات المؤلف اللسانية، لكنه لا يقدم التحليل العلمي ولا الفهم الفلسفي. لذلك، فعندما يفكر المترجم حقا، ولا يكتفي بنقل الدال بدل المدلول، فإنه لن ينشغل هذا الأمر، بل يحاول أن يقول ما أراد هيدجر قوله إن كان حقا قد فهم قصده؛ فيطلب المجالات الدلالية التي تعنى بها الفلسفة. والمعلوم أن هذه المجالات لا تحددها الوحدة التواردية المستندة إلى

7 "Daher muss kurz eroertet warden, was uberhaupt zu einer Frage gehoert, um von da aus die Seinsfrage als eine ausgezeichenete sichbar machen wu koennen. Jedes Fragen is ein Suchen. Jedes Suchen hat sein vorgaiengiges Geleit aus dem Gesuchten her. Fragen ist erkennendes Suchen des Seinden in seinem Dassund Sosein. Das erkennende Suchen kann sum 'Untersuchen' warden als dem freilegendenden Bestimmen dessen، wonach die Frage stehet. Das Fragen hat als Fragen nach...sein Gefragtes. Alles Fragen nach...is in irgendeiner Weise Anfragen bei...Zum Fragen gehoert ausser dem Gefragten ein Befragtes .In der untersuchenden, d.h.spezifisch theoretischen Frage soll das Gefragte bestimmt und zu Befriff gebracht warden. Im Gefragten liegt dann als das eingentlich Intendirte das Erfrage, das, wobei das Fragen ins Ziel knommt. Das Fragen selbst hat als Verhalten eines Seinden, des Fragers, einen eigenen Charakter des Seins. Ein Fragen kann vollzogen warden als 'Nur-so-hinfragen' oder als explizite Fragestellung. Das eigentuemliche dieser liegt darin, dass das Faragen sich zuvor nach all den genannten konstitutiven Charakteren der Frage selbst durchsitig wird. "( S.und Z.، s.5) 


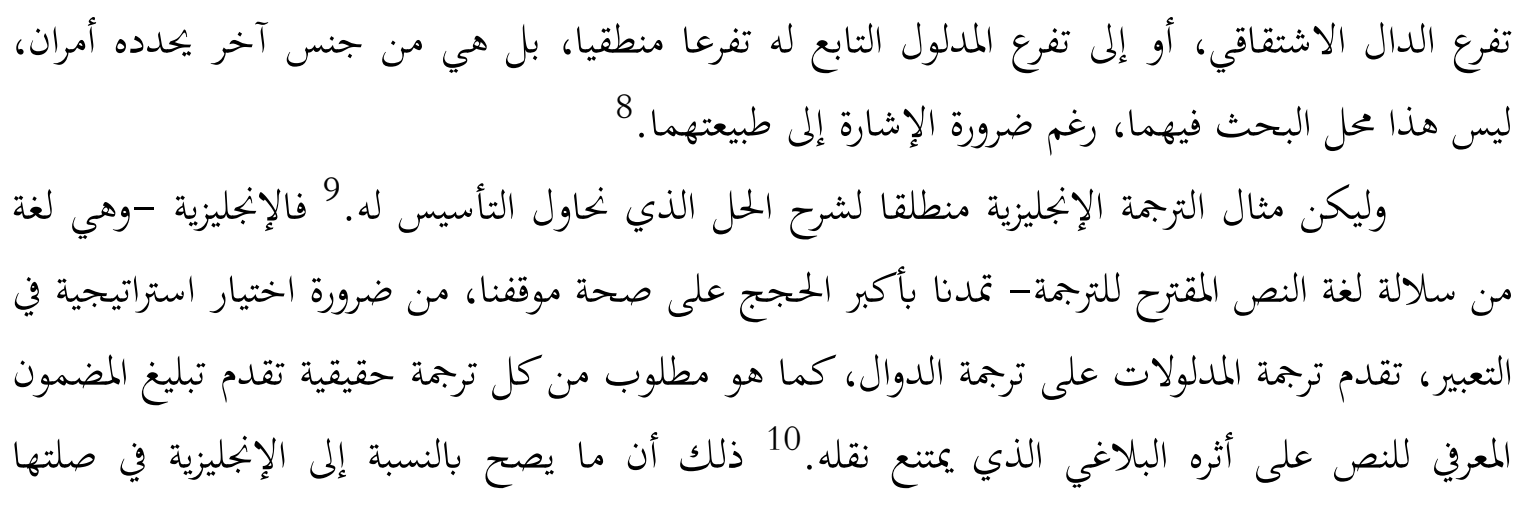

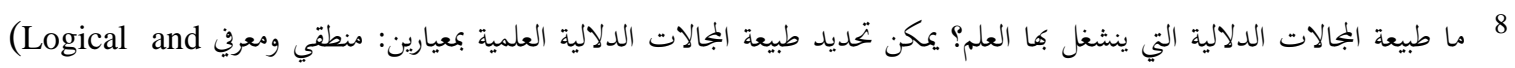

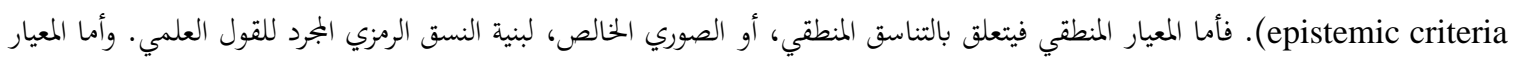

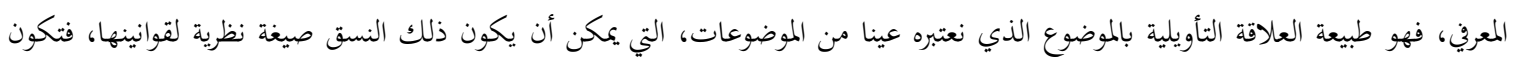

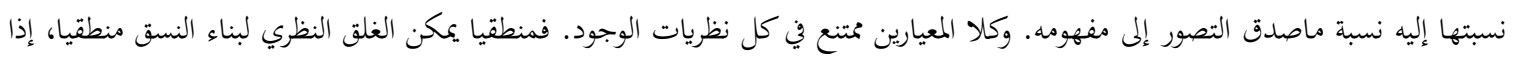

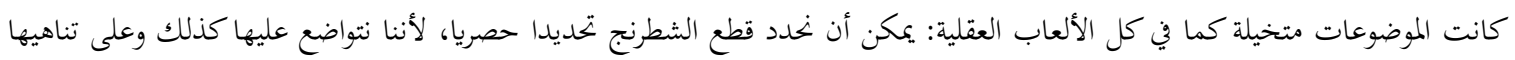

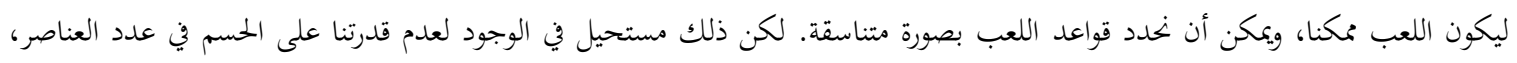

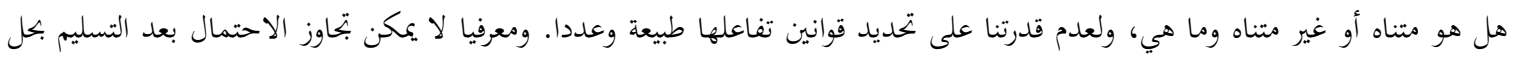

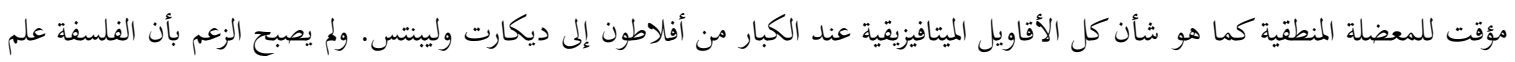

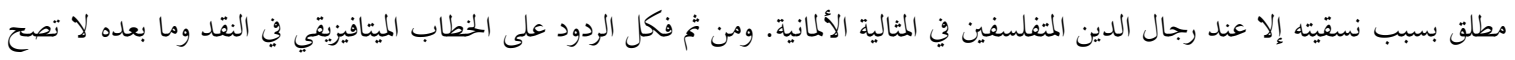

$$
\text { إلا على هذا النوع من القول الميتافيزيقي المنحط. }
$$

9 "We must therefore explain briefly what belongs to any question whatsoever, so that from this standpoint the question of Being can be made sensible as a very special one with its own distinctive character. Every inquiry is seeking [Suchen]. Every seeking gets guided beforehand by what is sought. Inquiry is a cognizant seeking for an entity both with regard to the fact that it is and with regard to its Being as it is. The cognizant seeking can take the form o 'investigating' [Untersuchen], in which one also bare that which the question is about and ascertains its character. Any inquiry, as an inquiry about something, has that which is asked about [sein Gefragtes]. But all inquiry about something is somehow a questioning of something [Anfragen bei..]. So in addition to what is asked about, an inquiry has that which is interrogated [ein Befragtes]. In investigative questions- that is، in questions which are specifically theoretical-what is asked about is determined and conceptualized. Furthermore, in what is asked about there lies also that which is to be found out by the asking [das Erfragte], this is what is really intended: with this, the inquiry reaches its goal. Inquiry itself is the behavior of a questioner, and therefore of an entity, and as such has its own character of Being. When one makes inquiry one may do so 'just casually' or one may formulate the question explicitly. The latter case is peculiar in that the inquiry does not become transparent to itself until all these constitutive factors of the question have themselves become transparent" (B.T. pp.24-25)

$$
\begin{aligned}
& 10 \text { نقل الأثر البلاغي مستحيل سواء نسبنا هذا الأثر إلى الدال، كما يمكن أن ينسب ذلك إلى ألى رأي أصحاب علم البديع، أو إلى المدلول كما }
\end{aligned}
$$

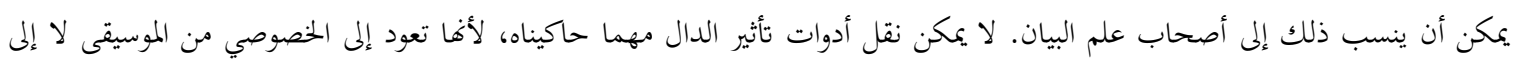

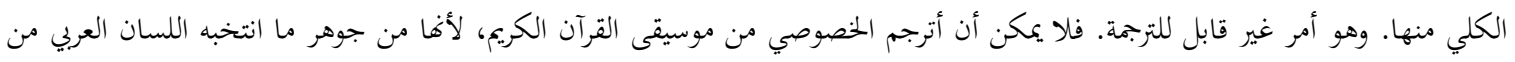

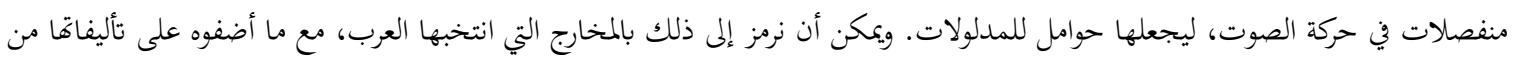

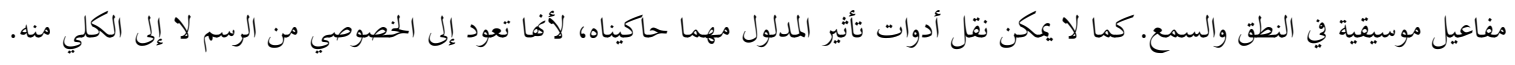

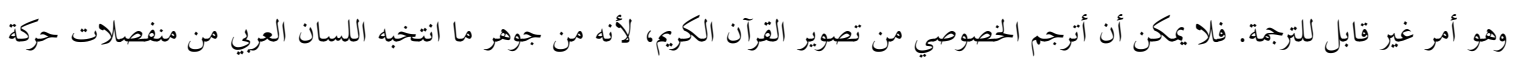


بالألمانية، هو بالأولى أصح على العربية التي هي من سلالة لسانية مختلفة تماما. فالنص الإنجليزي قد استعمل

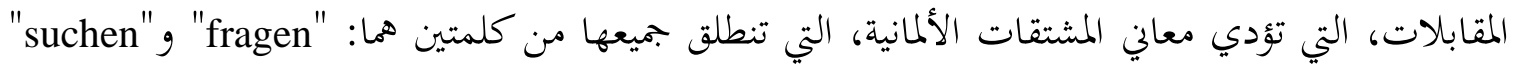
بآلتي الاشتقاق التقليديتين: الاشتقاق المستند إلى الاشتقاق من المادة الواحدة، بتغيير صورة المادة (اسم الفاعل واسم المفعول من مصدري سؤال وطلب)؛ والاشتقاق المستند إلى الزيادات المنحوتة أو المنفصلة في

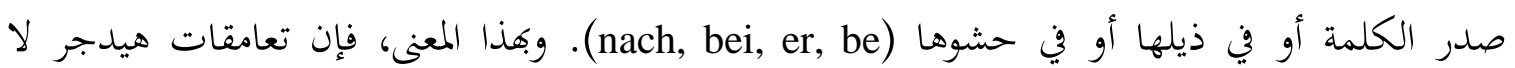
تتجاوز رد المعرفة العلمية إلى ما يقبل التحصيل، بآليتين من آليات اللسان الطبيعي لتحليل المعاني العلمية

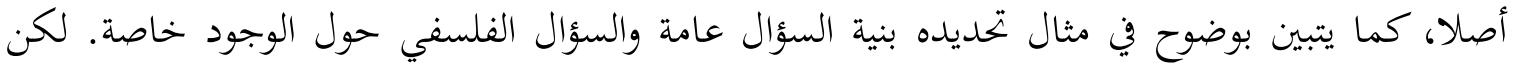
المترجم الإنجليزي لم يتقيد بهذا الشرط؛ بل سعى إلى المقصود من فعل الترجمة؛ أعني نقل المدلول بدوال مختلفة

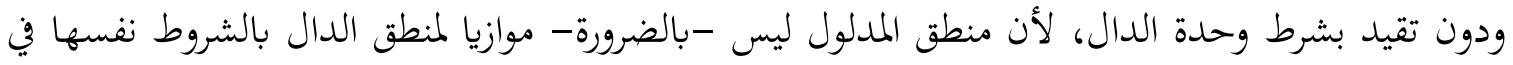

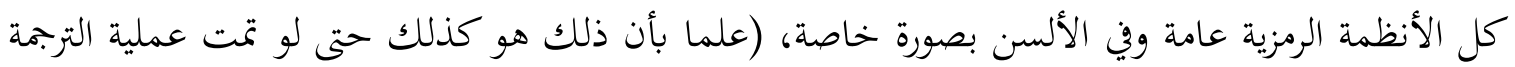

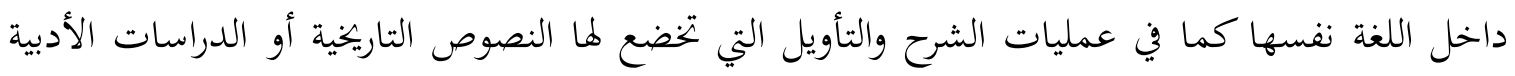
.question, enquiry, seeking, investigation:(لامث وبمجرد وضع هذه القاعدة تصبح ترجمة أي نص ممكنة، بشرط أن نعلم أن الترجمة يهكمها حد لا تتعداه. وهذا الحدد هو أنّ ما لا يقبل الترجمة من لغة إلى لغة، هو عينه ما لا يقبل الترجمة في اللغة نفسها،

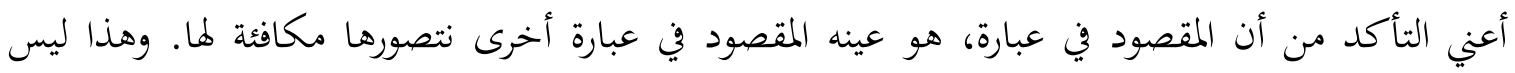

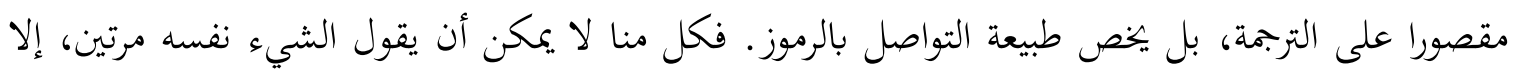

الإشارة، ليجعلها محمولات الدوال. ويمكن ان نرمز إليها بالأعراض التي ينتخبها العرب لتسمية الأشياء ووصفها مع ما يضفونه على تأليفاقا، من مفاعيل رسمية في الإشارة والبصر. لذلك اعتبرنا هاتين الخصوصيتين الموسيقية والرسمية، بدورهما، رموزا لما وراءهما من متعاليات كلية يشترك فيها البشر، لعل أفضل

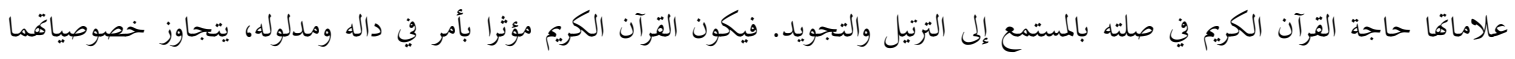

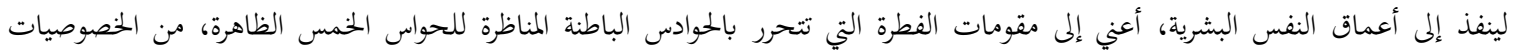

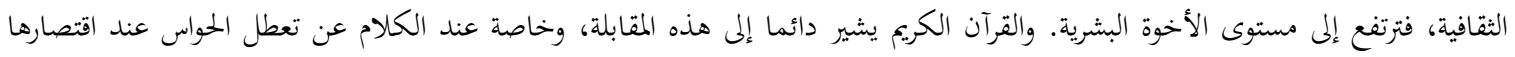
على الصلة الظاهرة، كما في المقابلة بين البصر والبصيرة. فلإنسان من حيث هو جسم حي، صلتان ظاهرة وباطنة بالوجود في تعينيه الظاهر

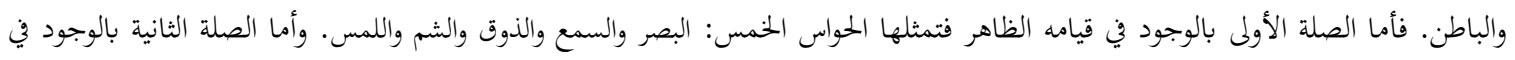

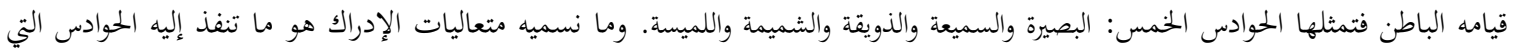

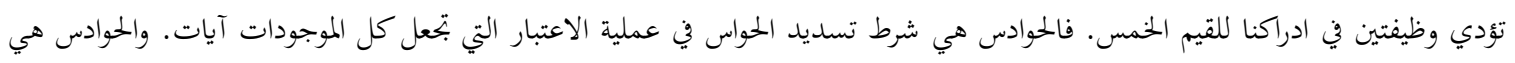

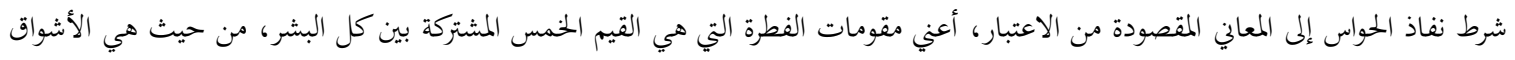

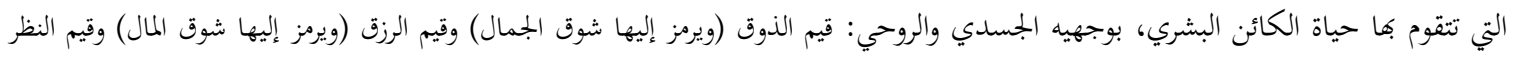
(ويرمز إليها شوق السؤال) وقيم العمل (ويرز إليها شوق الجلال) وقيم الوجود (ويرمز إليها شوق المتعال). 
بالحدود التي وجدناها في عملية الترجمة. وعندما يعيد الإنسان قول "الشيء نفسه" يعلم أنه يقوله مرة ثانية،

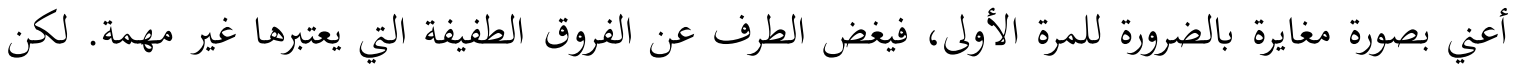
أشياء كثيرة تتغير من المرة الأولى إلى المرة الثانية، بما في ذلك النبرة النابتة عن الوعي بأن المرة الثانية ثانية،

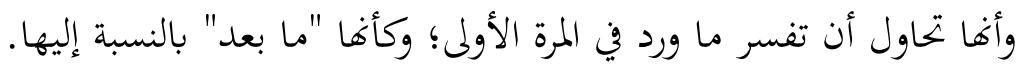
ومع ذلك فنحن قد حاولنا في ترجمة هذا النص المحافظة على ما يشبه التماثل الدالي مع النص

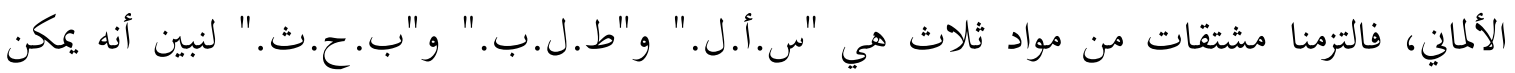
أحيانا احترام الشروط الخطابية، ذات المصدر الدالي في أداء القصد المدلولي، حتى وإن كنا لا نعتقد ذلك ممكنا دائما، فضلا عن أن يكون ضروريا أو مشروطا في أداء الترجمة وظيفتها التواصلية. لكن كل من يحلل المضمون المعرفي لمذا النص، يدرك أنه رغم كل ما فيه من "أسلوب خطابي" يشقق الألفاظ يبقى دون دقة

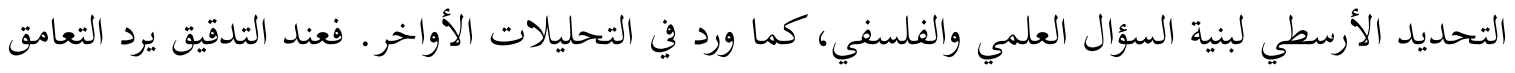
الهيدجري إلى بساطة التحديد الأرسطي بضربيه: تحديد السؤال النظري، وفيه لا يهتم أرسطو بالسائل، لئل

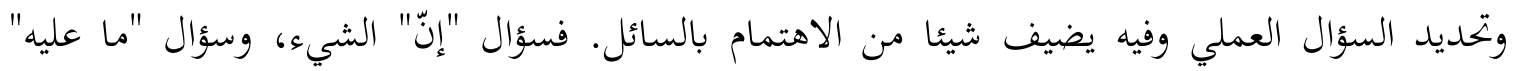

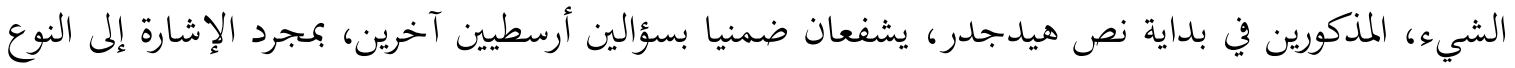

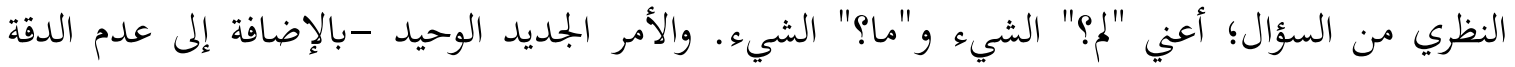

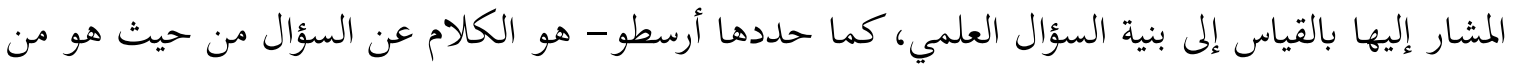

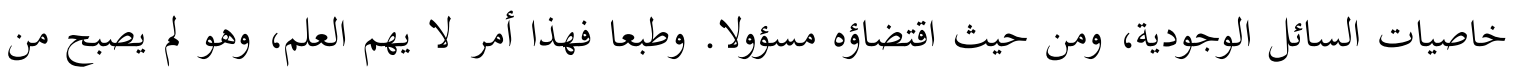

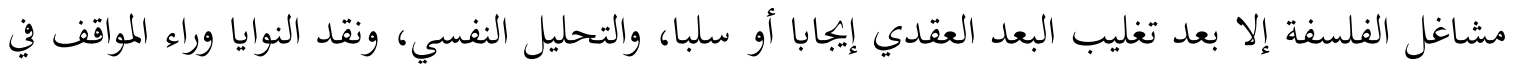

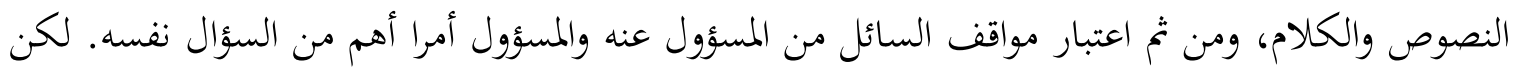

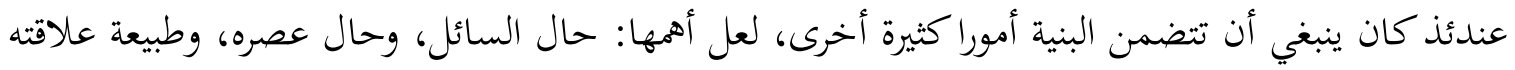
بالمسؤول وغير ذلك من محددات التداول في التواصل، فضلا عن شروط التواصل التقنية وأدواته الرمزية، فيصبح الأمر مما لا يحصره علم؛ كما هو الشأن في رأي السوفسطائية المحدثة، التي تحاول إزاحة ميزيزات

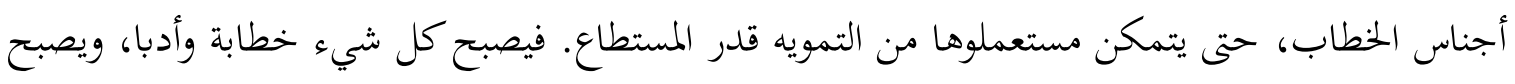

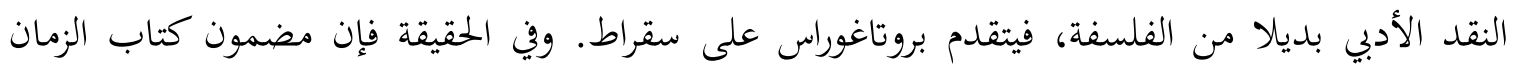

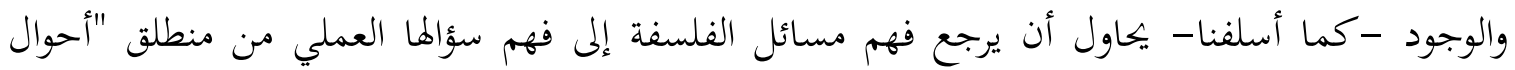

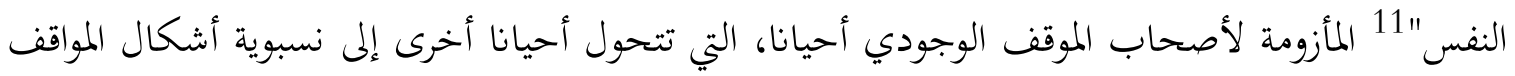

11 والحال نأخذها هنا بععنيين: بالمعنى الذي يتكلم فيه المتصوفة عن أحوال النفس، أحوالها المحددة للذوق الملازم لضروب الإدراك ودرجاته، وفي

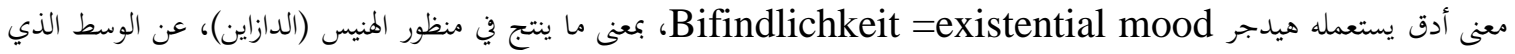


التاريخية الثقافية، أو تجليات الوجود وفهومه أحيانا ثالثة، أو أخيرا إلى مزاعم كل فلسفات الوعي المزعومة

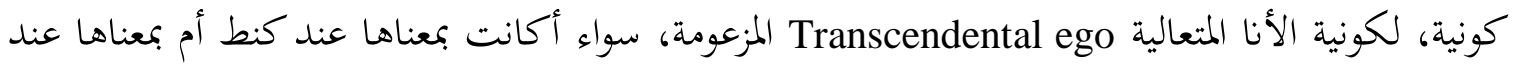

ويستند تعريفنا لشروط الترجمة السوية إلى علتين: الأولى: هي أن ثبات مادة الكلمة (الجذر) في

المشتقات لا يمكن أن يكون المعيار الوحيد لبناء بجالات الدلالة، حتى في غير العلم والفلسفة، وإلا لكانت دلالات اللسان الطبيعي بنية ثابتة ثبات بنيته الصرفية، ولاستحال أن تحصل الترجمة الداخلية في أي لسان طبيعي، لما تتصف به المواد من انفصال لا يقبل الجمسر، فتصبح بجالات الدلالة حتى في اللغة نفسها؛

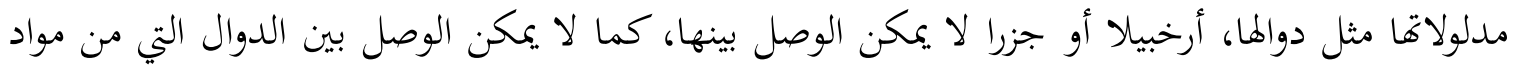

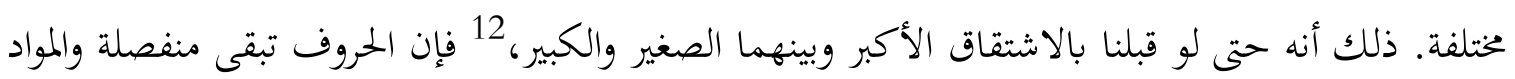

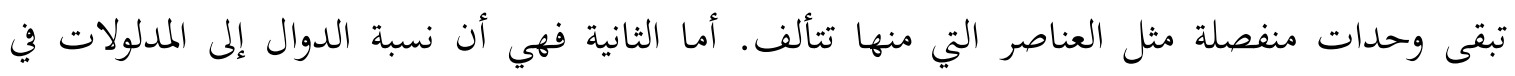

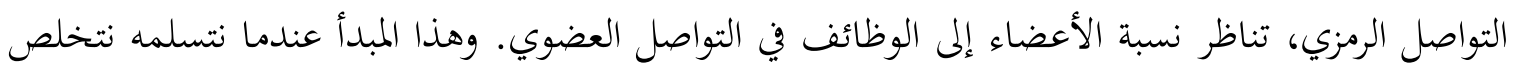

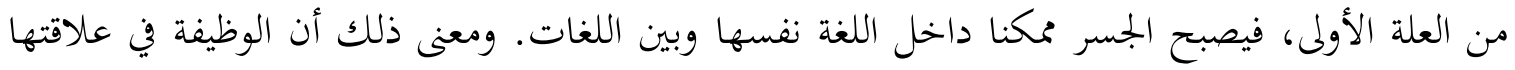

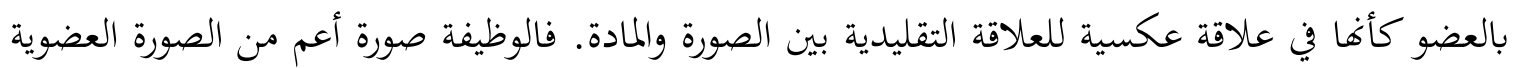

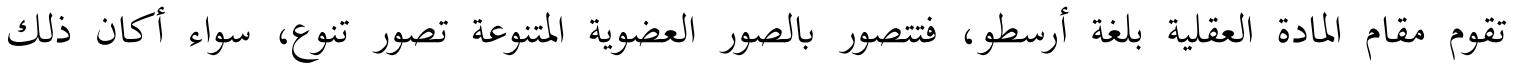

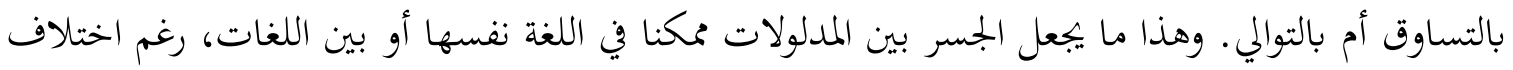

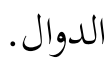

فلو اعتبرنا أن كل وظيفة (دلالة) مرتبطة بتعين وحيد هو الشكل العضوي الوحيد (الدال) الذي يحققها، لامتنع علينا أن نتصور وظائف الظاهرات الحية (المدلولات)، قابلة للمقارنة وللتصنيف أولا، وقابلة

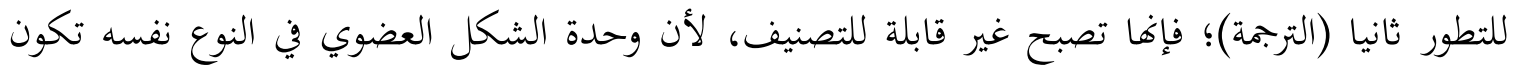
بدورها نسبية ولا يمكن أن تتحدد إلا بالتماثل بين أشكال أعيان هذا العضو، في أفراد النهاد النوع (المفترض واحدا بوحدة صورته العضوية) بشرط اعتبار ما بين هذه الأشكال من فروق، بالقياس إلى الفروق التي بينها وبين

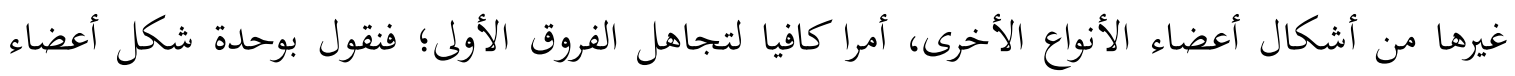

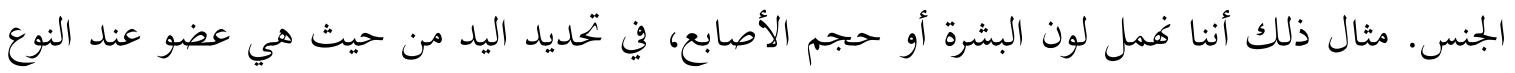
البشري، بالمقارنة مع القردة؛ أي إن الفروق بين أيدي البشر تبقى دون الفروق بينها وبين أطراف القردة.

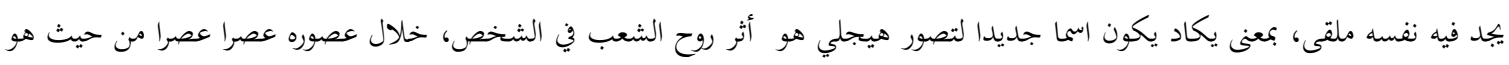

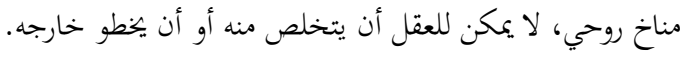

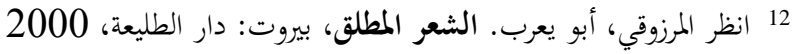


لكن لو اكتفينا بذلك لاستحال تطبيق مبدأ التناسب الأرسطي في التاريخ الطبيعي، ولامتنع تجاوز الفروق بين أعضاء الأنواع في الوظائف المشتركة بينها. ومن ثم فنحن نستنتج وحدة الأعضاء من وحدة الوظيفة، مهملين ما لا يؤدي دورا فيها من صفات العضو، الذي وحدناه بالمقارنة مع غيره من الأعضاء عند غيره من

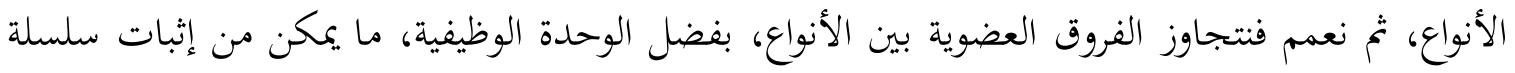
تطورية. وتلك هي العلة في تطبيق أرسطو مبدأ التناسب الوظيفي على الأعضاء، فتكون خياشيم الحيوانات المائية مناسبة لأنوف الحيوانات البرية في وظيفة التنفس. وبهذا القياس يكون دال مدلول التنفس الحيشوم عند السمك والأنف عند الإنسان. ويكفي أن نجعل التغير العضوي لأداء الوظيفة نفسها تجويدا لهذا الأداء، حتى نتتقل من التاريخ الطبيعي الساكن إلى التاريخ الطبيعي المتحرك؛ وتلك هي بداية نظرية التطور الأحيائي.

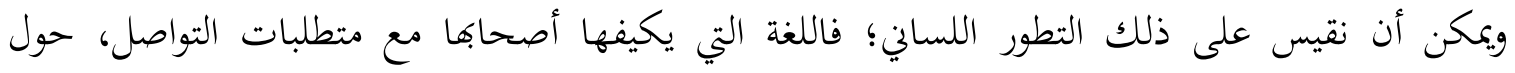

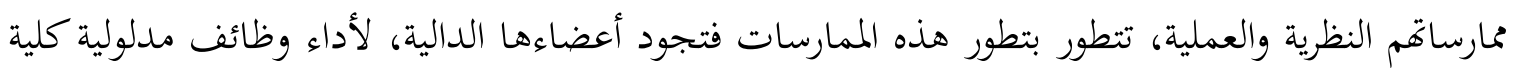
مشتركة، تتجاوز اختلاف الألسن؛ لأفا غير مدلولات أعيان الدوال. واللغة التي تتأخر الممارسات عند أصحاهما، تكون عرضة لصعوبة أداء هذه المعاني، عندما يحاول مترجموها نقل تلك الممارسات من لغة طورها أصحاهما نظير تطويرهم للممارسات. وللترمة في هذا التطوير دور أساسي، كوها المناسبة التي تتم فيها

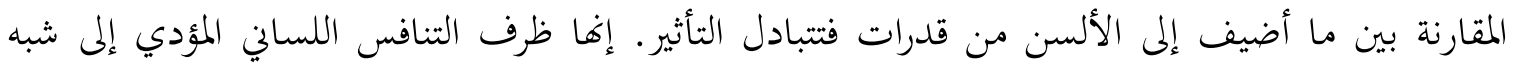
صراع من أجل البقاء بين اللغات (بين أصحاب اللغات في الحقيقة) فيكون البقاء لما يجعله أصحابه الأصلح،

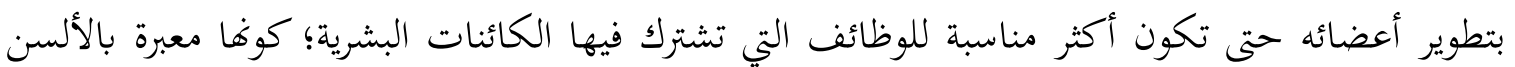

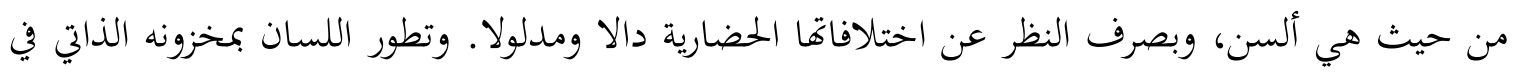
خلال صراع التنافس التعبيري دليل على حيوية الأمة، وهو جزء من عناصر تطور الأنواع. وهو في هذه الحالة من أقوى عناصر التكيف البشري.

وقد ترجمنا النص دون خوف من قمة الاستعراض، لأننا نعتقد أن صعوبة الترجمة واحدة أيا كانت

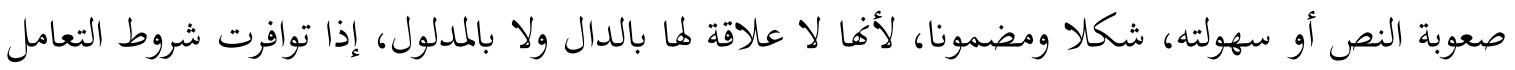

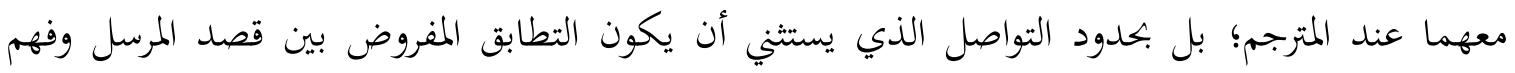

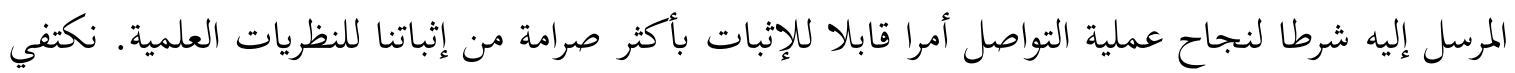

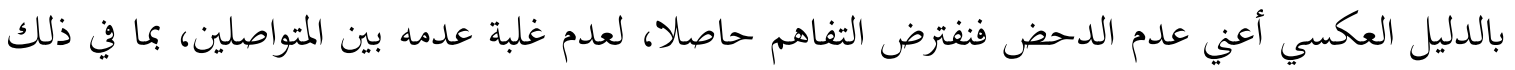

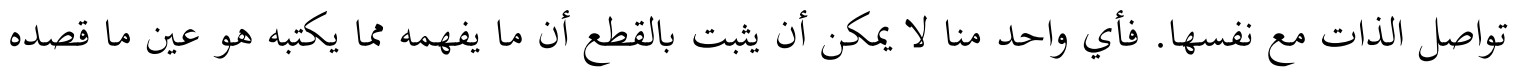
لما كتبه، وخاصة إذا مرت مدة طويلة نسبيا بين الكتابة والقراءة. لكن النفس البشرية لها القدرة على الجسر 
بين الأمرين، فتزيل الفروق المعتبرة، وتحقق شيئا من الوحدة بإهمال الفروق غير المعتبرة، حتى يكصل التواصل

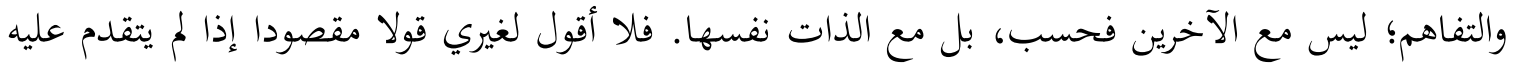
قولي لنفسي، لأن القصد هو أن يكون فعل القول في التواصل مع الذات، شرطا في التواصل مع الآخرين،

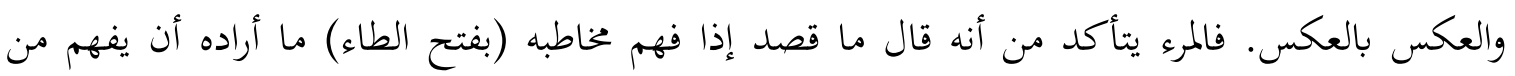

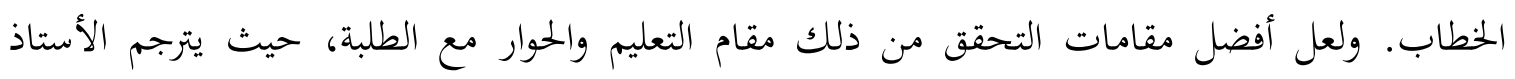
مقصده مرات عدة بعبارات مختلفة يعتبرها دالا متعددا على مدلول واحد، هو ما يريد أن يبلغه للطالب السائل سؤالا يدل على عدم الفهم، أو بصورة أدق على فهم عدم الفهم بتعيين مناط الأشكال.

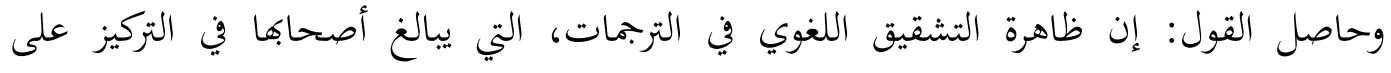

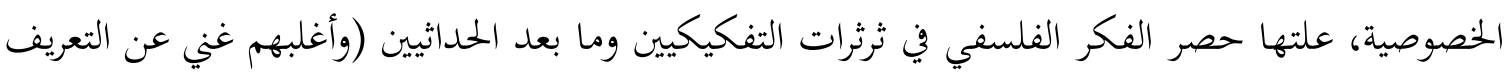

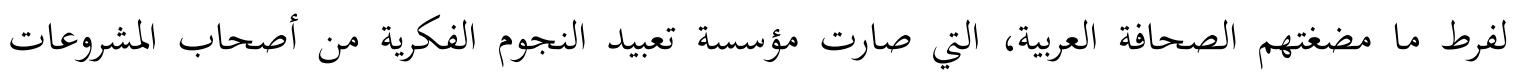

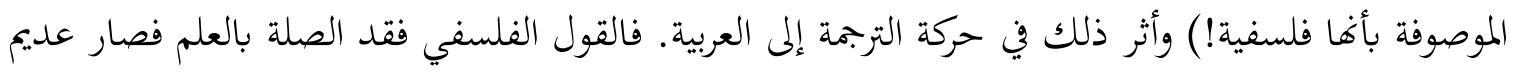

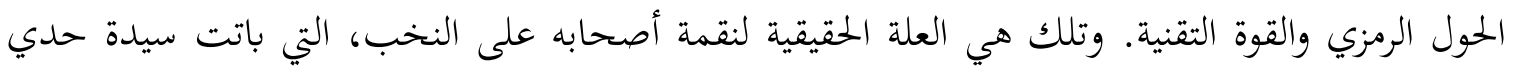

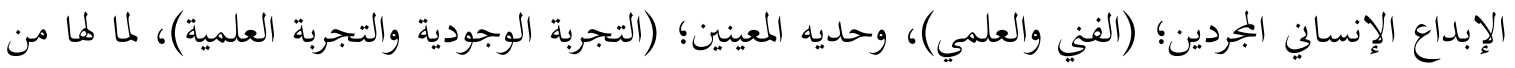

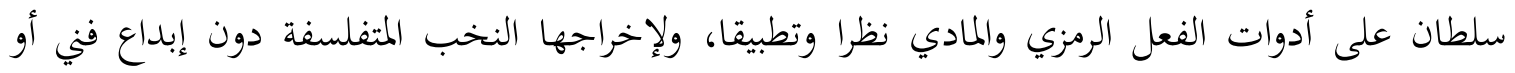

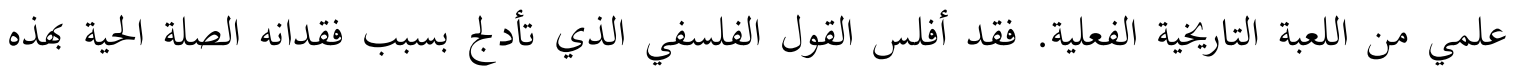

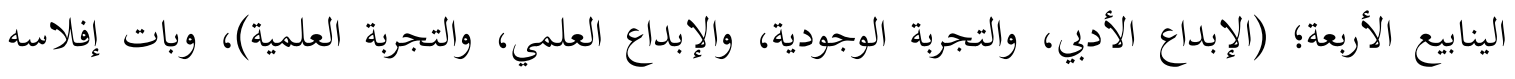

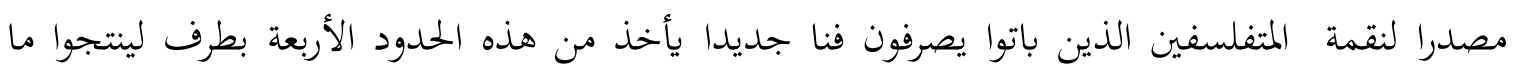

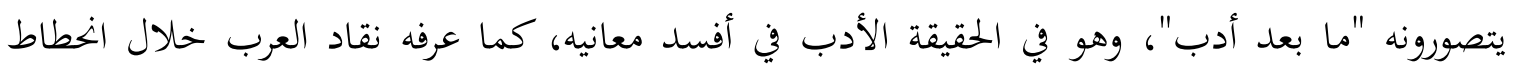
الإبداع العربي. فهو ليس أدبا، ولا علما، ولا تجربة وجودية، ولا تجربة علمية. ومن علامات إفلاس الفكر الفلسفي المعاصر، سوفسطائيته المحدثة التي حاولنا فحصها في محاولات سابقة، فبينا أهما التمهيد الفكري والتأسيس الضمني للمسيحية المتصهينة، التي تمثل العمود الفقري للعولمة

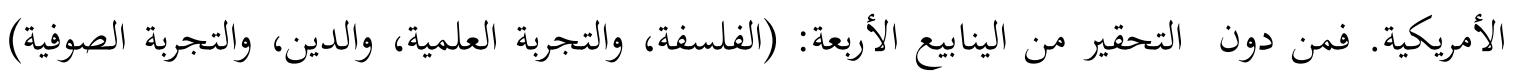

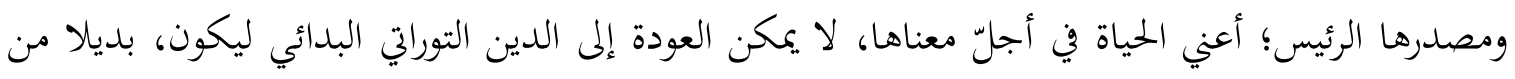
التطابق بين التنوير العقلاني والتنوير الوجداني في الرسالة الخاتمة. التي بفضلها يصبح الخطاب الفلسفي قابلا

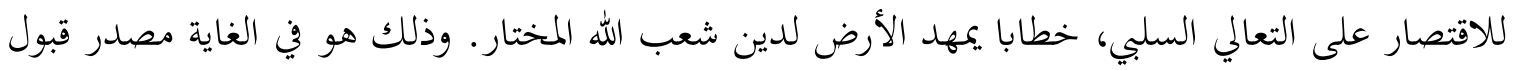

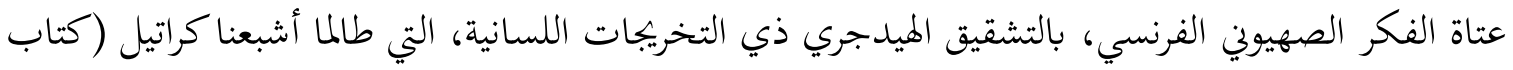
أفلاطون) منها "أسخورة" (من السخرية على وزن أفعولة كما في أمثولة وأسطورة). 
فكيف يككن أن تبلغ السذاجة ببعضهم إلى القبول بالسخافة القائلة: إن معاني الوجود التي من

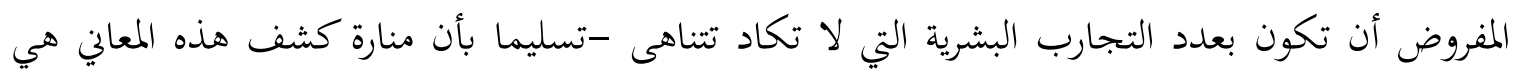

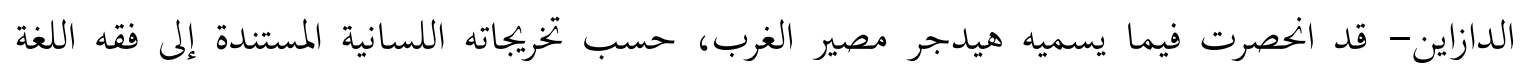

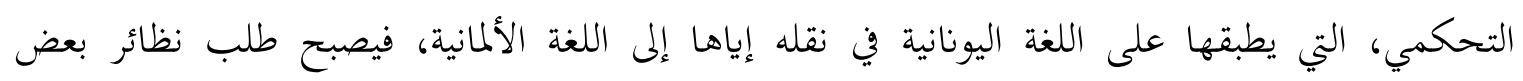

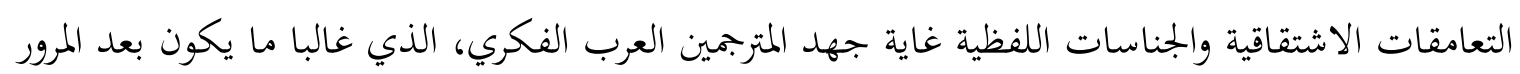
بغربال الفرنسية أو الانجليزية علنا أو سرا؟

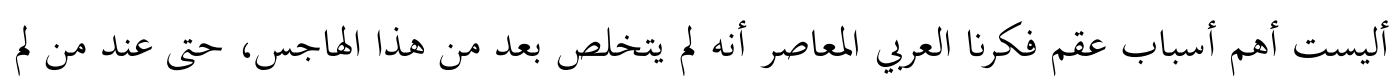

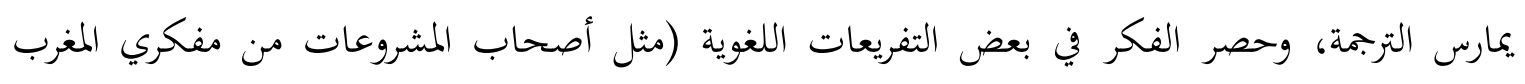

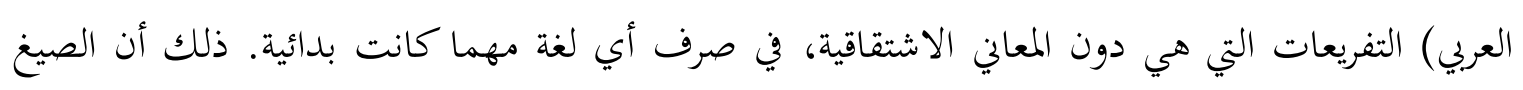

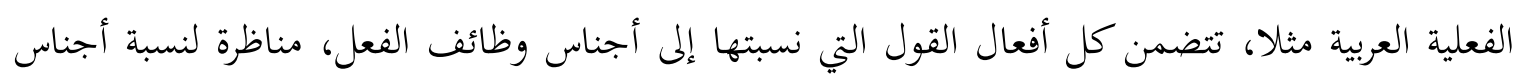

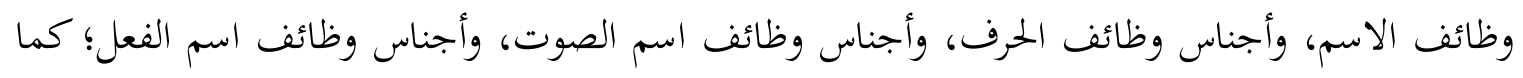

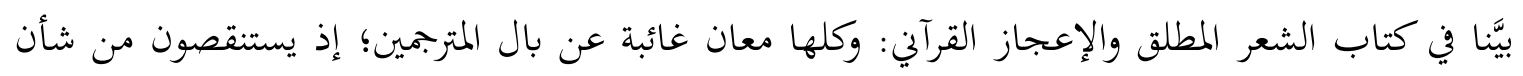

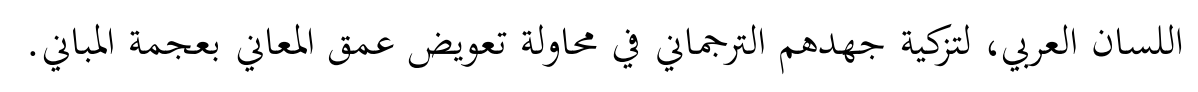

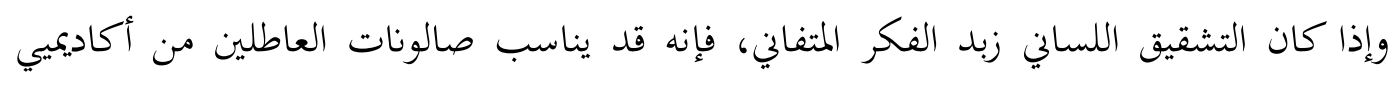

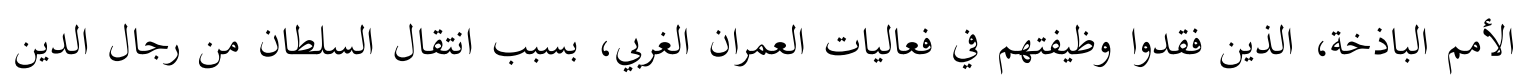

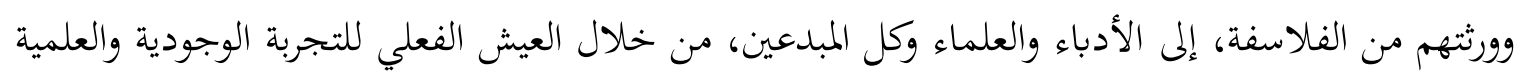

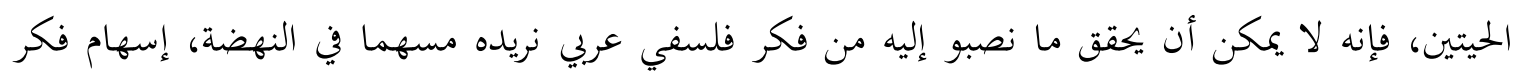

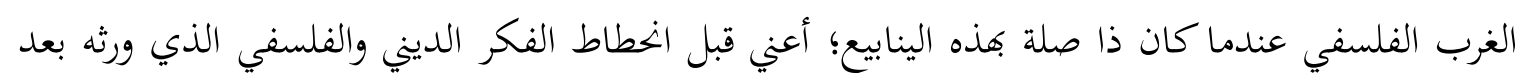
الإصلاح في الحضارة الغربية. ولا بد من فكر في العلوم ذات العمود الفقري (الطبيعية، والإنسانية، العندا،

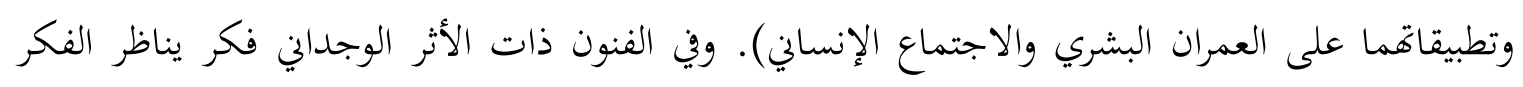

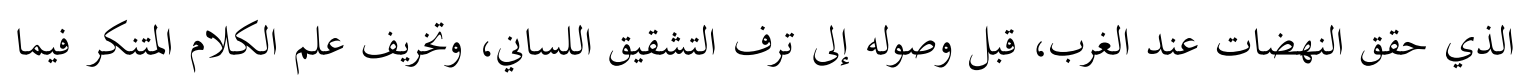

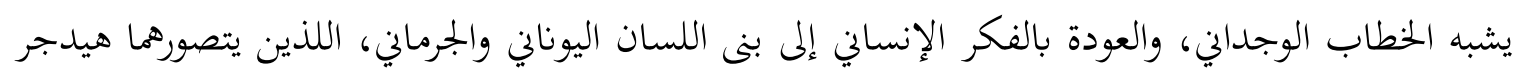
ومدرسته غاية البيان والعرفان. 
تبين الآن أنه يوجد بين الحل الذي نقترحه للتغلب على معضلات الترجمة (مسألة لسانية)، وحلنا لمعضلة التعالي على النسبية الثقافية (مسألة فلسفية) ترابط واضح. فنحن نشترط في الحل الأول الفصل بين الدال والمدلول لنجاح الترجة؛ سواء أكانت داخلية أم خارجية؛ لأننا لا نبحث عن المدلولات التي تكون ذات خصوصية بحانس خصوصية الدال. ذلك أن خصوصية المدلول مثلها مثل خصوصية الدال لا تقبل الترجمة. وللخصوصية هنا مستويان: الأول فردي، وهو مستحيل الترجمة الداخلية، وغير قابل للتواصل بين أفراد المجموعة لعدم انقياله (أي عدم القدرة على وصفه أو النطق به ineffable)، فضلا عنه بين المجموعات ذات اللغات المختلفة. ومستوى الخصوصية الثاني جمعي، وتشترط ترجمته الخارجية قابليته للترجمة الداخلية، التي هي شرط التفاهم بين أفراد المجموعة ذات اللغة الواحدة. ومعنى ذلك أن الجماعة الواحدة تتواصل، بشرط أن يكون كلامها قابلا للترجمة الداخلية، بفضل تعدد دال نفس المدلول وتعدد مدلول نفس الدال. ومن ثم فالتواصل في المجموعة يقتضي خصوصية سلبية، هي التخارج بين العموميات الثقافية الخاصة بالدال والمدلول. فاختلاف الدال يقتضي أن يوجد مدلول مختلف من جنسه إذا أردنا أن نبقى في دائرة الثقافي. ولعل الخطأ الذي أدى إلى النسبية الثقافية، هو الخلط بين هذا المستوى الذي لا يتجاوز عموم الجماعة الثقافية، ومستوى الكلية التي يقصدها الدين والفلسفة والعلم والأدب. ولهذا الخطأ مرحلتان: الأولى هي رفع الخصوصية الثقافية إلى الكلية الوهمية، التي تجعل كل ثقافة تدعي حصر الكلي في ذاتا، كما حدث في المراحل الأولى من تأسيس الفكر الديني والفلسفي والعلمي (ومثاله نظرية المقولات الأرسطية وعلاقتها بنحو اليونانية)، والثانية مقابلة لها، وهي محاولة إرجاع الكليات التي توصلت إليها هذه الأنواع من الفكر الكوين إلى الثقافي، بحط الكلي الذي هو هدف الفطرة البشرية الملازم ها دائما رغم خلطه بالخصوصيات الثقافية، حطَّ إلى الخصوصية الثقافية، (ومثاله نفي كلية المنطق وراء ضروب النحو المختلفة بحسب الألسن). فالخصوصية الفردية دالا (خصوصية نطق الفرد)، ومدلولا (ما يدور في ذهن الفرد)، لا تقبل الترجمة في الثقافة نفسها، وهي لا تحقق التواصل إلا بعملية لسانية غير واعية عند الأفراد المختلفين، يسمعون ما وراء المسموع الفعلي وهو المسموع الواجب. فهم يقيسون النطق الفردي العيني (نطق الطفل أو نطق ذوي العاهات التلفظية في إخراج الحروف) يقيسونه للفهم قيسا لا واعيا بنطق جمعي ججرد، فيحصل ما يسمى في علم الأصوات بالفرق بين الفونيتيك (الحروف في نطقها العيني)، والفونولوجيا (الحروف في دورها المجرد من حيث هي مفيدة بفروقها المؤثرة في دلالة المفردات الدنيا الدالة). ونفترض أن للمدلول كذلك حدودا نظرية مثل ما للدال من حروف؛ لأن الناس يقيسون المدلول الفردي بثا وتلقيا بعملية الجنس نفسه، بجيث يمكن أن 
نتصور نسبة بين المدلولات في أذهان الأفراد، والمدلولات المؤثرة في التواصل من جنس النسبة بين الفونيتيك والفونولوجيا.

ويمكن أن نصطلح على حدود المدلول قياسا على حروف الدال فنسميها النويتيك (المدلول العيني في ذهن الفرد)، لنميزها عن النويولوجيا (المدلول الجمعي في التواصل)، تمييزنا للفونيتيك عن الفونولوجيا.

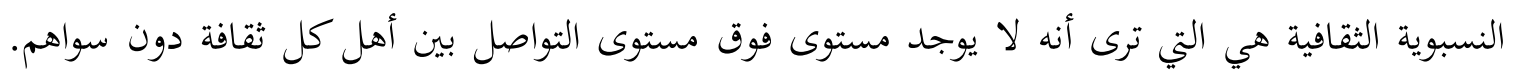

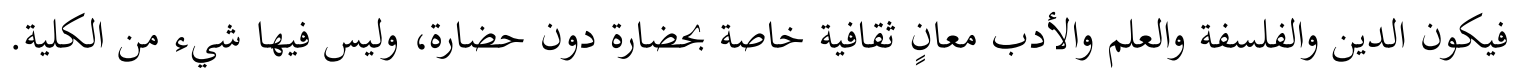

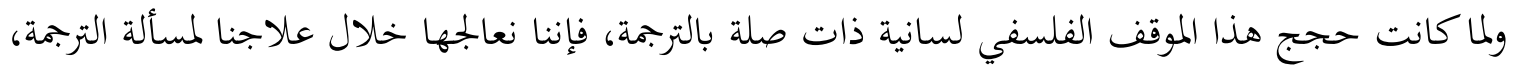

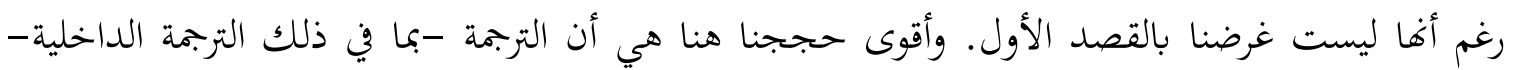

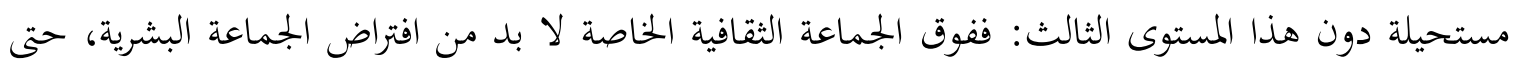

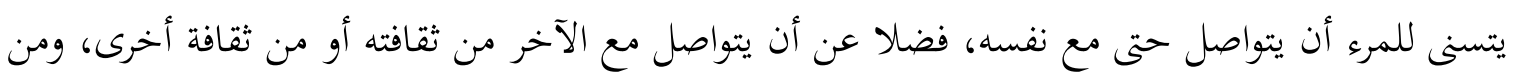

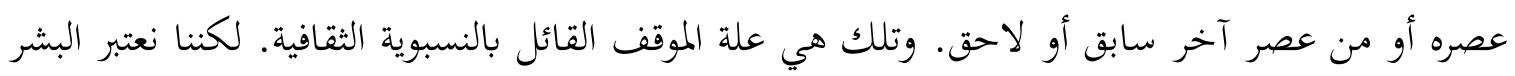

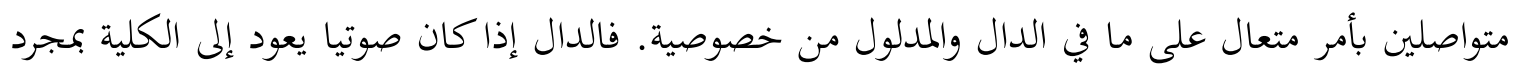

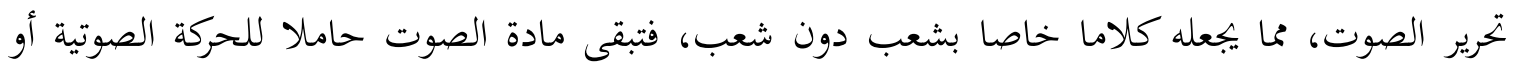
الموسيقى، مع محلها، أو الزمان ومتلقيها، أو السمع؛ وإذا كان شكليا فإنه يعود إلى الكلية بمجرد تحرير

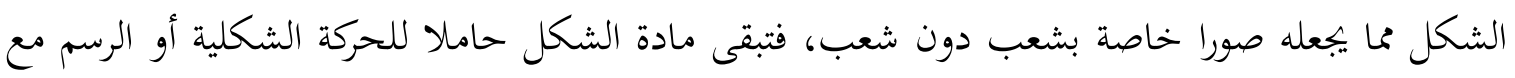
محله، أو المكان ومتلقيها، أو البصر. ومن ثم فنحن نتصور المدلولات المترجمة متحررة من النسبية الثقافية، التي تخضع لها الدوال

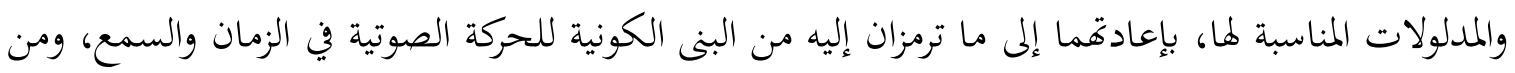

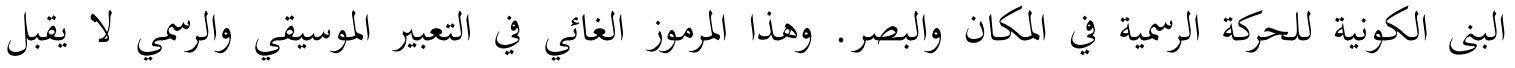
التحديد العيني، كونه يفيد بما يوجه إليه ذهن المبدع والمتدبر، من مسارات القصد اللامتناهية لإفادة الكليات القيمية المتعالية، التي سنبين طبيعتها سعيا إلى التعبير عنها. ويعني ذلك أننا لا نعتقد الترجمة ممكنة دون

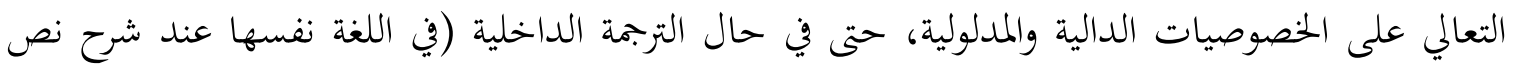

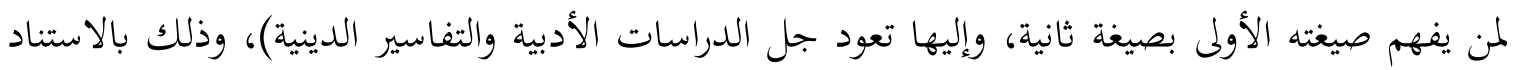

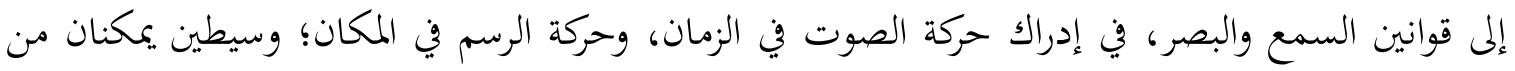

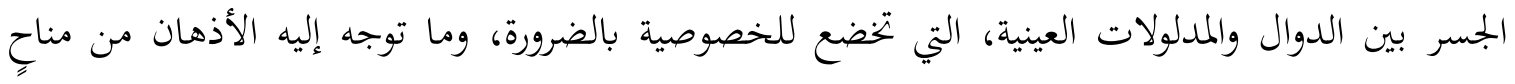
لامتناهية، تتحرر من الخصوصية بالضرورة. فهذا هو الحيز الاعتباري الذي يقيم فيه المترجم، خلال بكثه عن

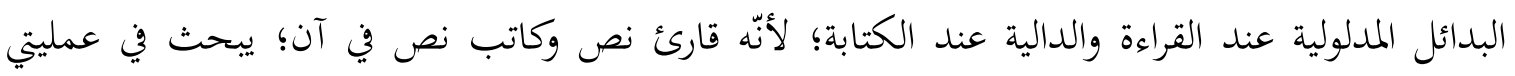


القراءة والكتابة عن التشاكل بين تطابقين مختلقين للدال والمدلول في لغة البداية (المترجم منها) ولغة الغاية (المترجم إليها). ذلك أنه لو بقى المدلول خاضعا لخصوصية الدال لبات الانتقال من صياغة إلى أخرى في التعبير عن المدلول نفسه أمرا مستحيلا، لأن المدلول عندئذ يكون خاضعا للخصوصية التي تجعله مؤلفا من منفصلات مثل الدال. فإذا كان الجسر بين منفصلات الدال مستحيلا، فينغي أن يكون الجسر بين مدلولاتحا مستحيلا، إذا حصرناها فيما بتحانسها به للتوازي التام بين الدال والمدلول في النسبية الثقافية. لذلك

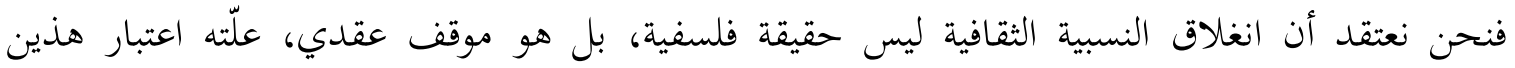
الضربين من الجسر تابعين للسان بدل تصور العكس. الموسيقى والرسم هما مصدر اللسان وليس العكس، ومن ثم فتجاوزه لا يتم دوغما، وليس فيه من حياة إلا بما يستمده منهما من جهد محرك بما كان هو بجرد

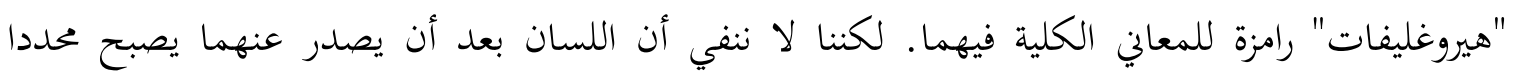

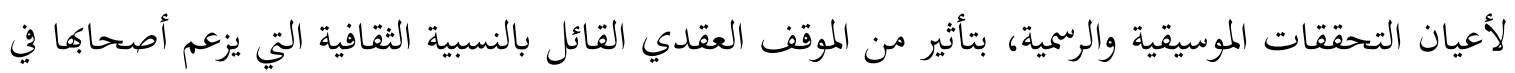
البداية أنها كونية.

ففي البداية يتصور كل شعب غناءه؛ (حركة الصوت التي تراكمت بحسب مصادفات التاريخ)

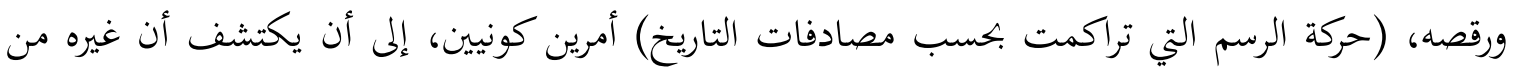
الشعوب له مثله غناء ورقص يدّعيان الدعوى نفسها. عندئذ يدرك كل شعب أن الشعب الآخر لم يختر العناصر نفسها لتكون مقومات ما ميزه من حركة الصوت وحركة الرسم، ليجعله داله ومدلوله لهذه الدعوى. فيتمكن من فهم وجهي هذه الدعوى: فلها وجه سلبي هو محاولة الجزئي أن يكون كليا بنفي الجزئيات

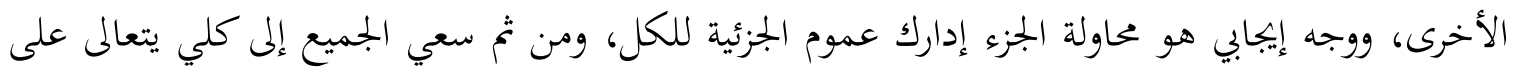

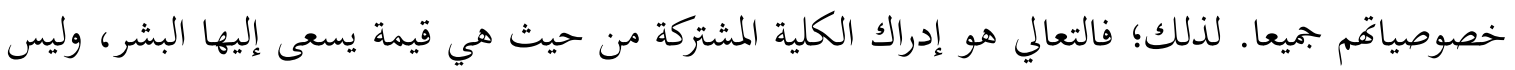

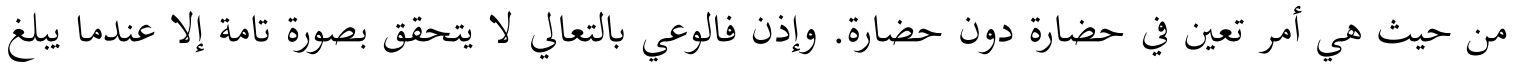
العقل الإنساني إلى مرحلة يعتبر فيها الخصوصية مرقاة للكلية بمبدأ التدافع الوسيلي (شريعة العمران المساعد

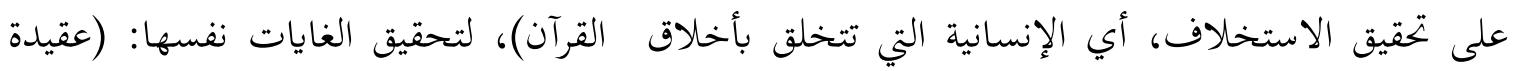
الاستخلاف أو التخلق بأخلاق القرآن).

وذلك هو الأمر الذي يسميه الإسلام فطرة الله التي فطر الناس عليها، وهي أصل الأخوة البشرية، دون أن تكون حالة في أي منهم للحفاظ على الكثافة الوجودية للفروق الثقافية والتعدد الاجتماعي.

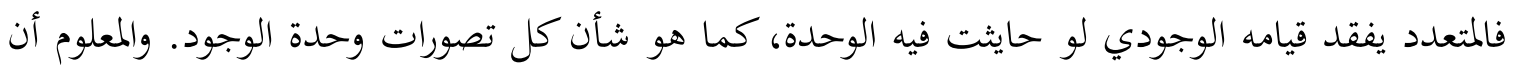
التعدد مطلوب في القرآن الكريم، بما في ذلك التعدد الديني؛ كونه شرط التدافع القيمي بما هو شرط التواصل العملي؛ (قيم تنظيم الحياة الجماعية السياسية وأدوات تحقيقها)، وشرط التواصل النظري؛ (قيم تنظيم الحياة 
الجماعية الفكرية وأدوات تحقيقها)، وشرط التواصل الذوقي؛ (قيم تنظيم الذوق العام وأدوات تحقيقها)، وشرط التواصل الرزقي؛ (قيم تنظيم العيش العام وأدوات تحقيقها)، وشرط التواصل الوجودي بين البشر؛ (قيم

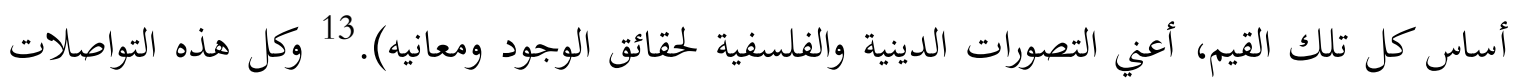
متعالية على الخصوصيات اللسانية دالا ومدلولا، وهي النسيج الواصل بين القبائل والشعوب المداعوة

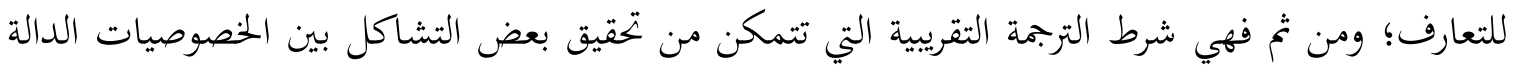

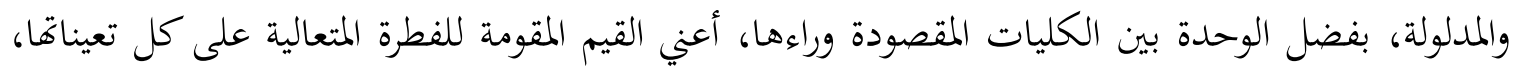
ما دامت قد نسبت في القرآن الكريم إلى الفاطر لا إلى المفطور. ومعنى ذلك أن دور الدال والمدلول في عقبات الترجمة ليس مصدره طبيعة الدال؛ (كون الترجمة بين هذه اللغة أو تلك أو العكس)، ولا طبيعة المدلول؛ (كون المدلول المنقول هو هذا المدلول أو ذاك بحسب الاختصاصات)، إلا سلبا؛ إذا قسناها بالإضافة إلى علم المترجم باللسانين وبالاختصاص. ومن ثم، فبمجرد توافر هذين الشرطين في المترجم يزول

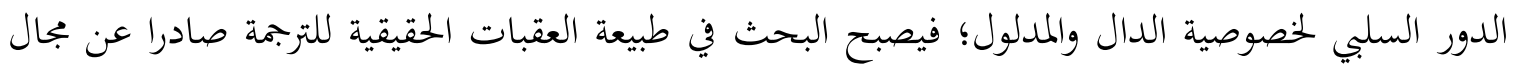

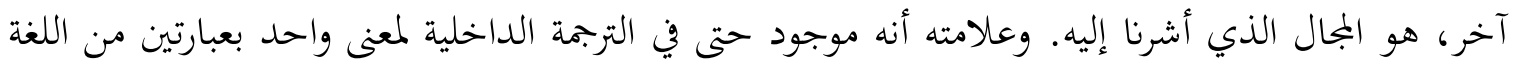

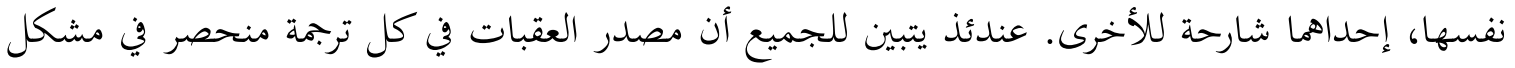

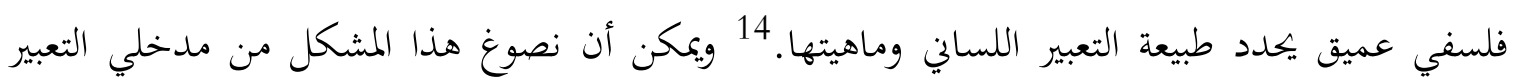

13 والقرآن الكريم يؤسس العلاقة بين المستويين، فيميز بين الدين الواحد في كل الرسالات المتوالية عموما توزيعيا؛ (لكل أمة رسول بلساها)

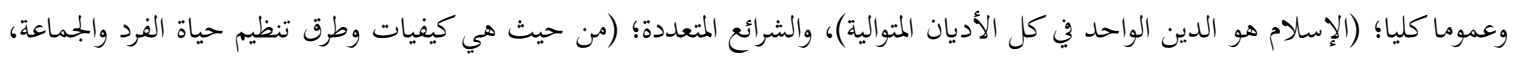

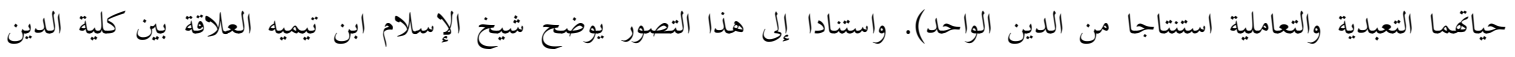

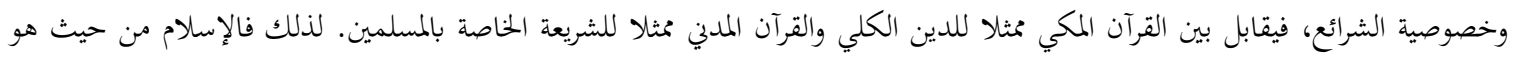

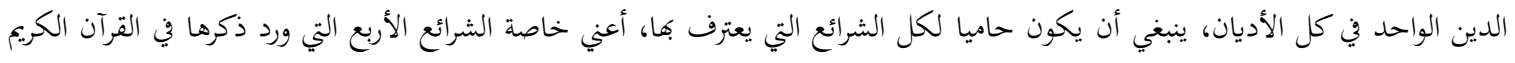

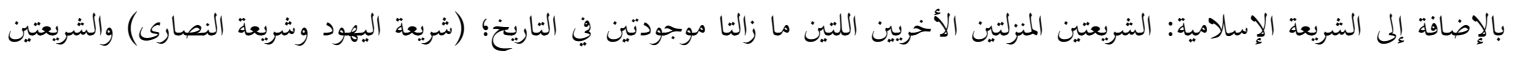

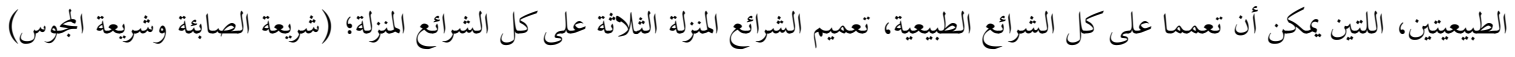

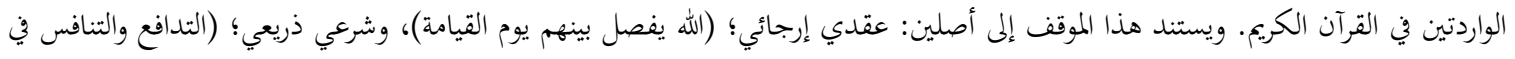

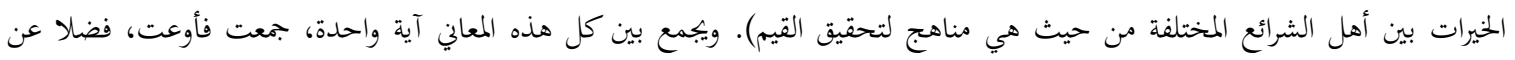

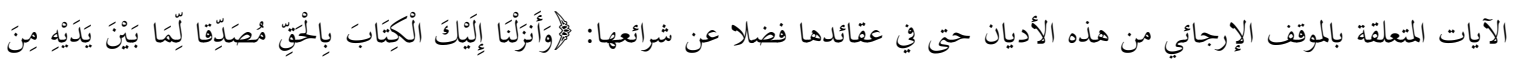

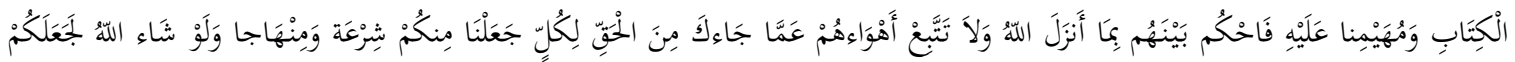

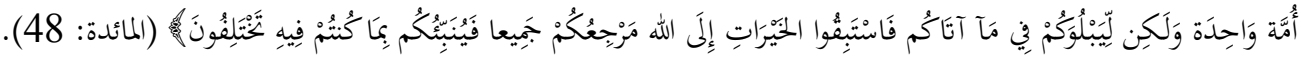

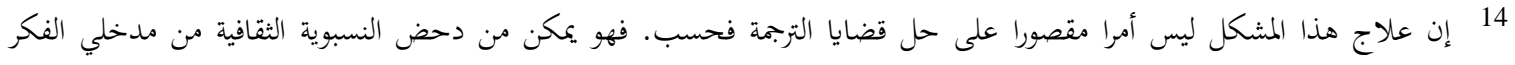

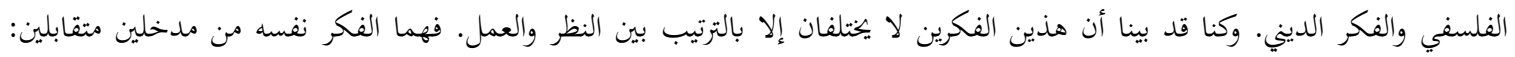

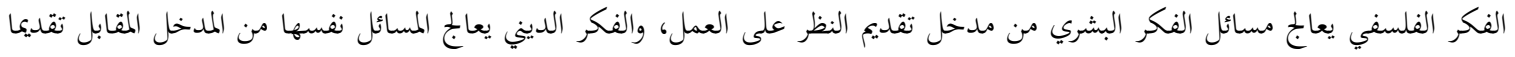


اللساني الدالي والمدلولي: كيف يمكن أن يتطابق دالان في الدلالة على المدلول الواحد، أو كيف يمكن أن يكون لدالين مختلفين المدلول نفسه؟

فهل الترادف التام بين المفردات والمؤلفات منها ممكن في اللغة نفسها فضلا عنه في لغتين مختلفتين؟ أم إن الترادف الحدي والتأليفي هو في الحالتين ترادف تقريبي دائما؟ ومن ثم فالترجمة تقتضي عملية من جنس تصنس استنفاذ الفضل Exhaustion method، بين مقدارين يتقاربان بتدرج في توجهمها أحدهما نحو الآخر، يتقاربان من غاية لا يمكن البلوغ إليها أبدا. فالدال اللاحق الذي نجربه يتقارب من الدال الموالي؛ (أي إنه

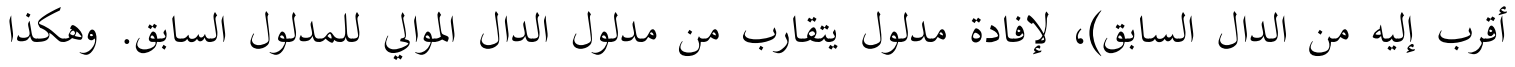
دواليك في كل المحاولات المتوالية لاستفادة الفضل بين الدالين وبين المدلولين بالتثبيت الممناوب: نثبت الدال

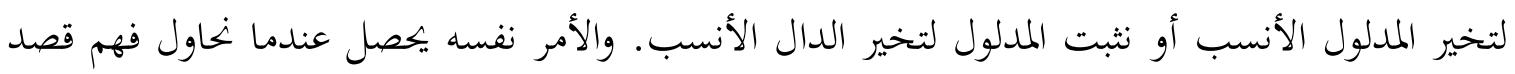

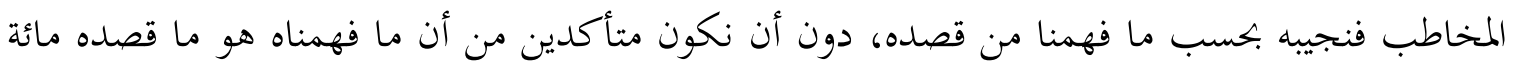

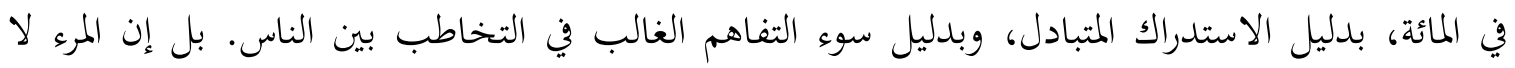

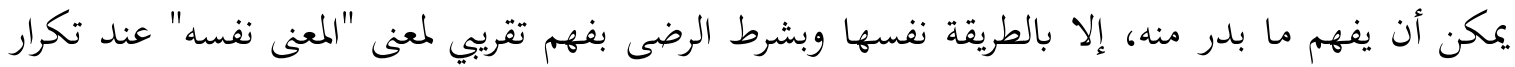
التعبير عنه بعبارة أخرى غير الأولى.

ولعل السر في ذلك هو أن التواصل الفعلي لا يكون بنظام رمزي واحد؛ (اللسان في حالة الترجمة)،

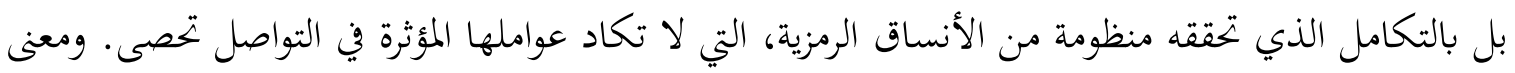

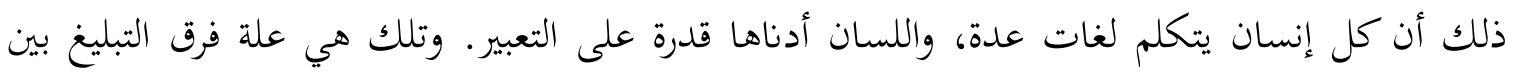

للعمل على النظر. لذلك فنحن نعالج القضية من المدخلين معا بمناسبة حل قضايا الترجمة. وبتجمع هذه الأبعاد الثلاثة في حل قضية علاقة

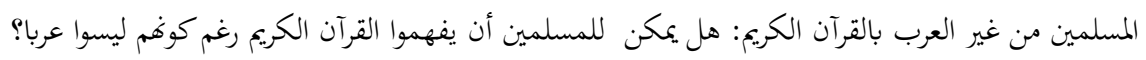

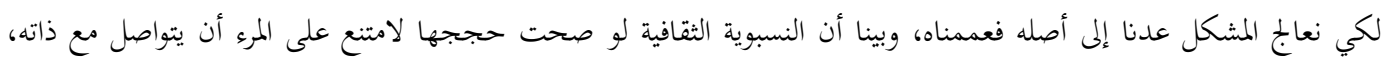

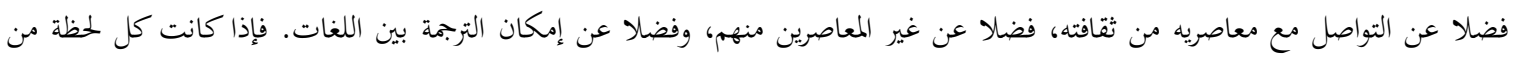

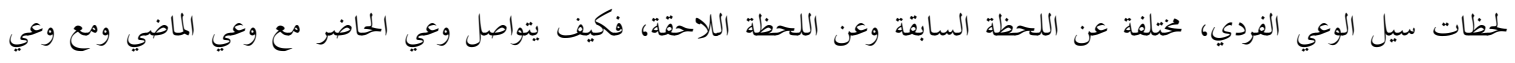

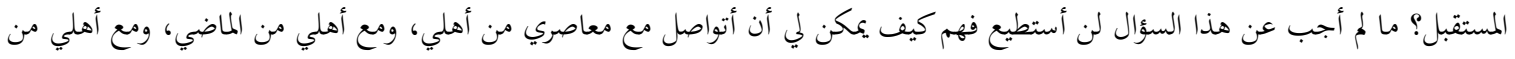

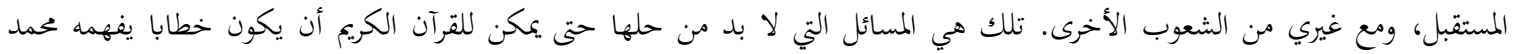

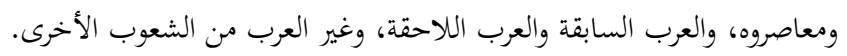

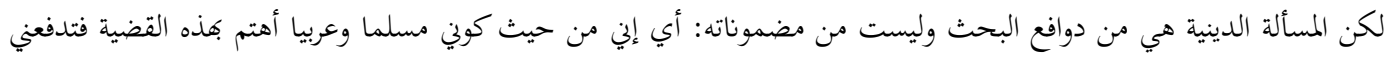

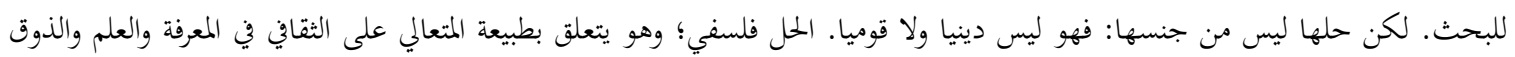

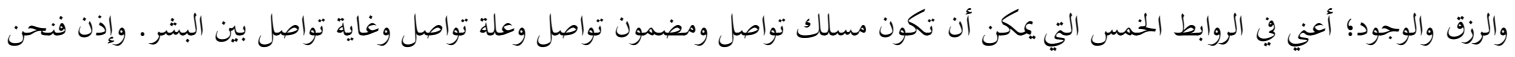

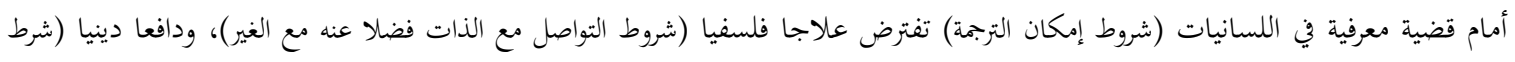

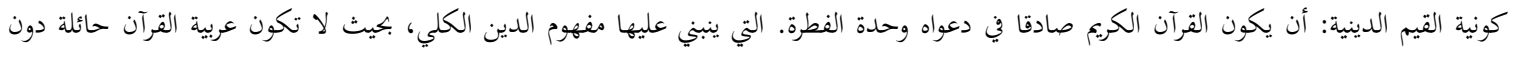

$$
\text { الشعوب غير العربية من أن تفهم معاني القرآن الكريم). }
$$


الخطاب الحي في التخاطب بين شخصين متواجهين حقا في مقام معين، كلاهما على دراية بمحدداته ومفروضاته، والخطاب الميت بين شخص من عصرنا وشخص من عصر آخر يقرأ خطابه المكتوب، مع معابه استحالة الإحاطة بالمحددات والمفروضات، مهما عمقنا البحث فيهما. فمهما أضفنا إلى النص المكتوب من معلومات وآثار تتعلق بالشخص والمقام؛ محددات ومفروضات، يبقى الإدراك الحي للأمرين أتم (من هنا

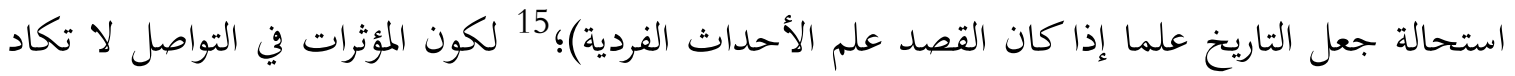
تتناهي، وجلها لا يقبل الكتابة ولا التسجيل، حتى بعد تقدم فنون تسجيل الواقع بآليات البث الحي.

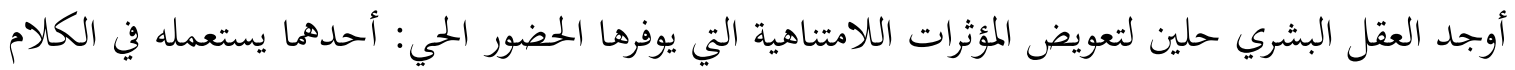
النظري، والثاني في الكلام الأدبي.

فالخطاب النظري يسعى قدر المستطاع إلى تعويض دور المؤثرات اللامتناهية، التي تجعل المقام الحي يكقق التواصل بالمحددات الحاضرة والمفروضات الغائبة، يعوضها بنسقية الخطاب وبتعريفات الحدود والمبادئ، تاركا التأويل المضموني لحرية الفكر الباحث عن التشاكل بين بنية النظرية وخصائص الظاهرات التي تصاغ بها. ذلك أن التأويلات الممكنة لكل نسق نظري لامتناهية، ومن ثم فالخطاب النظري نفسه يبقى في حاجة إلى تعيين المقام، الذي هو بالأولى من جنس التأويل المضموني للحدود، حتى يصبح للمصاحبات الإفادية

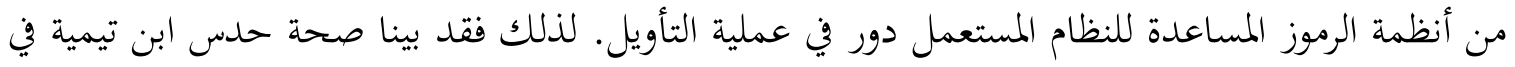

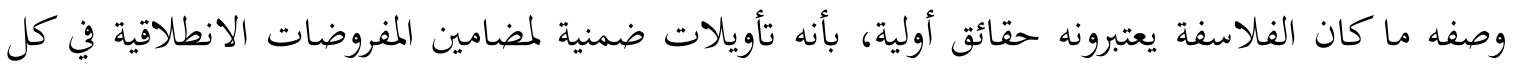

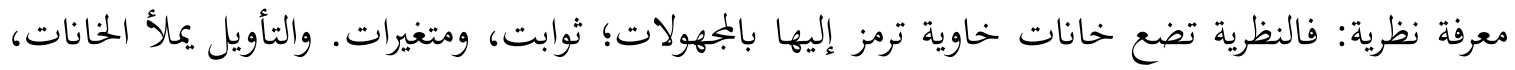
فتصبح لما في المعادلات النظرية قيم معينة، وذلك هو مدلول التأويل العلمي.

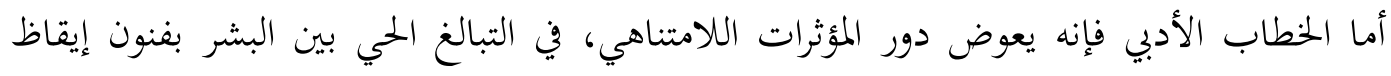

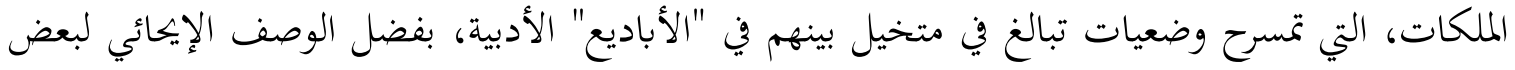

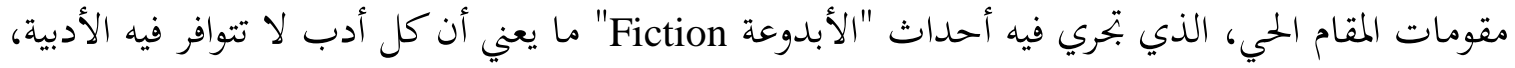

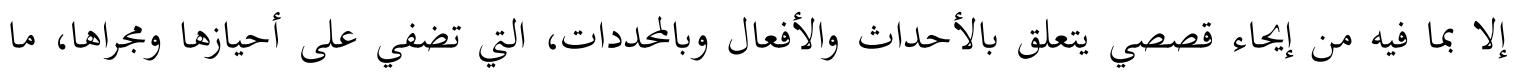

15 لذلك فابن خلدون يعتبر قد تخلى غائيا عن هذا الفهم لعلمية التاريخ، لمجرد كونه قد اعتبره منهج نقد الخبر بتوسط قوانين العمران، التي هي

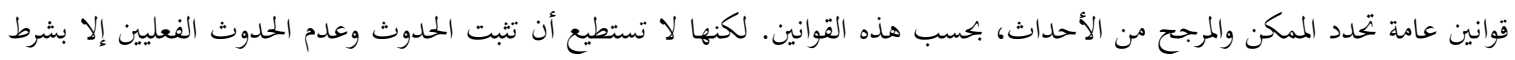

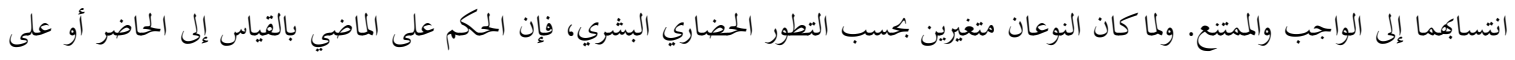

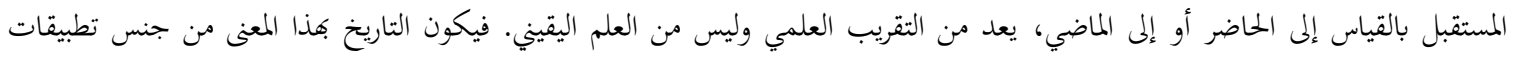

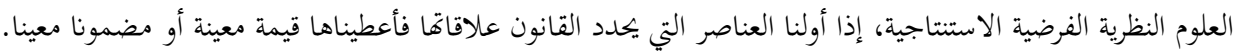

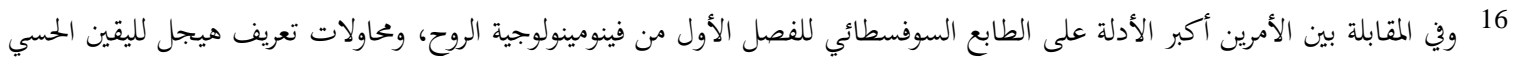
بإرجاعه للعموم الخاوي كما بينا في كتاب: الشعر المطلق والإعجاز القرآين، مرجع سابق، 2000. 
يجعلها تولد في خيال القارئ أو السامع وضعية التبالغ الحي، وكأن ذهن المرء يتحول إلى مخرج مسرحي للأبدوعة الواردة في الأثر؛ شعريا كانت أم روائيا، مكتوبا أم مسموعا أم ممسرحا (في المسرحة الحية أو أو إن المسجلة سينمائيا أو تلفزيا) وكل هذه الفنون يتوسلها القرآن الكريم في التعبير، الذي يجعل القارئ هو المبدع للمقروء، بما تثيره في ملكاته من قدرة على المسرحة الخالقة لوضعيات التبالغ الحي، الذي هو الأسلوب تصني

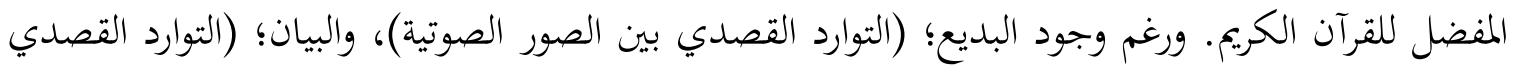
بين الصور الذهنية) في الأسلوب القرآن؛ فإن أدوات تحقيق الأثر التبليغي هذه ليست أهم ما في القرآن لأفها

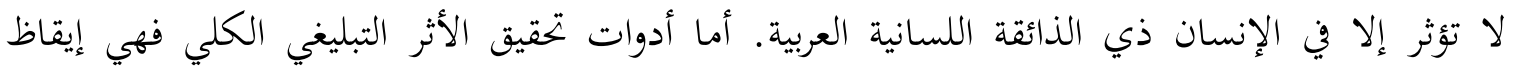
ملكات المتلقي؛ ملكاته لمسرحة الأباديع التي تعتمد دالين ومدلولين في الوقت نفسه؛ الدراما التاريخية وما

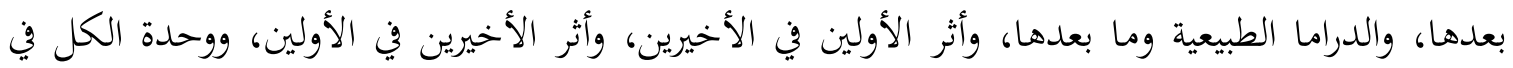

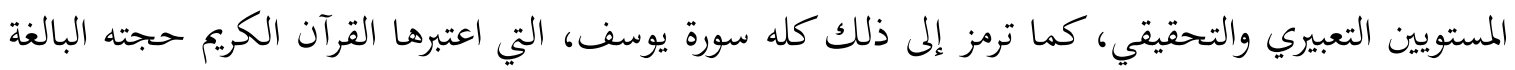
في التبليغ. لذلك فإن أفضل تحليل علمي لعملية الترجمة من هذا المنطلق أن نقول: إذها عملية ترجمة ذات مستويات خمسة، تفترض كلها الخروج من التعبير اللساني إلى المتعاليات غير اللسانية، شرطا في تحقيق تفاهم الذات مع نفسها، ومع غيرها من ثقافتها، ومع غيرها من غير ثقافتها، أما المستويان الأول والثاني فنهم عبارة النص في لغته الأصلية، وهذه ترجمة داخلية في اللغة المنقول عنها في عملية فهم النص، الذي يراد نقله،

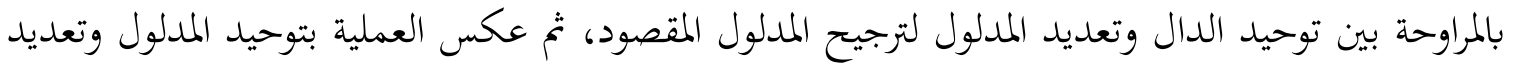
الدال للغرض نفسه؛ أي إن البحث عن المقابل في اللغة المنقول إليها مشروط بتنويع دوال المعنى في اللغة بهنة

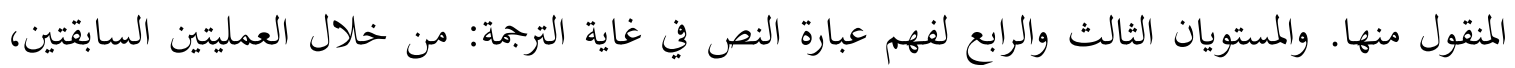
ولكن في اللغة المنقول إليها في شكل مسودات ترجمة، بحسب الآليتي؛ توحيد الدال وتعديد المدلول، ثم

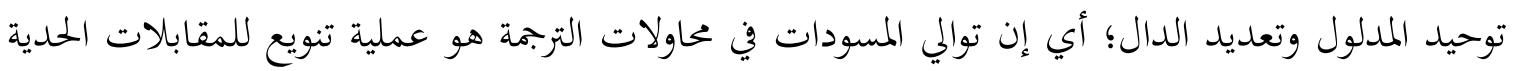
التأليفية في اللغة المنقول إليها بحسب التنويع في اللغة المنقول منها. أما المستوى الخامس: فالشعور بالمطابقة

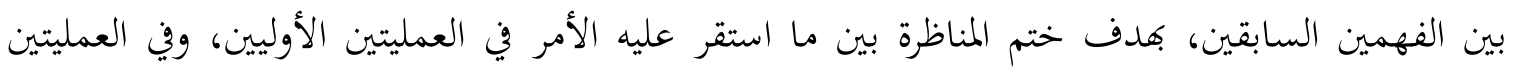

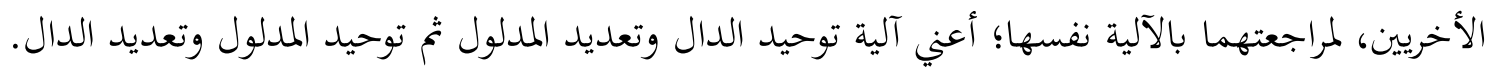

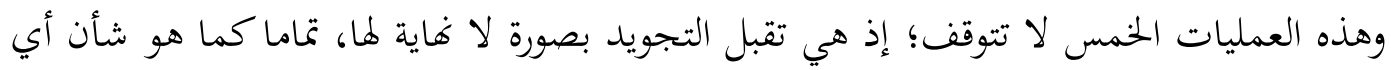

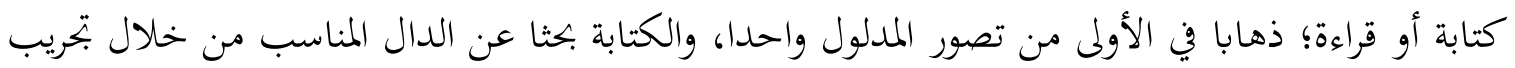
17 انظر تحليلنا لمعاني سورة سيدنا يوسف عليه السلام وعلاقتها بالقيم الحمس وبمؤسساقا العمرانية، ووظائف التربية والاقتصاد والعلم والسياسة والدين، في كتاب الشعر المطلق والإعجاز القرآني، مرجع سابق. 
أدلة عدة، وفي الثانية من العملية المقابلة؛ حيث نتصور الدال واحدا، والقراءة بحثا عن المدلول المناسب من

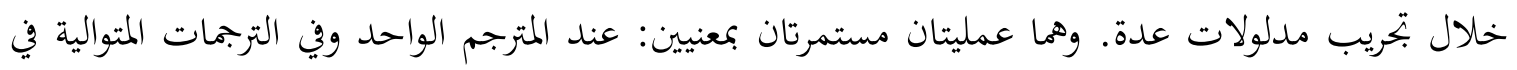

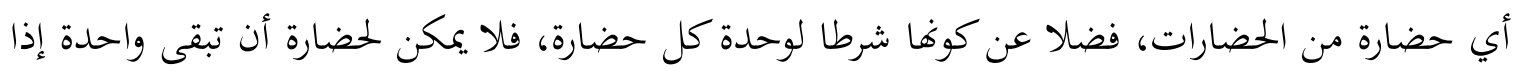

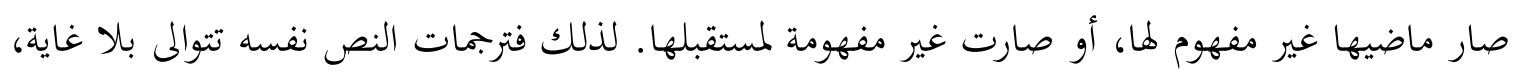

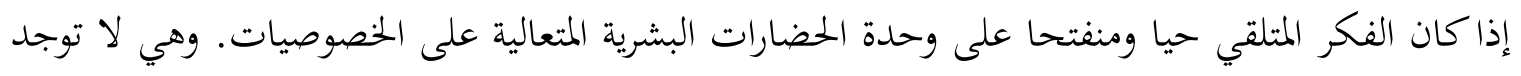

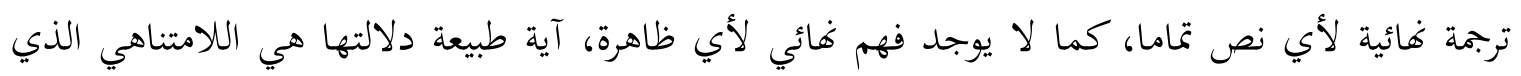
يسعى إليه الإدراك وراء المتناهي الذي ينطلق منه. وبذلك يتبين أن الترجمة قراءة نص باللغة المنقول عنها، وكتابة نص باللغة المنقول إليها. وكلتاهما

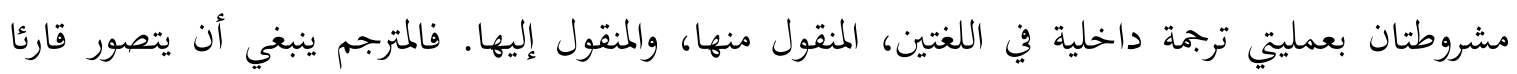

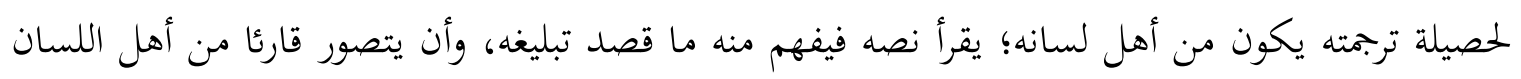

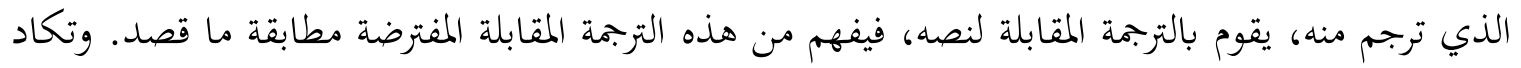

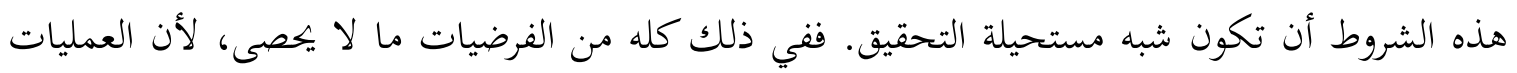

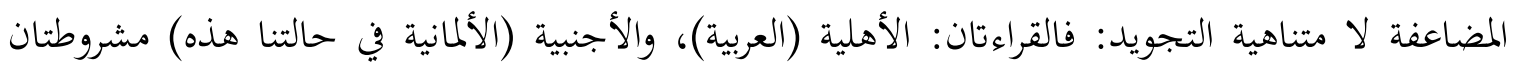

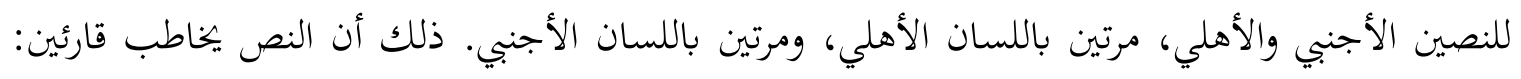

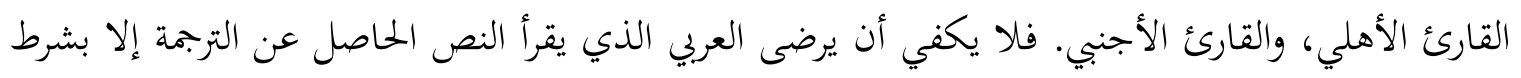

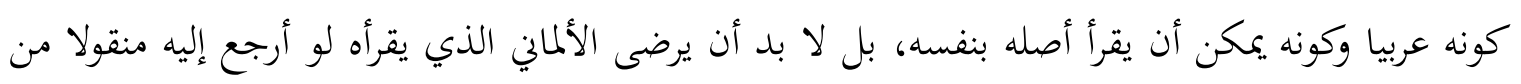

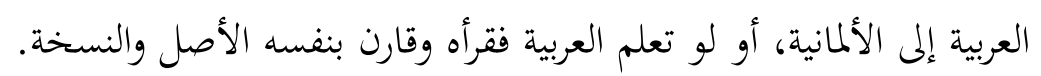

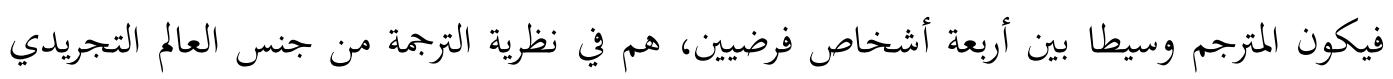

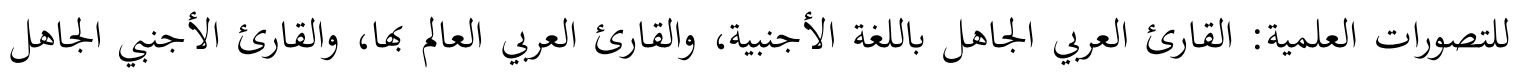

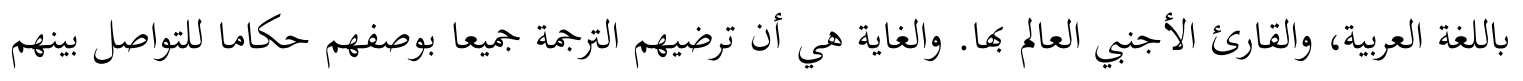

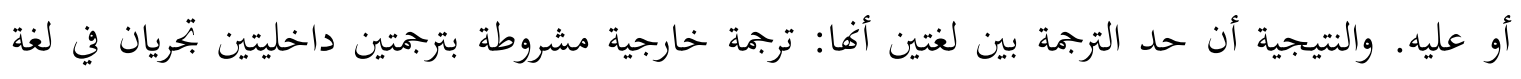

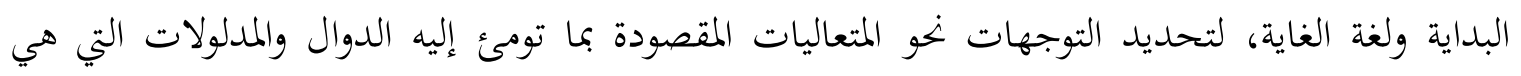

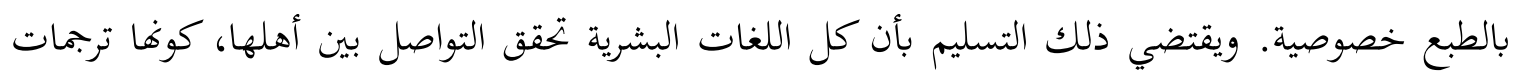

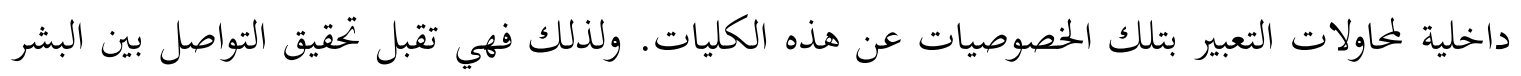

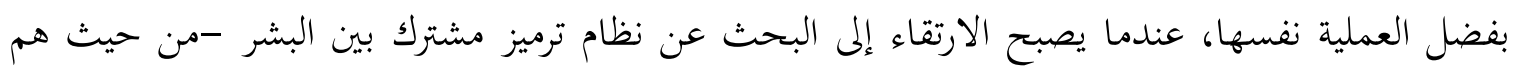

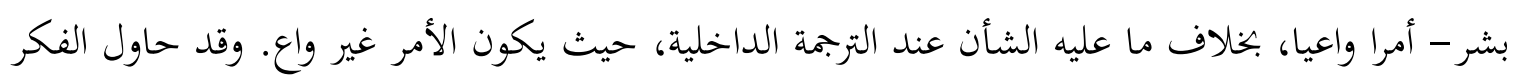

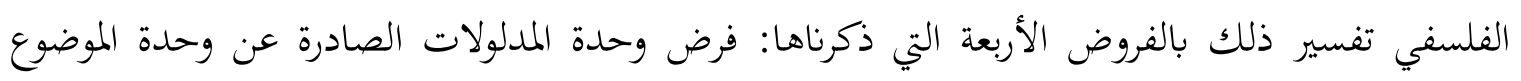


بنوعيها؛ (أفلاطون، وأرسطو)، وفرض وحدة المدلولات الصادرة عن وحدة الذات بنوعيها؛ (كنط،

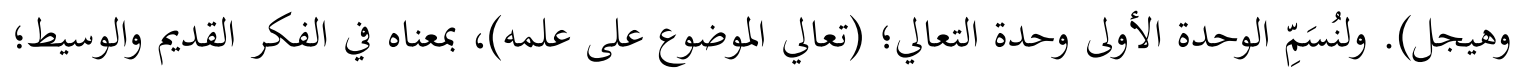
(ترانسدنس؛ أو تعالي الموضوع الذي في غاية القصدية المعرفية شرطا لقيامه)، والوحدة الثانية وحدة التعالي؛ (مشروطية علم الموضوع ببنية العقل المدرك: وذلك هو مدلول القبلي الشارط للتجربة ولموضوعها في النظرية الكنطية)، بمعناه في الفكر الحديث والمعاصر؛ (ترنسندنتال؛ أو تعالي الذات التي في بدواية القصدية التصاية المعرفية

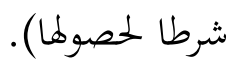

لكن هذه الوحدات الأربع لا يمكن تصورها دون أصلها جميعا؛ أعني الأصل الذي يمكن من بحاوز تعدد الذوات وما بينها من الانفصال والاتصال، وتعدد الموضوعات وما بينها من الاتصال والانفصال، والتقابل بين الذوات والموضوعات في نظام الآيات المتعالية على الفروق بين الموجودات الحائلة دوها،

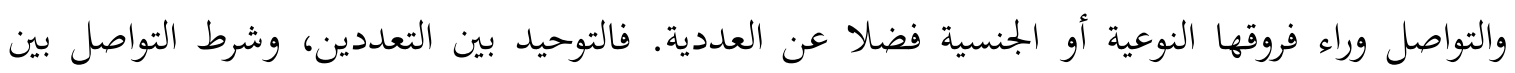

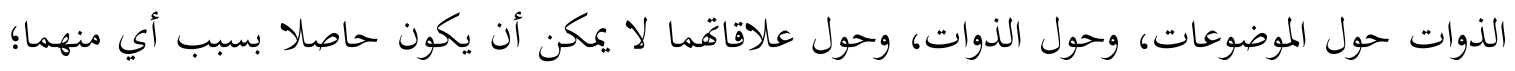

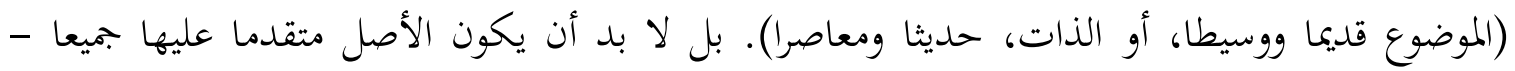
بوصفه ما تنفصل به الذوات والموضوعات وتتصل - تقدما يجعله مصدر قيام الموجودات، ومن ثم تم مصدر انفصالها واتصالها، ومصدر إدراكها، ومصدر تقويم ضروب الإدراك بمقتضى ضروب القيم الخمس، التي هي:

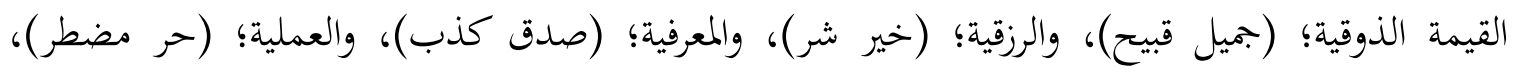
والوجودية؛ (شهود جحود)، ذلك أنه دون التحرر من فصامات الفكر الفلسفي والديني لا يمكن للتآخي البشري أن يحصل، فيبقى البشر في حرب أهلية لا تنتهي حتى وهو يزعم أنه قد حقق العولمة التي آلت إلى إلى

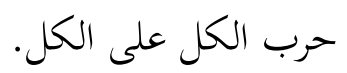

ثالثا: شروط التواصل الكلية ومقوماته: ولكن، كيف يمكن التوفيق بين اعتبار المدلولات نفسها وضعية، مثل الدوال التي تفيدها؛ (ومن تم فهي متغيرة ليس بتغير الثقافات فحسب، بل وكذلك بحسب الممارسات والأجيال في الحضارة نفسها، وهو موقف ليس بالبعيد عن نظرية ابن تيمية في العلم المستند إلى التصورات التمثيلية والرمز اللساني)، وبين القول بوجود ما يتعالى على الحضارات والثقافات، بحيث يمكن للبشر أن يلتقوا وراء خصوصياقم الحضارية، في توجهرم نحو مدلولات كلية وراء المدلولات الخصوصية. ماذا يمكن أن تكون طبيعة هذه المتعاليات إذا لم تكن هي المدلولات، التي تفاد بالدوال اللسانية التي هي بالضرورة خاصة بالأمم أمة أمة؟ والأجوبة تتوزع يتوزع 
على هوامش كثيرة تعالج وجوها يختلفة من المسألة، لكننا يمكن أن نشير إلى أصل هذه الأجوبة بعد التمييز بين أمرين أساسيين، يمكن الاصطلاح عليهما بعقيدة الكلي العملي وفرضية الكلي النظري.

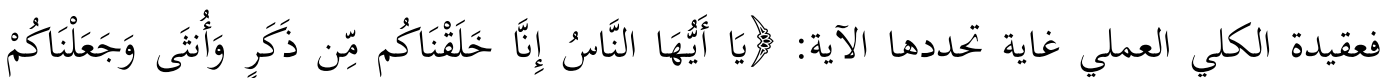

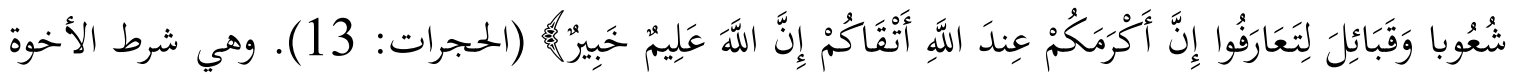

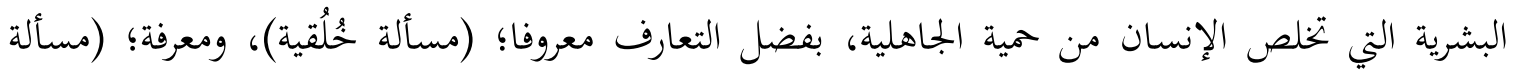
معرفية). وهي من ثم شرط الوجود الخلقي للبشر. وتلك هي العقيدة التي يعتبرها القرآن الكريم نابعة من الفطرة التي فطر الله الناس عليها؛ الفطرة المحددة للغايات الكلية. وفرضية الكلي النظري أداة، ويمكن أن تعد لفيد شرطا في صحة تصور العقيدة الأولى، ومن ثم فهي مثلها عقيدة؛ لأفا كانت في مرموزة استخلاف آدم؟ الحجة التي رد بها الله حجة الملائكة ضد استئهال آدم الاستخلاف. إها شرط المعرفة العلمية التي تخلص تصن الإنسان من الظنون. لذلك فهي الفطرة التي تحدد الأدوات الكلية. إفا تحقق الشروط الإجماعية لطلب

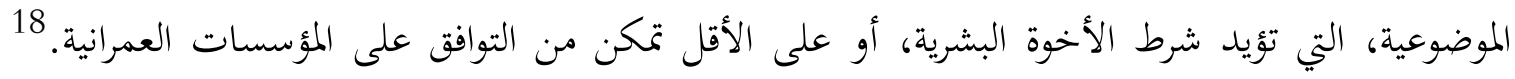

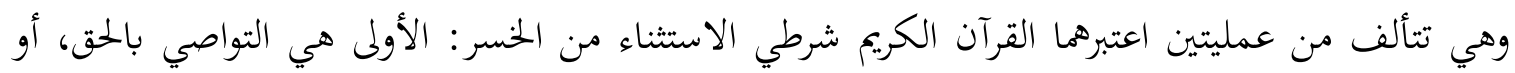

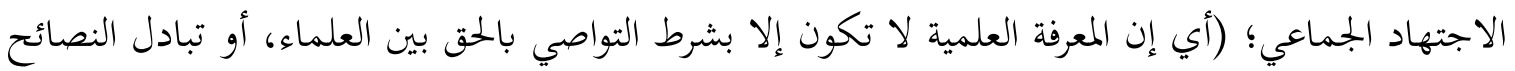

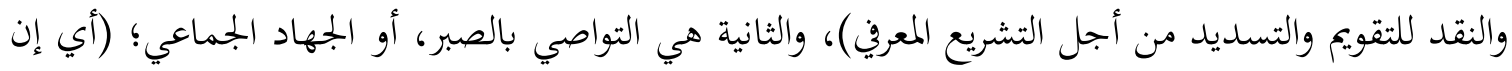

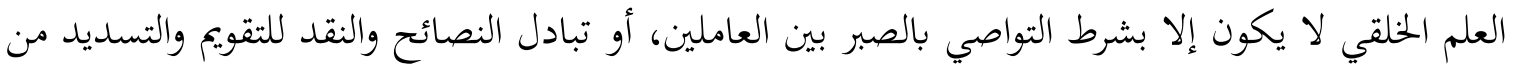

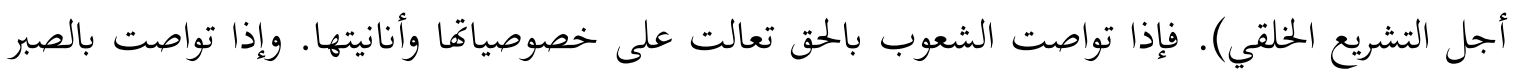

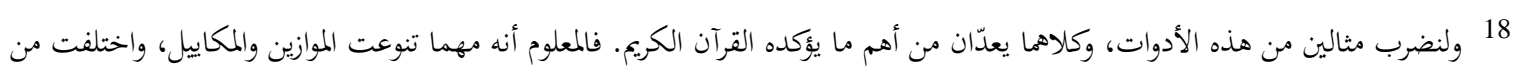

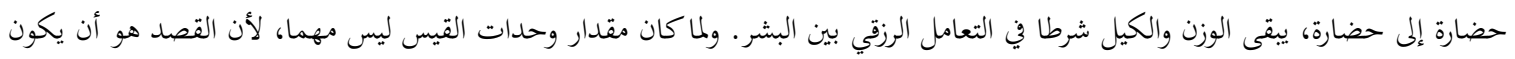

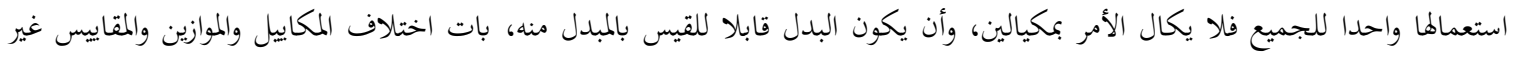

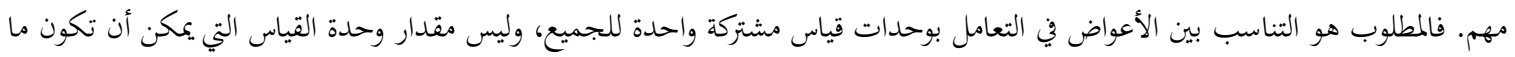

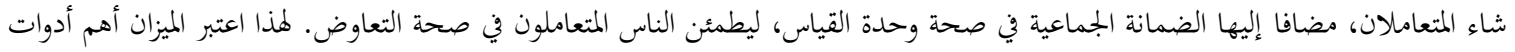

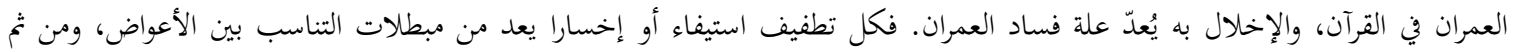

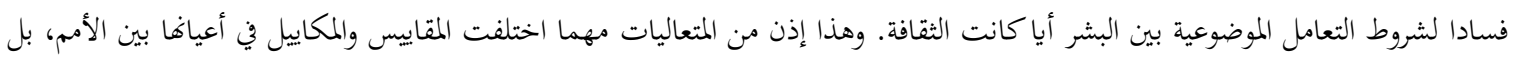

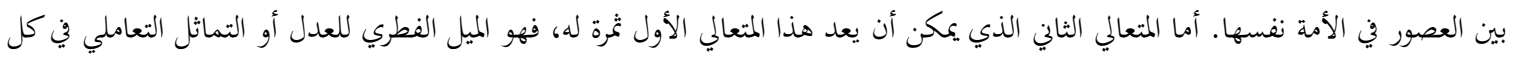

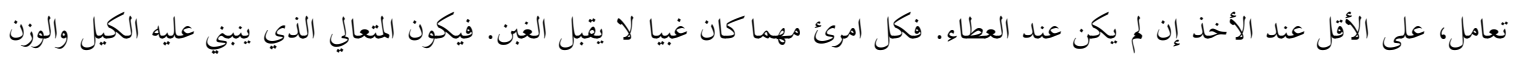

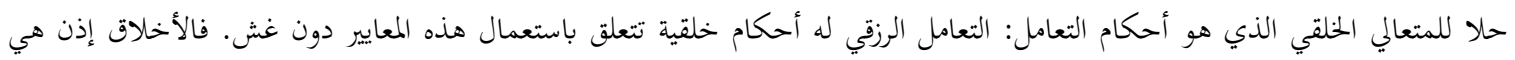

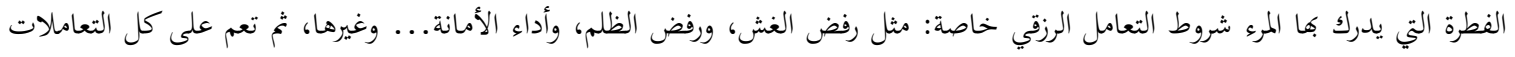

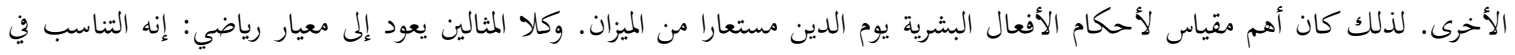

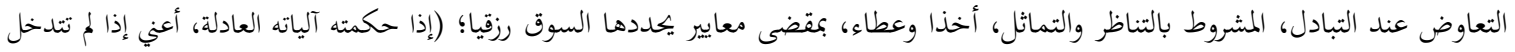
فيه اعتبارات سياسية أو احتكارية)، ويعددها العرف خلقيا؛ (إذا لم تفسد الفطرة، أعني إذا لم تتدخل اعتبارات سياسية تستعمل القوة لغير خدمة الحق). 
تمكنت من قبول الاختلاف، فاستمعت للآخر وحققت شرط التواصي بالحق. ومن ثم فصيغة المشاركة في

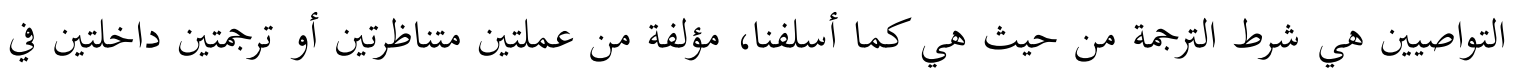

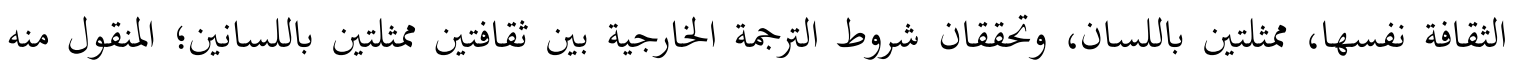

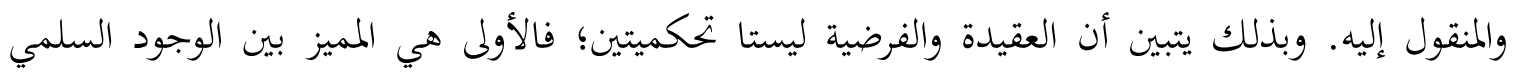

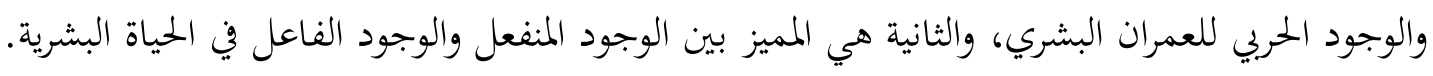
لكن التفسير الحقيقي لمسلمة هذه المحاولة في تحديد العقبات الحقيقية لعملية الترجمة نجده في اعتبارنا

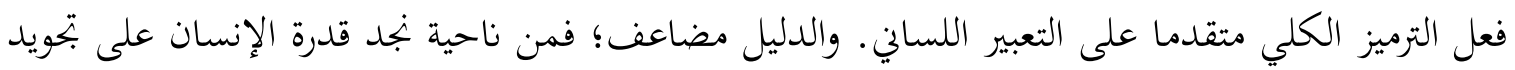

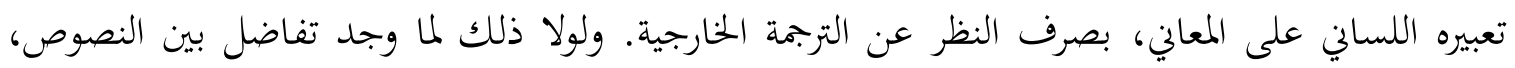
ولكانت الأمم دون آداب. ومن ناحية أخرى قدرة البشر على التواصل دون ترجمة لسانية عند تعذرها أو أونها

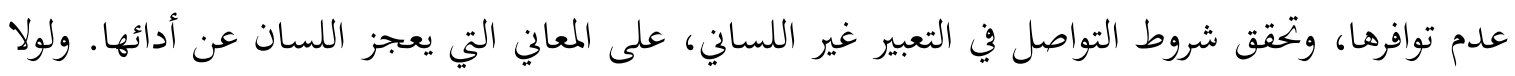

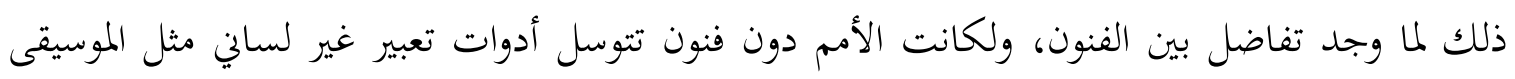
والرسم.

وكلتا التجربتين تفيد بوضوح أن التواصل الرمزي العام -مع الذات ومع الآخر، من الثقافة نفسها أو

من ثقافات مختلفة- متقدم على التواصل اللساني؛ (بععنى تقدم الشارط على المشروط)، ومتأخر عنه؛ (بمعنى

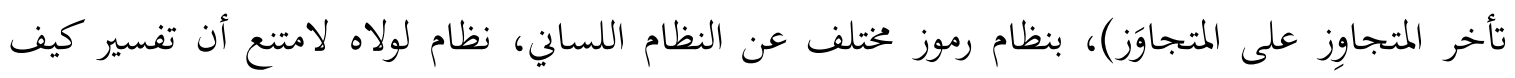

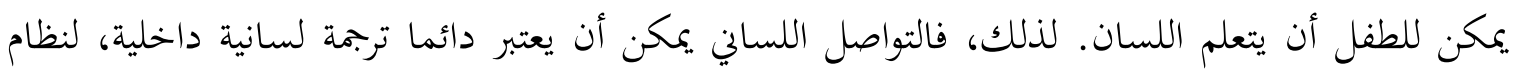

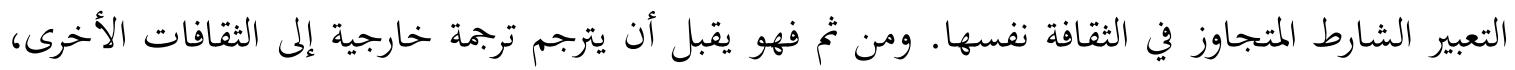

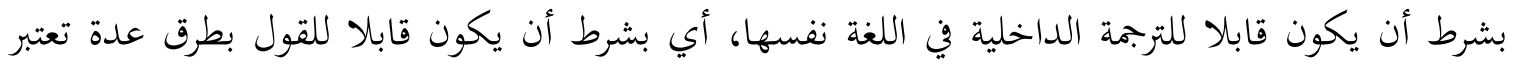

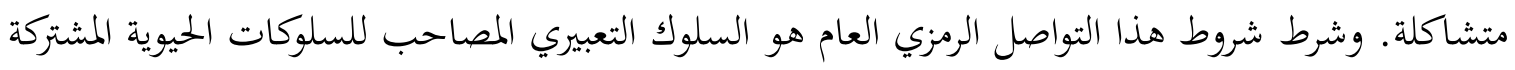

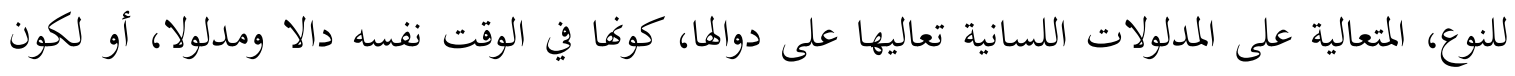
دالها وملولها كليهما عين القيام العضوي، وعين التعبير عن الكيان العضوي.

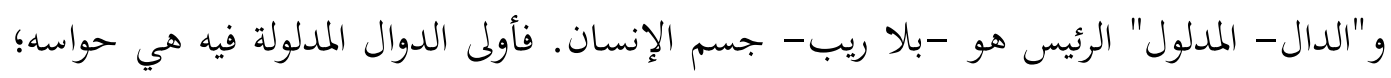

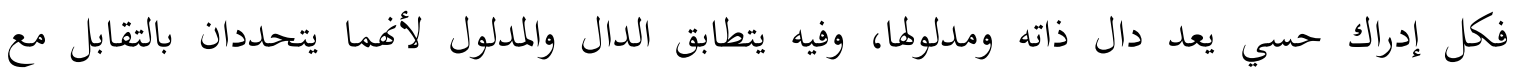

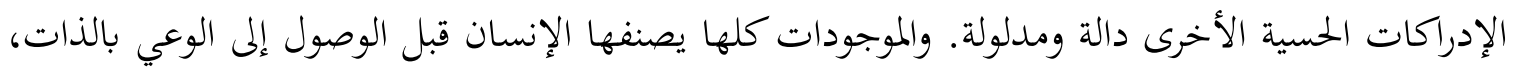

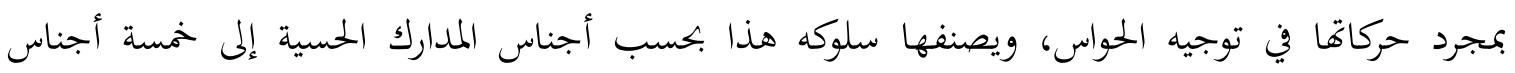

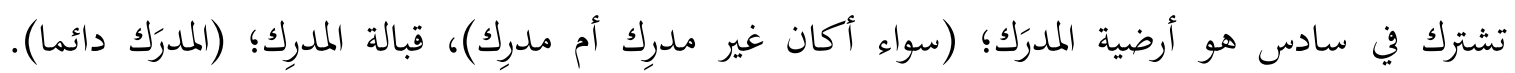

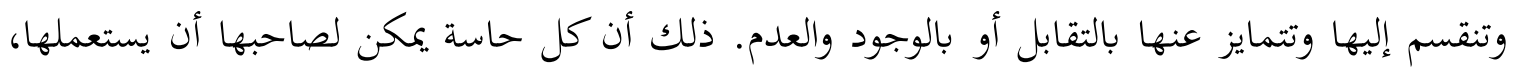


وأن يوقف استعمالها باختياره، أو بحسب تأثير المؤثرات المحسوسة، فيوجد مدركها ويعدمه بفعل الإدراك أو

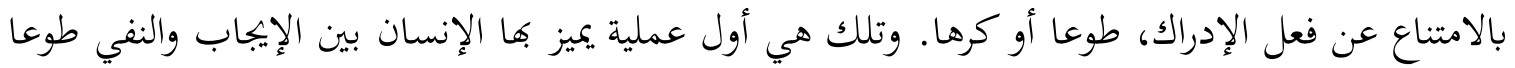

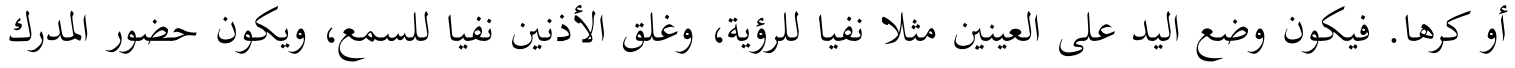

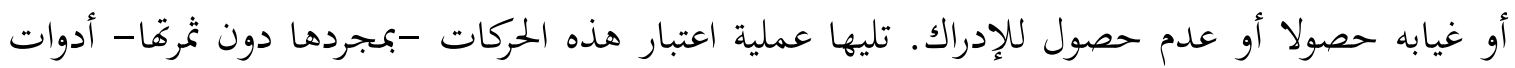
تعبير يستعملها إشارات ليخاطب بها الآخرين، فيبلغهم هذا المعنى أمرا وهيا أو يتبلغ منهم هذه المعاني؛ ولولا

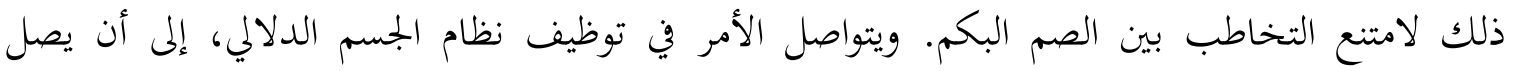

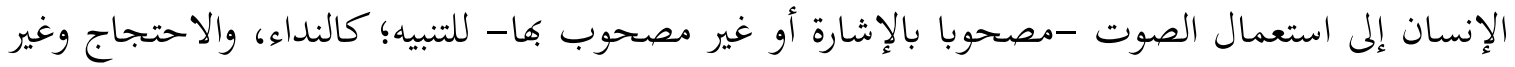
ذلك، وتلك هي بداية التعبير اللساني، الذي هو نظام اختزالي لنظام أكثر منه تعقيدا وشمولا. 19 وكل هذه الدوال المدلولة من حيث هي بدايات إشارية، تتحدد فيما بعد بحسب السنن الحضارية والتقاليد الثقافية، وتعتبر قبل هذا التحدد الشرط المشترك للتواصل المتقدم على التمايز الحضاري والثقافي. وهي ليست معاٍٍ قابلة لصياغة بعينها، بل هي من جنس نقاط المناظر الغائية في لوحة الرسم Point de

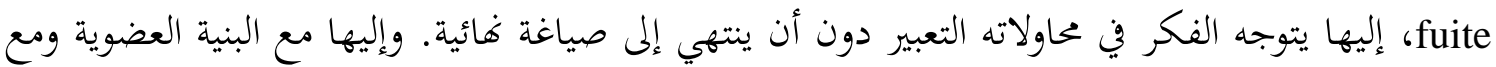

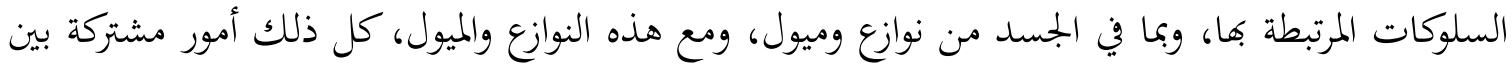
البشر من حيث المضمون، حتى وإن اختلفت من حيث شكل التعبير عنها، أو من حيث كيفيات تحقيقها.

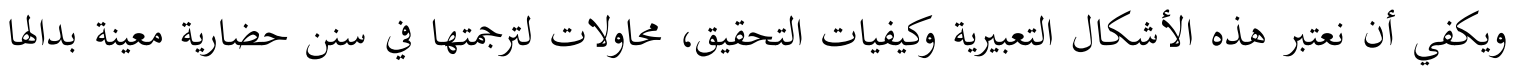
ومدلولها. وتلك هي الدوال والمدلولات المختلفة من حضارة إلى حضارة. لكنها جميعا قابلة للترجمة بعضها إلى بعض، بفضل نسبتها إلى تلك القاعدة المرجعية، التي فيها من التماثل ما يكفي لتحقيق المعاني الكلية المتعالية على المناظر التي انتخبت منها، لتعبر عنها بوصفها في كليتها وكونيتها: "فطرة الله التي فطر الناس

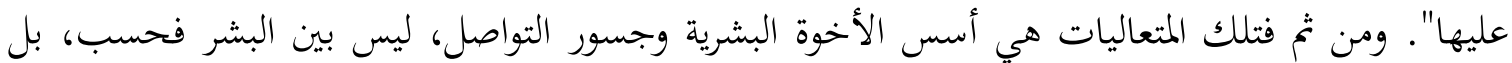
بين أي شخص ونفسه، ومع كل الظاهرات الحية والظاهرات الطبيعية. ولعل أهم المتعاليات الخصائص العضوية للجسد الإنساني، ليس من حيث البنية فحسب، بل وكذلك من حيث الوظائف والحاجات والميول

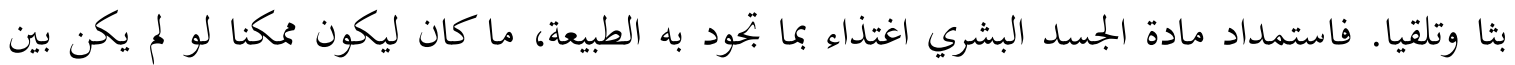
الجسد والنبات والحيوان المغذيين تواصلٌ عضويي،، يحقق النقلة الجوهرية منهما إليه، وإليهما منه. فثمار

19 لا بد هنا من فهم الفرق بين الكلية والتجريد. اللسان أكثر تحريدا من الإشارة. لكن الإشارة أكثر كلية منه لأها توجه الذهن إلى المتعالي

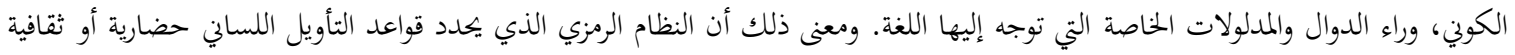

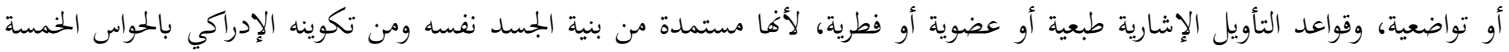
وأرضيتها؛ فعلا، وانفعالا، وعدم فعل وانفعال. 
الأشجار تخاطبنا فتغرينا بنفسها، والمغديات كالمتكلم مع المحتاج إليها وخاصة عند بلوغ الجوع مبلغا معينا.

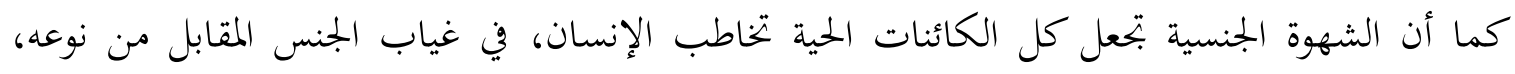
فيتفاعل مع الحيوانات كما هو مشهور في البوادي والأرياف. والتواصل الرمزي مصاحب لهذا التواصل الجوهري، مصاحبة لا تقتصر على التواصل الذي لا يتدخل في مادة الكيان العضوي فحسب، بل يتعداه للتدخل فيه من حيث كيفيات إدراك الكيان العضوي لذاته ولمنزلته في الكون.

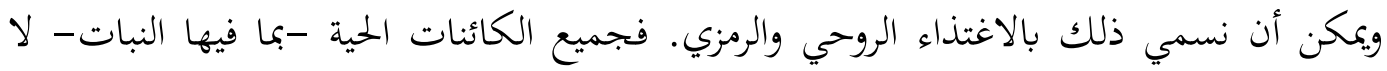
يقتصر التواصل فيها على جسور التواصل العضوي، بل إن الأجيال اللاحقة تأخذ عن الأجيال السابقة ما فالهات يكتسب، دون أن يكون قابلا للوراثة، أو ما يمكن أن يسمى تعلما. ومن خصائص القيم الخمس؛ (الذوقية،

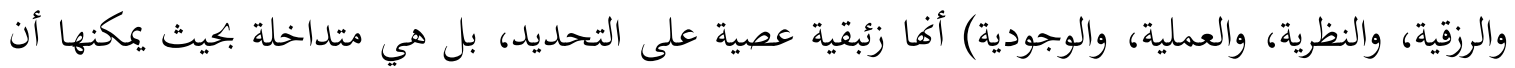

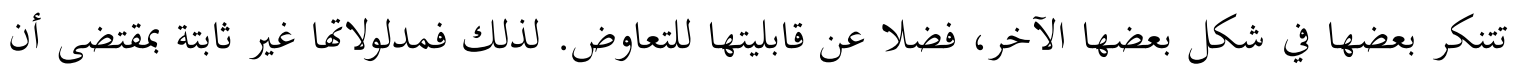

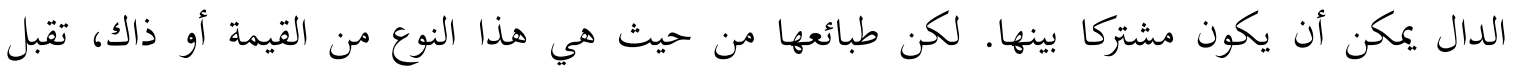

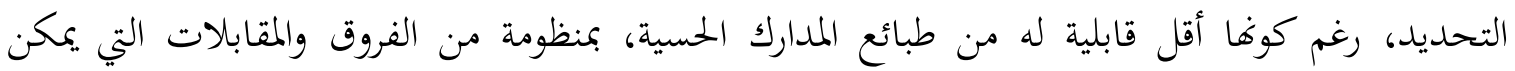

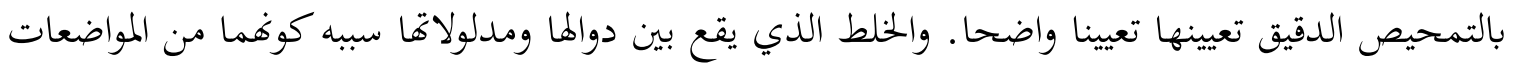
الثقافية والحضارية. لكن ترجمة الدوال والمدلولات يبقى ممكنا بمقتضى التحديد الدقيق لتلك الطبائع، في محاولات التمحيص الدقيق لطلب شرط العمل، وشرط النظر، وشرط الذوق، وشرط الرزق، وشرط الوجود؛ أعني أجناس القيم قياسا على طلب أجناس المدارك الحسية.

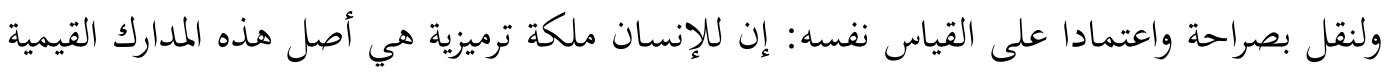

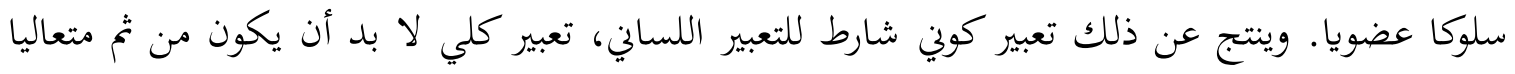
على التمايز اللساني بين الشعوب. وقد سبق أن ناقشنا في كتاب الشعر المطلق، ما ورد في الفصل الأول من فينومينولوجيا الروح حول اليقين الحسي، حيث بينّا الأساس الزائف الذي بنى عليه هيجل كل استنتاجاته، فهو ينتقل من مضمون يقين الإدراك الحسي الذي لا تستوعبه عبارة، إلى عبارته التي لا تستوعب منه إلا

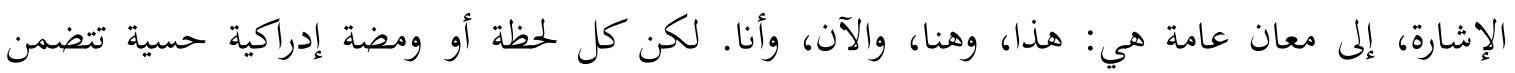

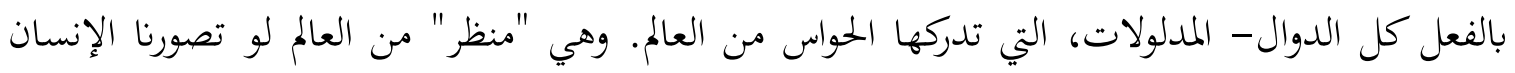
أوقف بعده كل إدراك وسعى إلى التعبير عنه، لتعذر عليه استيفاؤه مهما طال عمره، ودون اعتباره ما يسميه التهيه

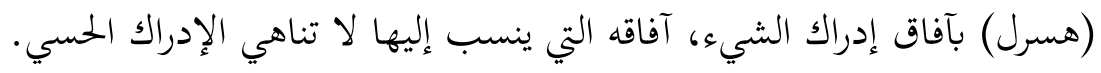

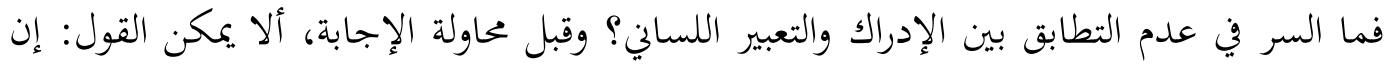
عدم التطابق هو علة وظيفة اللسان الفنية؛ وظيفته التي تنقله من وظيفة الإخبار بدال هو بجرد علامة على 
مدلول سابق له في الوجود، إلى وظيفة الإنشاء لدال هو عين المدلول، أو رحم وجود المدلول؟ فتكون

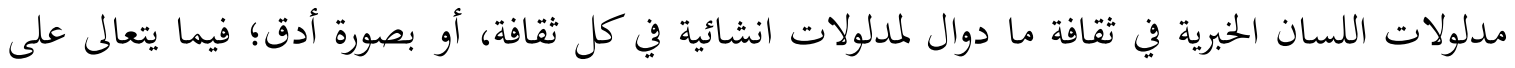
الثقافات؟ لذلك فإن الحل الأمثل ينبغي أن يكون في افتراض وجود مستويين للدلالة، الأول منهما: مستوى الدلالة الخاصة عندما يكون اللسان بمدلوله محيلا على ممارسة ثقافية معينة، وعندئذ يكون الدال والمدلول

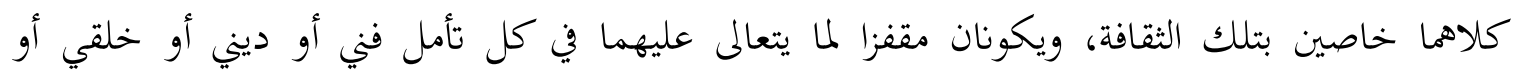
فلسفي، يتعالى على الخصوصيات الحضارية إلى الكليات البشرية. والمستوى الثاني هو مستوى الدلالة الكونية، عندما تتحول تلك الإحالات، إلى دوال مستقلة عن ارتباطها بالممارسة الثقافية المعينة، التي تصبح دوال لمدلولات تتعالى عليها، فتكون مدلولاهما المعنى الأول بالإضافة إلى المعنى الثاني بلغة الجرجاني. ففي المستوى الثاني تتعالى الدلالة الكونية على الدلالة الثقافية، إلى أفق كوني يتمثل في العودة

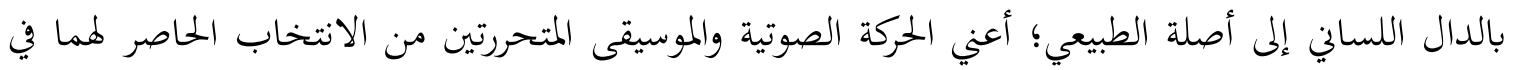

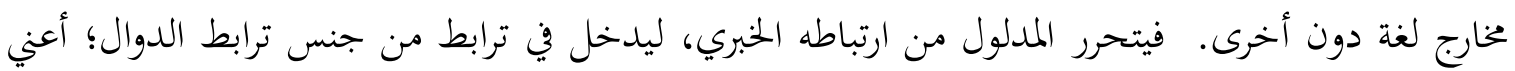
التوازي الموجود بين توارد الأصوات الموسيقي، وتوارد المعاني البلاغي، والعودة بالمدلول اللساني إلى أصله

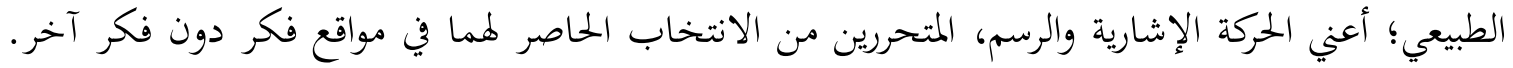

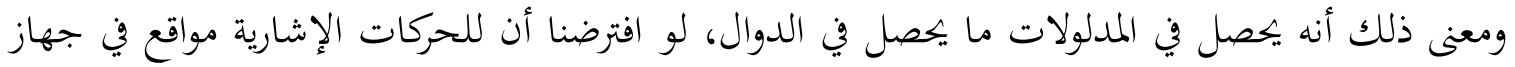
الإشارة الإنساني والبصر، مثل ما للحركات الصوتية مخارج الحروف في جهاز التصويت الإنساني.

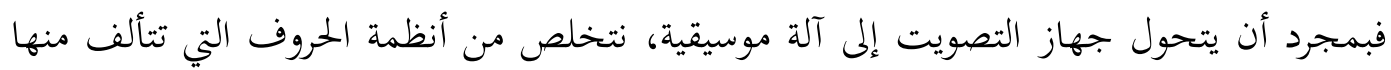
دوال اللغات المختلفة، ليصبح الفم آلة موسيقية كونية. وبمجرد أن يتحول جهاز الإشارة إلى آلة رسمية، نتخلص من أنظمة التصورات التي تتألف منها مدلولات اللغات المختلفة. فيصبح التعبير إيحاءات موسيقية موازية لإشارات رسمية. والإيحاءات الصوتية والإشارات الشكلية توجه الانتباه إلى المعاني الكلية، حيث يكون التعبير مناخا روحيا، يمكن من الآيات المطلقة التي يتطابق فيها وجها الموجود، فلا يبقى بمجرد شيء يدور حوله التعبير، بل يصبح وجوده هو مطابقا للتعبير، فيكون دالا ومدلولا على فعل الوجود المدرك لذاته، في ضرب من الوعي الفني المبدع له.

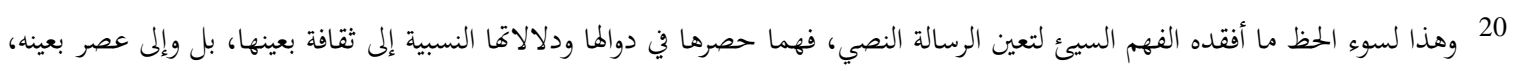

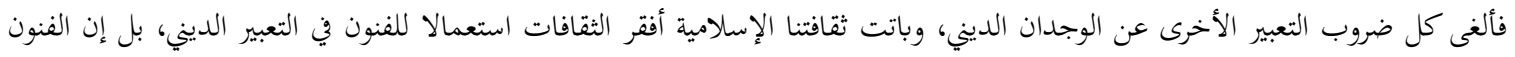

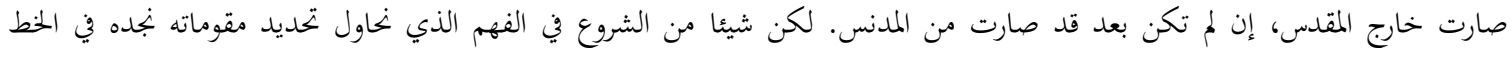

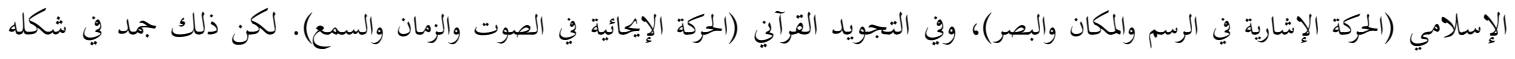

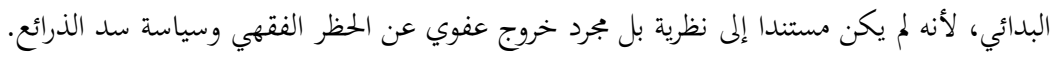


وهذا المتعالي الترميزي لا يتعين بحق إلا في التواصل الحي سلوكيا، وفي الفنون الجميلة تعبيريا، (خاصة

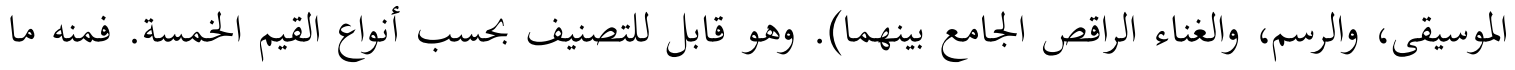

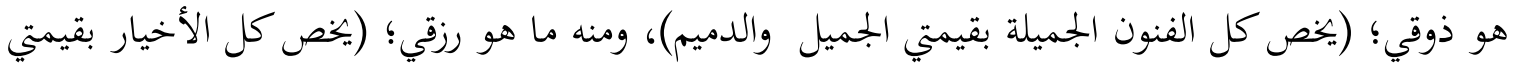

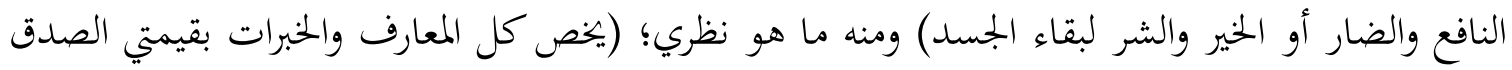

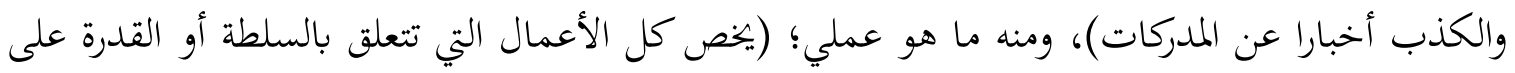

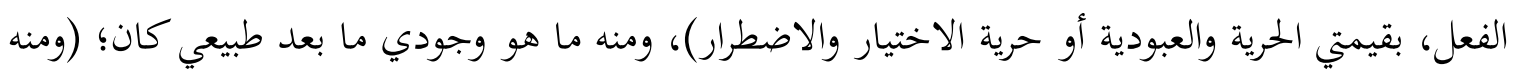
النزوع الفلسفي للبحث فيما وراء الطبيعة لتأسيس حقيقية القيم)، أو ما بعد تاريخي؛ (ومنه النزوع الديني

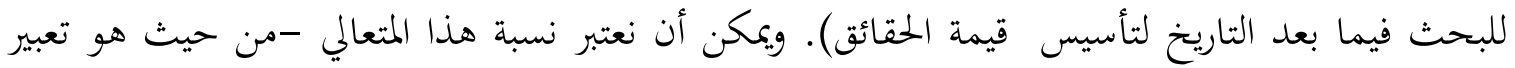

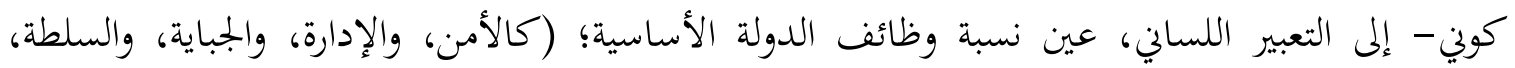
والعنف المنظم) إلى المؤسسات التي تقوم بهذه الوظائف. أما من حيث هو سلوك فنسبته هي نسبة وظائف الحياة ونوازعها إلى الأعضاء وأفعالها.

ولا أحد ينكر أن السلوك الحيوي في الشوق الجنسي مثلا وألا -سلوكا وتعبيرا- تعبير رمزي سلوكي كلي، داله هو عين مدلوله، وهو متقدم على التعبير اللساني، الذي هو في الحقيقة محاولة للترجمان عنه ترجمانا يختلف فيه الدال عن المدلول، ويختلف من ثقافة إلى ثقافة بالدال والمدلول المتغيرين. ولكنه قبل الترجمة

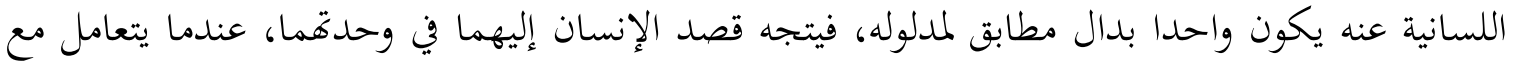
إنسان من ثقافة أخرى ليفهم قصده. لذلك فالتعبير اللساني يتوقف إذا حصل التواصل الفعلي، بالمؤثرات

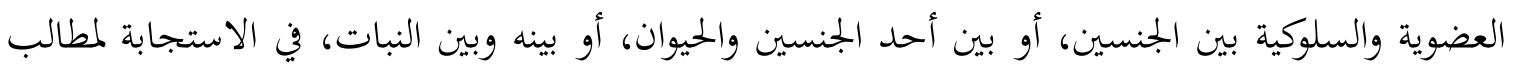

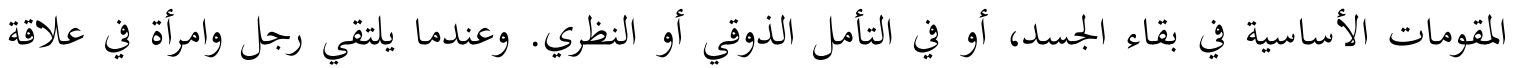
عشق حقيقية مثلا يكونان غنيين عن الكلام، حتى لو كانا من حضارة واحدة فضلا عنهما إن كانا من حضارتين مختلفتين، بل هما قد يعتبران الكلام في الغالب عاجزا عن التعبير الصادق، بل هو أحيانا من التعبير المنافق المخادع المادف إلى الحجب لا إلى الكشف. وكذلك الشأن عندما يستغرق المرء في تأمل منظر طبيعي

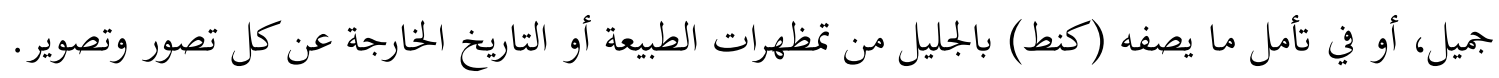

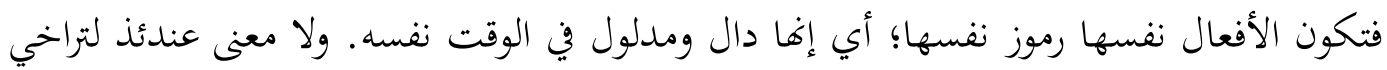

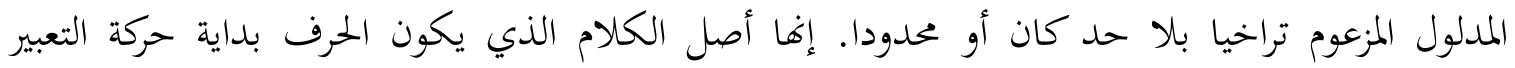
اللساني عنه، بداية هي "صوت - إشارة" تصبح بالتدريج صوتا دون إشارة، كما تصبح القراءة الصامتة

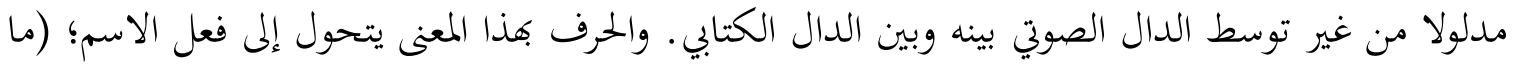
يسمى عادة باسم الصوت)، واسم الفعل؛ (مثل صه وحدك) اللذين يعدان الجسر الواصل بين الترميز المتقدم 
على اللسان، والترميز اللساني كما حاولنا بيانه في كتاب الشعر المطلق. ويكفي أن نتأمل الحروف الدالة على بداية الحركة وغايتها واتجاهها، مثل: من وإلى وعن وعلى، وكل حروف السؤال، وحروف الربط المنطقي والبلاغي. ولعل جُجل أسماء المكان والزمان حروف؛ فدلالتها على الوجهة المكانية والزمانية في الحركة من جنس دلالة حروف الوجهة بالمعنيين. وهي تقال مثل الحروف غالبا مصحوبة بالإشارة المفيدة لمعناها، برفع

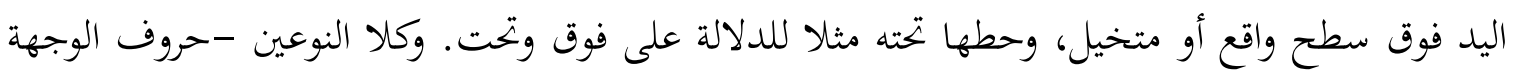
بداية للفعل، أو غاية، وأسماء الوجهة المكانية والزمانية- غالبا ما تكون أصواتا مصحوبة بإشارات مفهومة في كل الحضارات تماما، كما تكون إشارات الأمر بتشغيل إحدى الحواس أو النهي عن تشغيلها مفهومة في كل

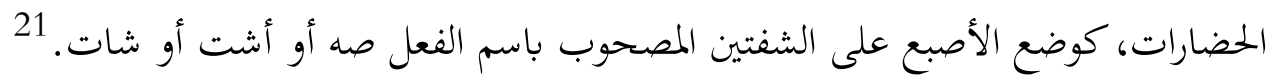

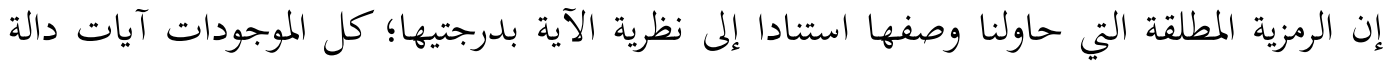

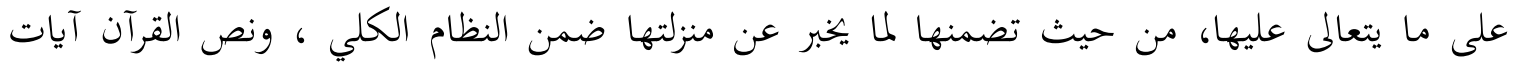

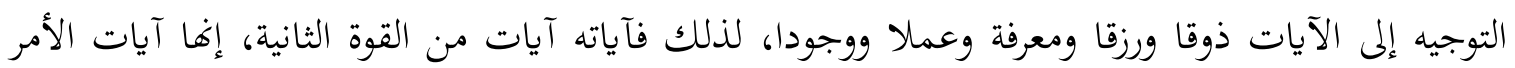

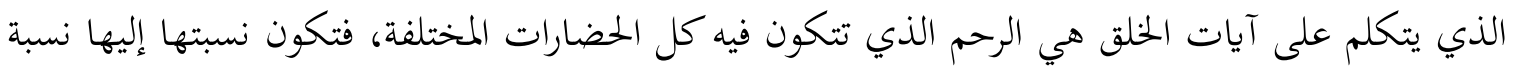
القوارب إلى المخيط. لكن العودة إلى الخيط، تحقق التفاهم بمجرد الخروج من القوارب والسباحة فيه. والخروج

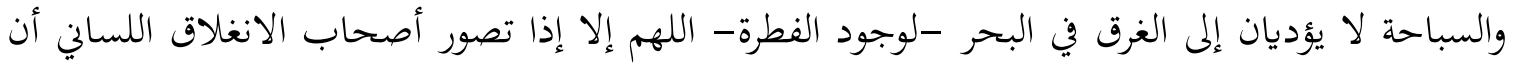

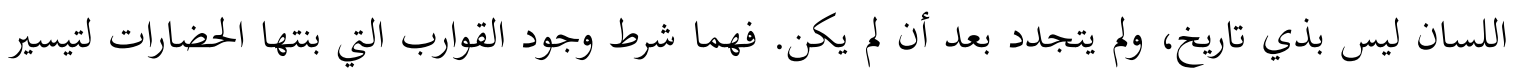
الوجود، دون الحاجة إلى بناء القوارب مطلق البناء في كل جيل، كما هو شأل هأن كل المؤسسات البشرية التي هذه وظيفتها، والتي يتواصل بناؤها خلال أدائها الوظيفة.

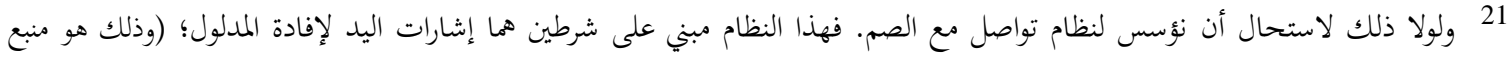

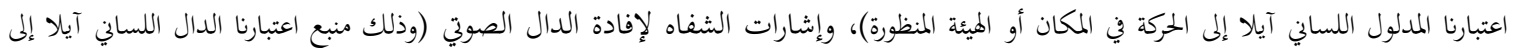

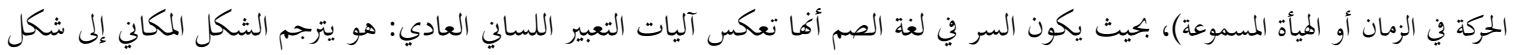

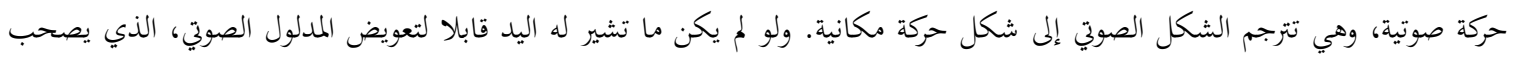

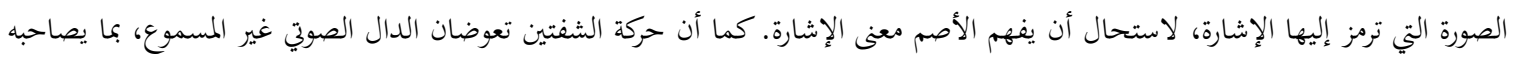

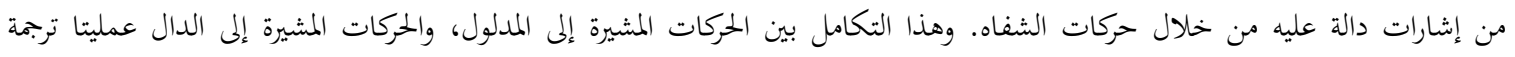

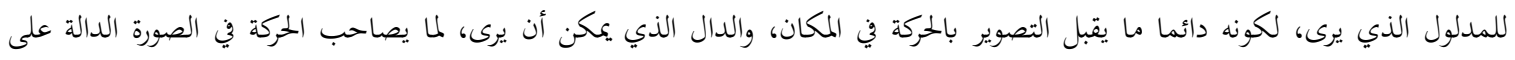

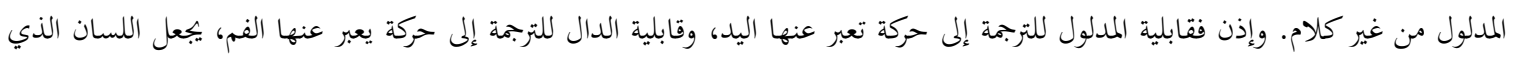

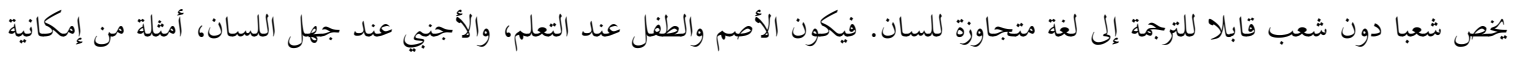

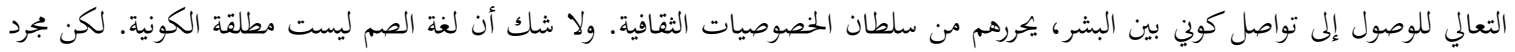

إمكانا حتى في نفس اللغة يجعل الأمر ممكنا كونيا. 
لكننا نعلم أن كل مبدع في كل الحضارات، يكون مبدعا لأنه يواصل بناء القارب، سلبا بمدم ما

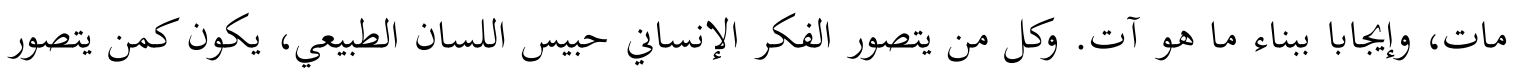

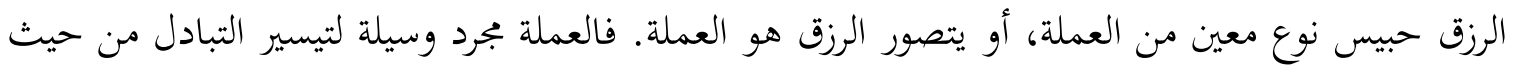

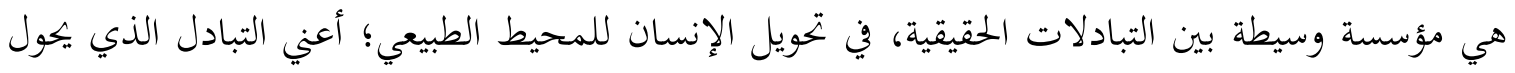
جها العمل إلى حصيلة هي المنتوج، ثم في الغذاء والطاقة بينهما، عند استمداد الإنسان قيامه البدني من

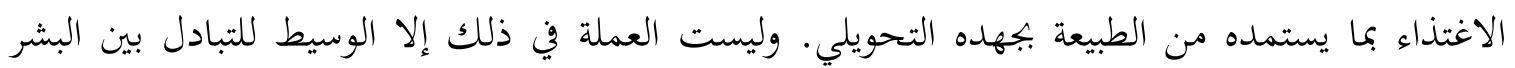
تيسيرا لمعاملاقم، دون أن يكون لها دور من طبيعة التبادل الحقيقي بينهم وبين الطبيعة. 22

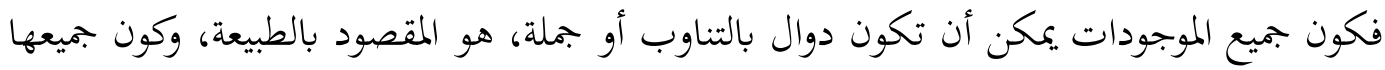

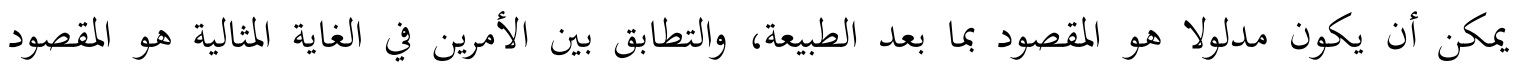
بالوجود، بحيث يكون كل موجود من حيث نتوئه على أرضية، هذه الغاية المثالية هو نسبته إليها، التي يدل عليها محله منها. فإذا اقتصرنا على ما انتخبته حضارة من الحضارات من دوال، وما انتخبته من مدلولات، ليس إلا منظورا هو بنفسه ينتأ على هذه الأرضية، فيتضمن قيامه الذاتي من حيث هو نتوء بالضرورة ذاتية

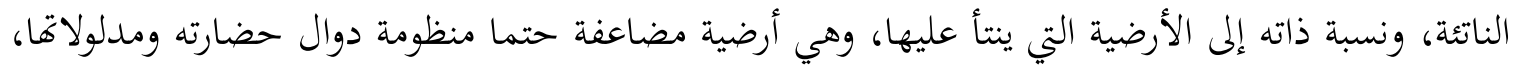

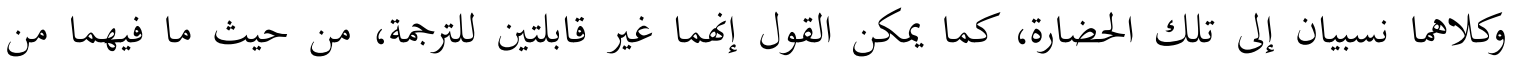
خصوصي، وتقبلان الترجمة من حيث ما تسعيان إليه من متعاليات تشترك فيها كل الشعوب. وبتحاوزهما إلى

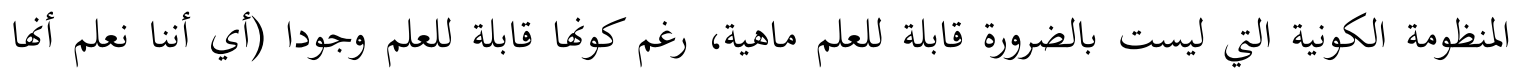

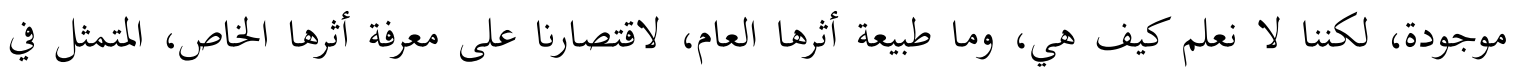

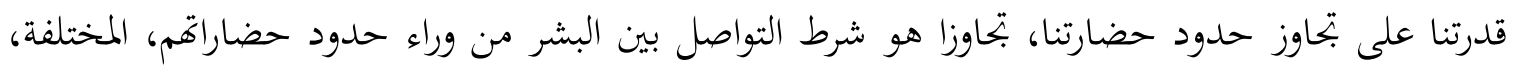

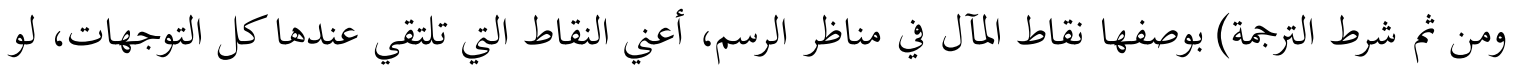

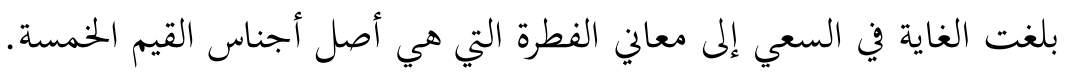

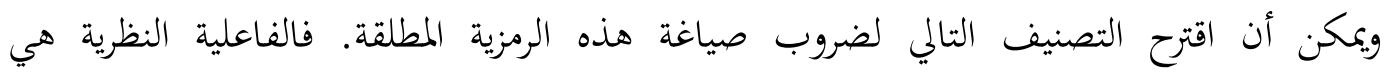
الرياضيات، وعلمها هو المنطق (بالمعنى الضيق)، والفاعلية العملية هي السياسيات، وعلمها هو التاريخ (بالمعنى الضيق). والفكر الفلسفي يعالج هذه الضروب الأربعة، من الصياغة من منطلق الفاعلية النظرية إلى الى

22 وفي الحقيقة فإن اللسان لا يقول شيئا عن الأشياء، وليس له دلالة إلا في نظام التبادل الوسيط بين البشر، من حيث التداول حول التبادلين

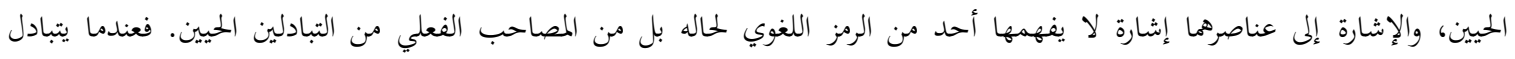

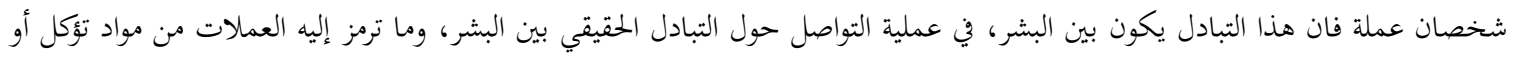
تلبس أو تصنع، فلا يتم التفاهم إلا من خلال هذه الممارسات المصاحبة للتباد التبادل الرمزي اللساني. 
الفاعلية العلمية. والفكر الديني يعالج نفس الأمور من المنطلق المقابل، أي من الفاعلية العملية إلى الفاعلية

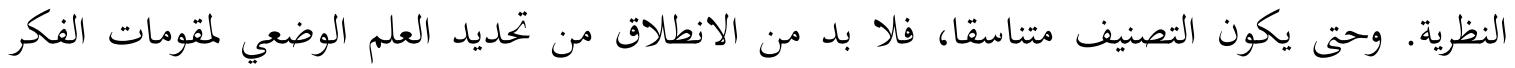
الديني، ومقومات الفكر الفلسفي، في هذين التوجهين المتقابلين (مشفوعا بموقف الإسلام منها رمزا إليه

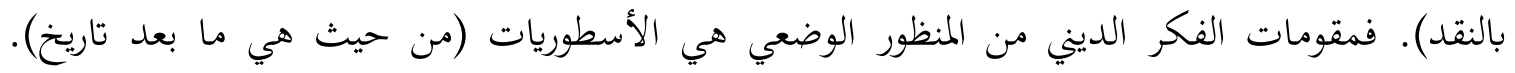

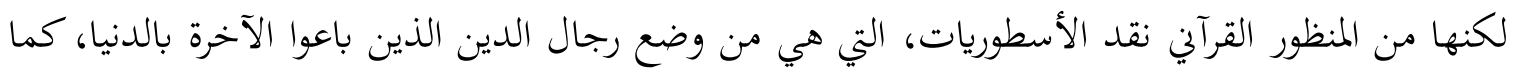

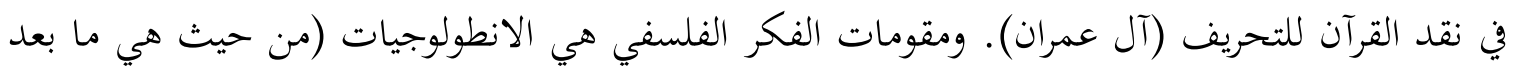

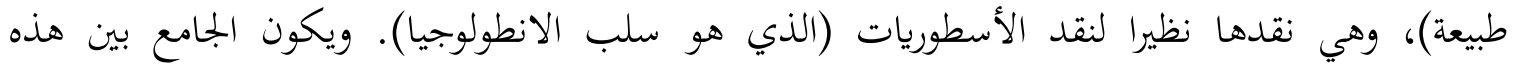

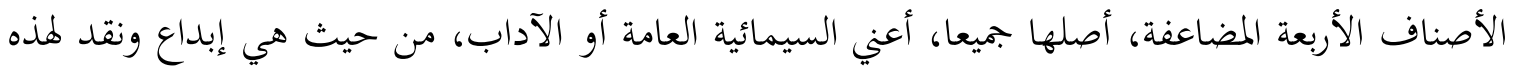

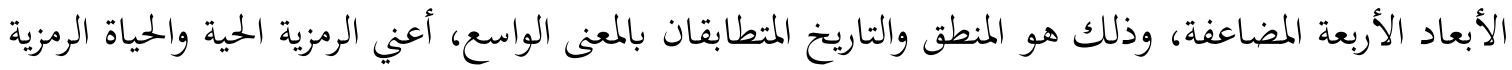

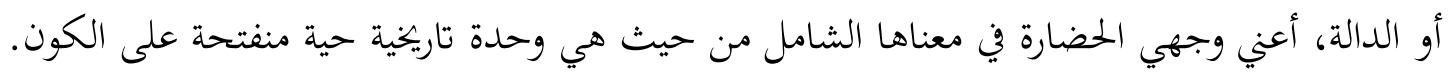

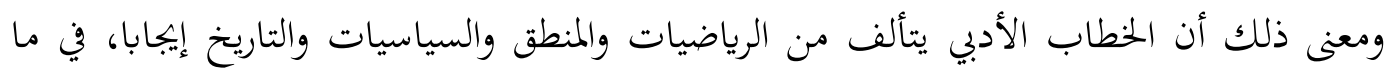
يشبه البعد الواعي من الحضارة (باستعمال قانوني الشكل وقانوني المضمون)، وسلبا في ما يشبه البعد اللاواعي من الحضارة (باستعمال نقيض ما يتصنعه تلك القوانين). وذلك لأن الخطاب الأدبي يتضمن هذه

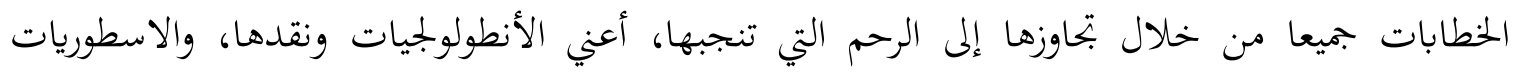

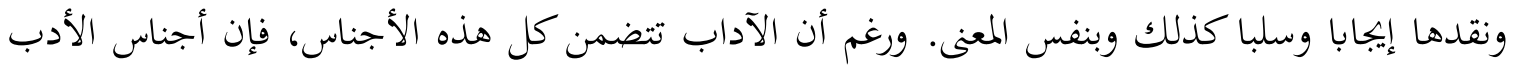

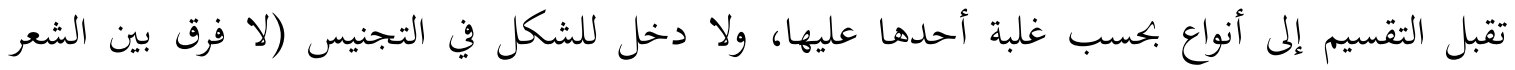
والقص، لأن للقص شعرية معينة وللشعر قص معين). فيكون الأدب أدب خيال رياضي ومنطقي (المنطق

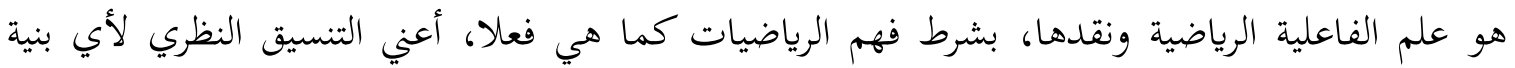
مجردة، لتقبل العلاج والتحقيق العقليين)، وأدب خيال سياسي وتاريخي (التاريخ هو علم الفاعلية السياسية ونقدها، بشرط فهم السياسيات كما هي فعلا، أعني التنسيق العملي لأي فعل ليقبل العلاج والتحقيق

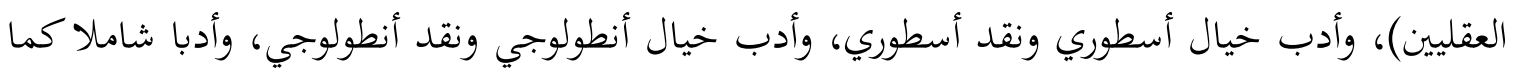
هو شأن النصوص الدينية الأرقى. وادئ. وهذه النصوص عندما ننظر إليها في ذاتا، وبصرف النظر عن الاعتقاد إيمانا بها أو عدم إيمان، هي

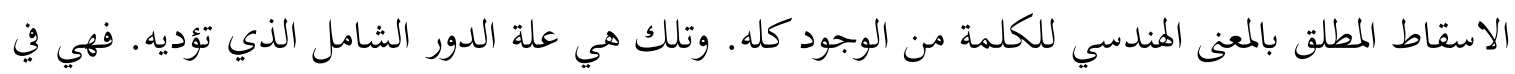
نسبتها إلى السيمياء أو الرمزية العامة التي أشرنا إليها، تقبل استعارة نسبة العالم الصغير (النص الديني المرجع)، إلى العالم الكبير (نظام الموجودات من حيث هو نظام دوال شامل، لنظام الموجودات. من حيث هو نظام مدلولات شامل). وكل نوع من هذه الأنواع مع الممارسة التي يتوجه إليها في التاريخ الفعلي، هو الرحم 
الذي يتصور فيها النوع الذي يستمد منه وصفه وينمو ويتطور . فالعلم الرياضي مثلا يتصور في الخيال العلمي

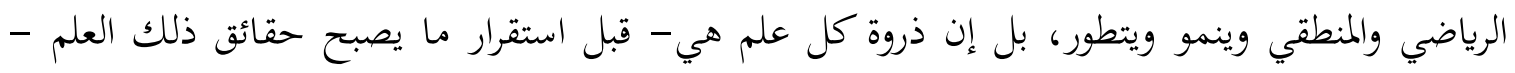

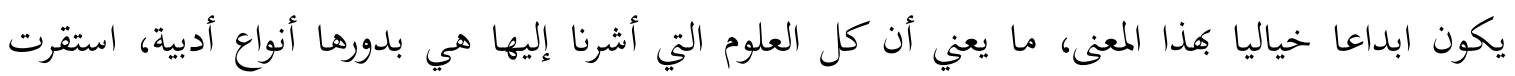

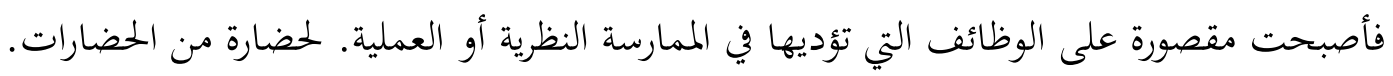

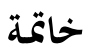

وقد اقترح العقل البشري لعلاج شروط التواصل السوي بين البشر، حلَّين مضاعفين، أحدهما معرفي

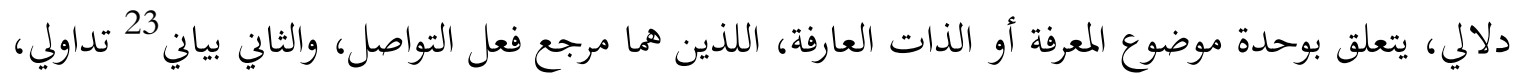

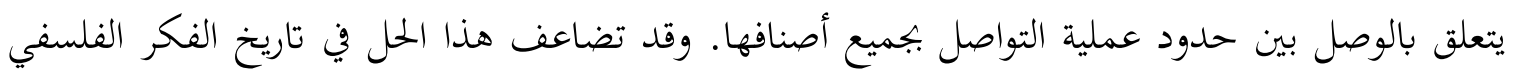

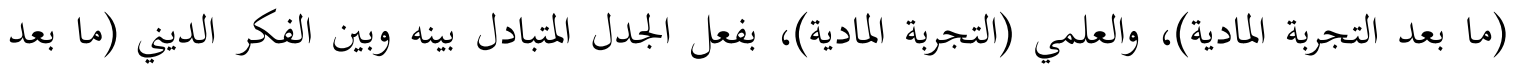

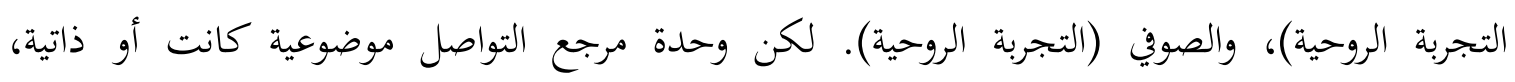

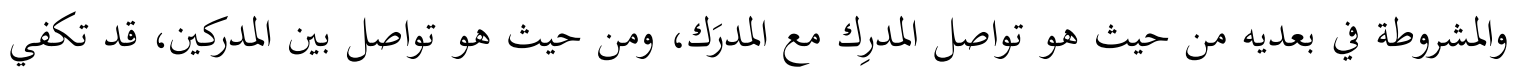

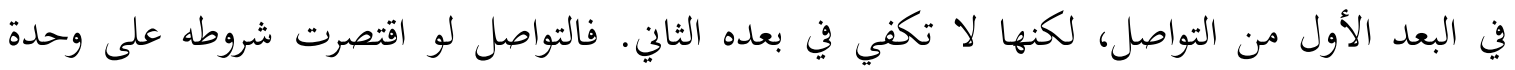

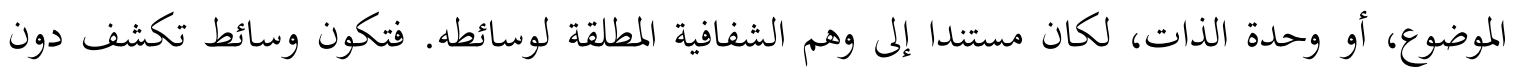

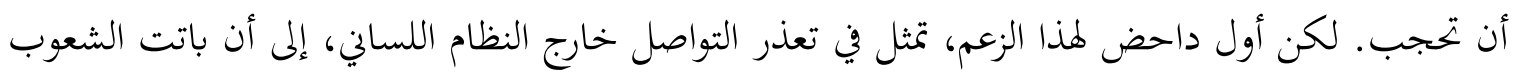

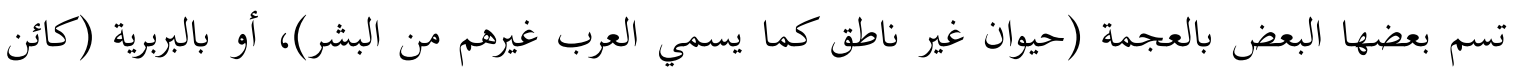

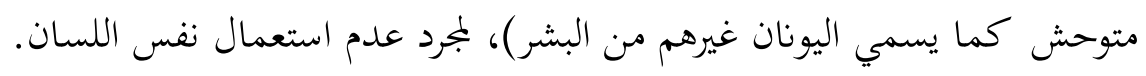

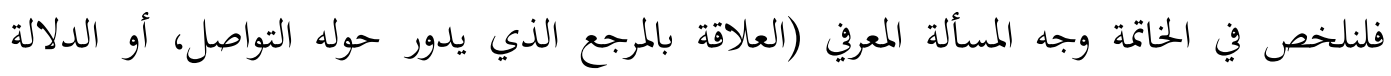

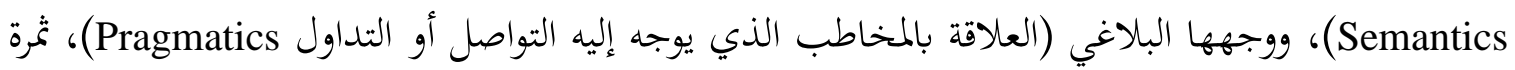

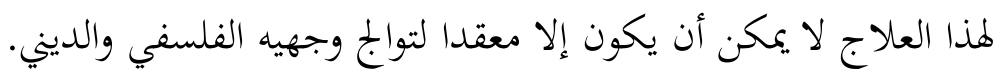

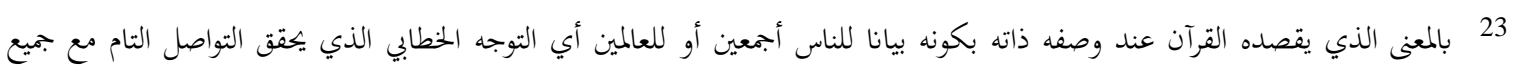

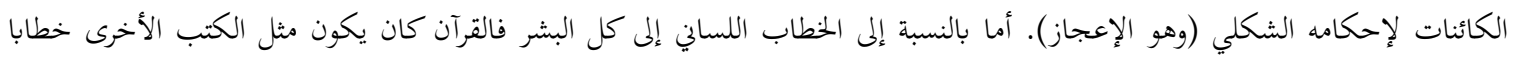

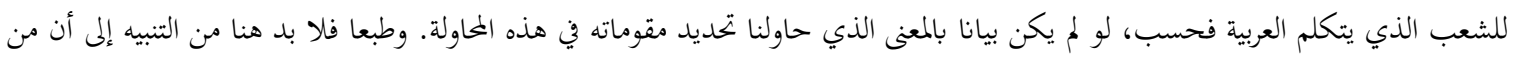

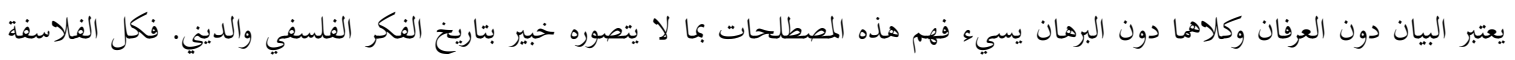

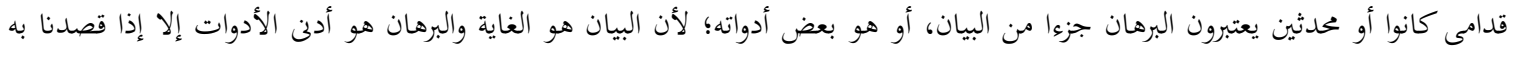

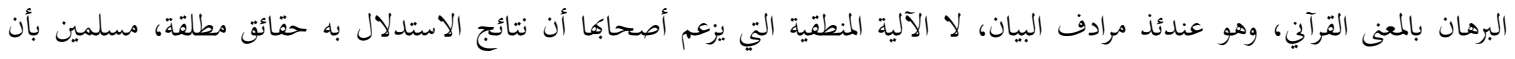

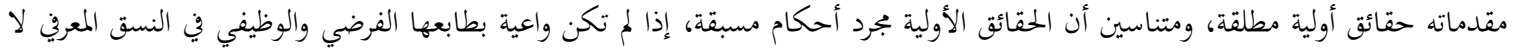

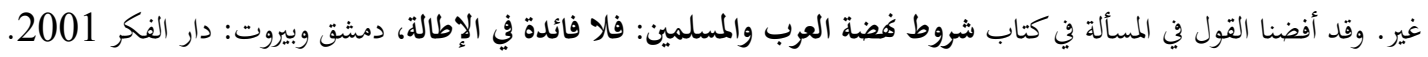


فالحل المعريف الدلالي يتفرع إلى: حل الوحدة الصادرة عن وحدة موضوع العلم، وحل الوحدة الصادرة عن وحدة الذات العالمة. فالموضوع يعتبر مصدر وحدة المعنى، لكونه الجامع بين الرموز الدالة عليه، إما مباشرة عند من يتصور الشيء مرجعا مباشرا للدال من حيث هو مجرد علامة، أو بتوسط معنى ذهني تصوره الفلاسفة كونيا مشتركا بين كل البشر. وجملة كل المعاني التي توازي جملة الموجودات هو ما يسمونه

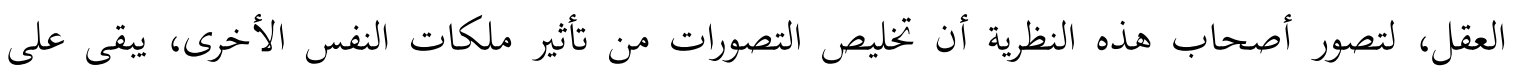
العقلي من المدارك، فيحصل التطابق بين المنطقي والوجودي. وهذا هو الحل القديم إلى حدود قلب العلاقة بين الموضوع والذات بتوسط الفكر الديني، الذي لا يقبل أن ينسب وحدة العلم الإلهي إلى معلومة، لتقدم العلم على المعلوم في العلم الإلمي، ثم عمم ذلك على العلم الانساني في الفلسفة الحديثة والمعاصرة. والذات تعتبر مصدر وحدة المعنى، لما وقع التمييز بين قيام الشيء في ذاته، وقيامه موضوعا للعلم الانساني. وبهذا المعنى فإن الفكر الفلسفي الحديث ديني إلى الأذقان، لأنه اعتبر وحدة الموضوع مصني مصدرها

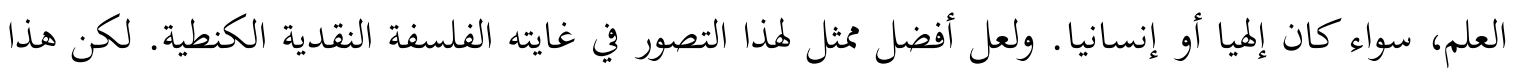

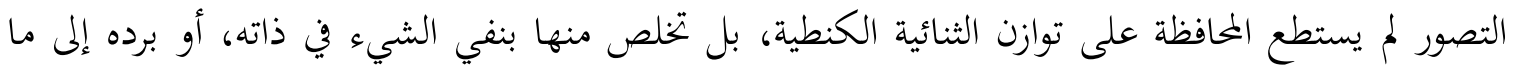
يدركه البشر. لذلك كانت الوحدة مستمدة من ذاتوية إنسانية خالصة، تنتهي إلى النسبوية الثقافوية، التي غلبت على فكر ما بعد الحداثة، ويككن أن تكون الوحدة مستمدة مما تقول به المثالية الألمانية، التي عادت إلى أصل هذا الانقلاب، أعني أن يكون العقل الذي تستمد منه الوحدة عقلا إلهيا، حل في الإنسان تأويلا فلسفيا للعقيدة المسيحية. ولعل أفضل تعين لهذا التصور نظرية الروح الهيجلية.

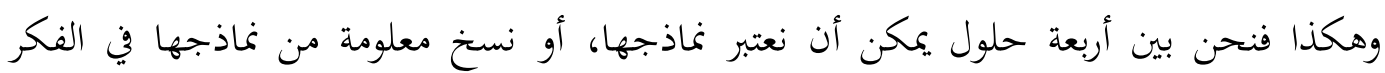
الانساني المعلوم منها، الفلاسفة الأربعة: أفلاطون وأرسطو وكنط وهيجل. وطبعا فلا واحدة من هذه الفرضيات بقابلة للإثبات أو للنفي عقلا، لأهما فرضيات أو عقائد بحسب درجة الالتزام هما. ومن ثم فكلها حلول فرضية أو إيمانية. وفي الحالتين يصبح معيار الحيار بينها معيارا نفعيا وذريعيا، في مستوى النظر أو في

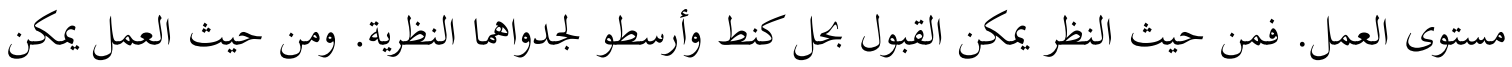
القبول بحل أفلاطون وهيجل لجدواهما العملية. والحل البياني التداولي يتفرع إلى مسألتين هما: مسألة التواصي بالحق غاية منظورية في النظر الذي يطلب الحقيقة، لتجاوز خصوصية مدلولات الحقيقة بالاجتهاد الجماعي: وذلكما هما وجهاه. ومسألة التواصي بالصبر غاية منظوية في العمل الذي يطلب الحق، لتجاوز خصوصية مدلولات الحق بالجهاد الجماعي: وذلكما هما وجهاه. فيكون الاجتهاد والجهاد بما هما فرضا عين لا يتحققا إلا جماعيا (من هنا صيغة المشاركة)، هما مرقاتا التجاوز الواصل بين خصوصية التعينات وكلية الغايات. ذلك أن ضرورة التوحيد 
بين معايير النظر ومعايير العمل من المنظور القرآي -كما نسعى أن نثبت في غير موضع- توجب البحث

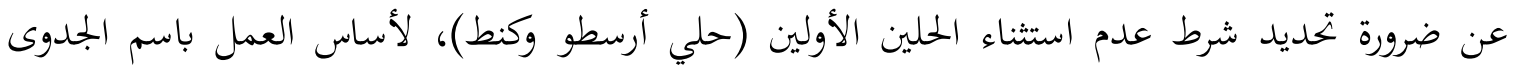
النظرية، وعدم استثناء الحلين الثانيين (حلي أفلاطون وهيجل)، لأساس النظر باسم الجدوى العملية. وهذان المعياران السالبان لعدم الاستناء، هما بالضبط معيارا الاجتهاد والجهاد، ومن ثم فهما الداعيان إلى التشكيك في الحلول الأربعة المتفاصلة، للبحث في حل خامس يصل بينها، لاها تنبع منه جميعا تأويلا له بتغليب هذه الوجوه في فهم الوحدة. لذلك كانت نظرية المعرفة القرآنية نظرية تربية في آن. فالتواصل المعريف لا يتحقق بين

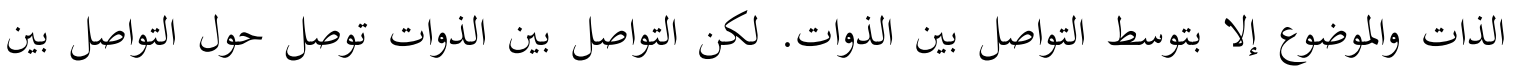
الموضوعات، لان ما نعلمه ليس عين الموضوع، بل شبكة علاقته بالموضوعات الأخرى. فتكون المعرفة في حقيقتها فعل تربية جماعي، للتوصل بين البشر فيما بينهم وبينهم وبين عالمهم، برعاية خالق الجميع (وذلك هو مدلول نسبة الرب إلى العالمين في القرآن جمعا بين العالم والمقيمين فيه).

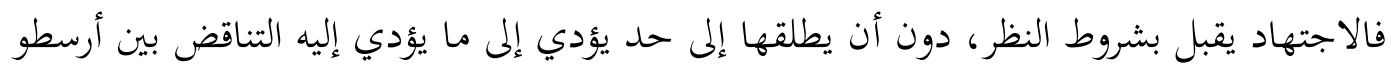
وكنط. فكنط يقبل بالحل الأرسطي بشرط أن يحصر الصورة في ظاهر الطبيعة، فيكون شرط النظر ان يكون

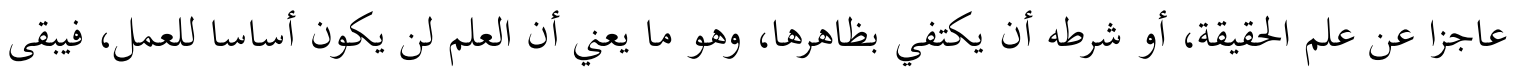
العمل مستندا إلى مجرد العقد. والجهاد يقبل بشروط العمل، دون أن يطلقها إلى حد يؤدي إلى ما يؤدي إليه التناقض بين أفلاطون وهيجل. فهيجل يقبل بالحل الأفلاطوني بشرط حصر المثال في حاصل التاريخ، فيكون

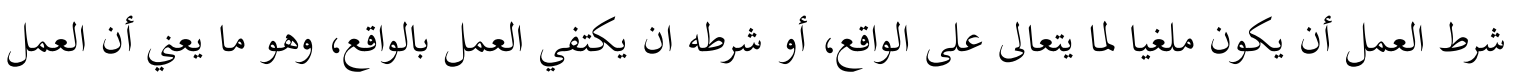
لن يكون غاية للعلم فيصبح مستندا إلى بجرد القوة. الهدف إذن في كل صحوة إسلامية ملتزمة بمعيار التصديق والهيمنة (أي قبول الحق من منظور الإسلام)، هو أن نحقق شروط الاجتهاد (العلم)، الذي يجعل الجهاد (العمل)، أمرا يكون متحررا مما آل إليه الحلان المضاعفان، أعني مجرد عقيدة عملية وبجرد قوة نظرية، كما في ثمرة هذه الحلول التي هي عين العولمة،

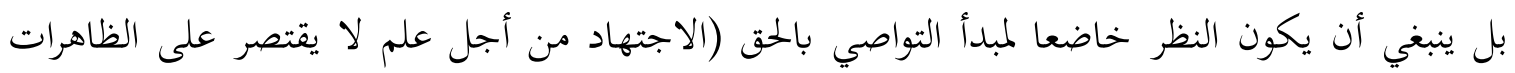

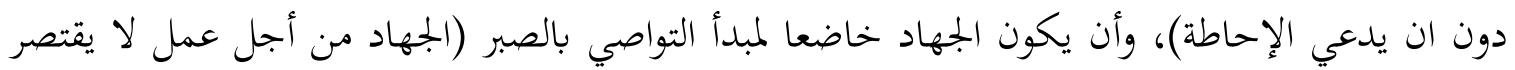
على العنف والقوة، دون أن يلغي اللجوء إليهما عند الضرورة، وهو معنى الصبر والحلم بديلا من الجاهلية التي هي نفي للحلم).

فكيف يمكن تصور حل للنظر يجمع بين حل أرسطو وحل كنط ويتعالى عليهما؟ وكيف يمكن تصور حل للعمل يجمع بين حل أفلاطون وهيجل ويتعالى عليهما؟ ذلك هو الهدف من كل فلسفة مقبلة تتخلص من الظن أن عهد الفلسفة انتهى، دون تحديد لنوع الفكر الفلسفي الذي انتهى. فكل القائلين بأن 
عهد الفلسفة قد انتهى، لم ينتهوا إلى هذا الموقف إلا من نفس المنطق الذي ظن أصحابه، أن بدايتها كانت

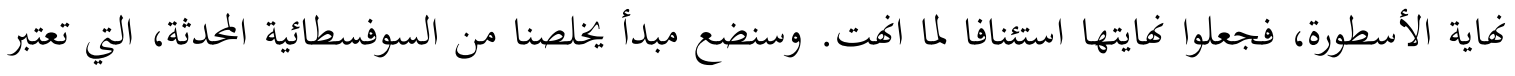
الفلسفة (نقد العلم للحد من الإطلاق النظري الموصل إلى التسيب العملي)، والدين (نقد العمل للحد من الاطلاق العملي الموصل إلى التسيب النظري) أمرين منتهيين.

فيكفي أن يقبل كل صاحب نظرية بوجوب اتصاف مقدماتها بنفس خصائص نتائجها المعرفية

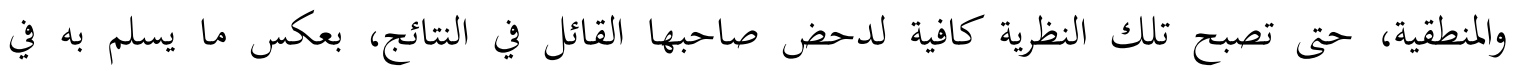
المقدمات. ومثال ذلك ما يقوله كنط عن العلم النظري: فإذا كان العلم النظري مقصورا على الظاهرات، فإن علمه بالنظر الذي هو ظاهرة، ينبغي أن يكون علما ظاهرا وليس علما حقيقيا، فيكون للعلم باطن غير ظاهره، وتكون كل النظرية الكنطية لاغية. فكيف يمكن إذن البناء عليه لعزل العمل عنه، وظنه مشروطا بالمقابلة بين الظاهر والباطن؟ ومثال ذلك كذلك ما يقوله هيجل عن العلم العملي: إذا كان المثال ليس غير

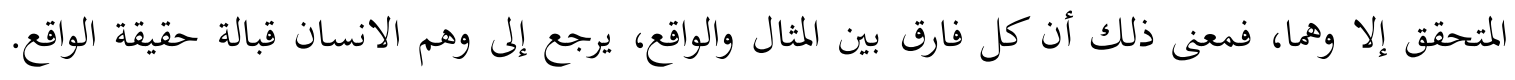

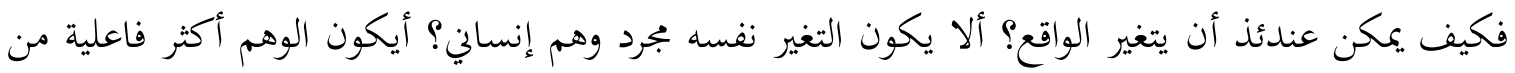

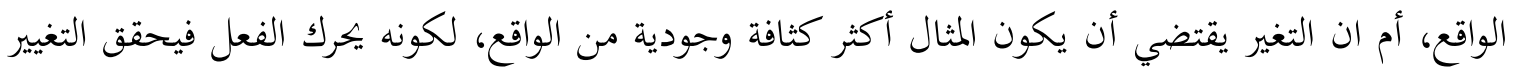

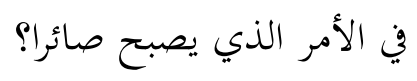

لذلك فالواقع المقصود عند هيجل ليس الحاصل في الخارج، كما هو في مدارك الناس العاديين، مهما

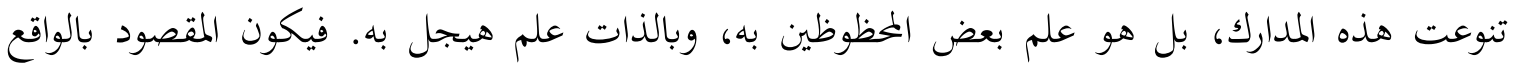

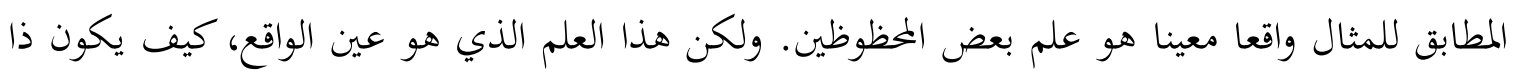
تاريخ، هو غير سخافة حركة التصورات في صيرورة بعضها، في علم هيجل، مهما زعم أن الحركة في العلم هي لهي

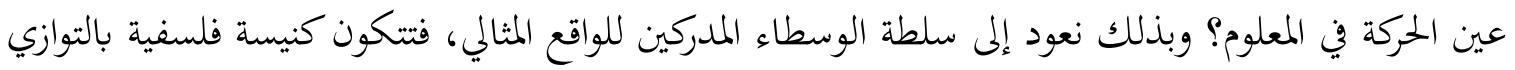

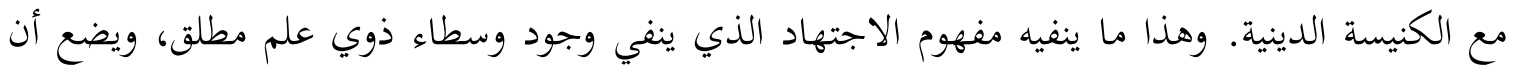

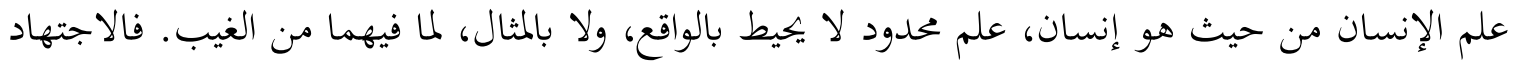

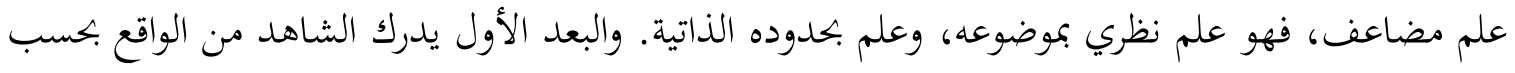
شروط شهوده المعرفية والخلقية. والبعد الثاني يدرك حدود تهرئ تحقق الشروط المعرفية والخلقية، فيحتاج إلى معيار

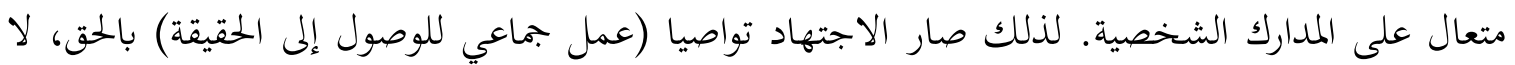
يتم من دون التواصي بالصبر (عمل جماعي للعمل بها). ونفس الأمر يقال عن العمل، لأن التواصي بالصبر هو العلة الحائلة دون نقيضه. فالإنسان يصل

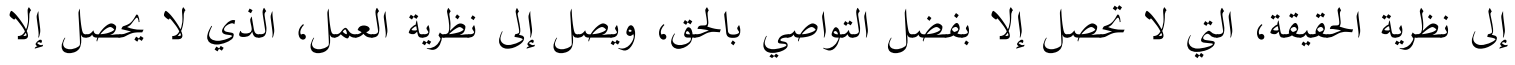


بفضل التواصي بالصبر. والعمل تواص بالصبر حتى تحصل ثمرة التواصي بالحق، إذ من دون التواصي بالصبر،

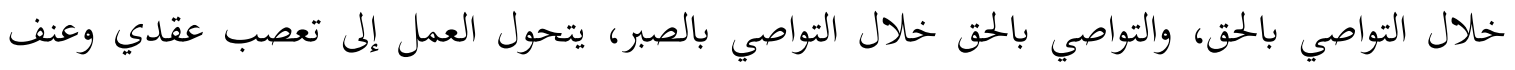

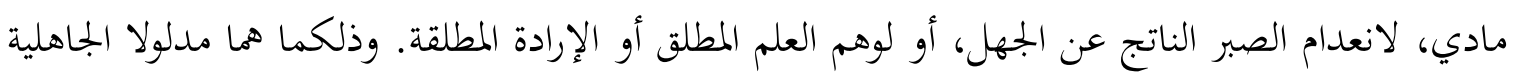
من حيث هي نقيض العلم (الجهل)، والحلم (العنف). فتكون نظرية العمل نظرية الشروط السلوكية والقيمية

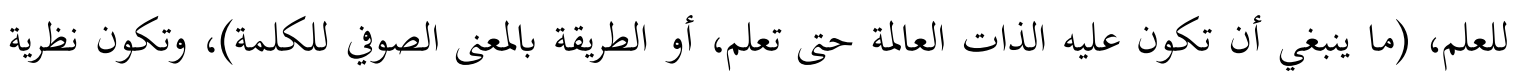

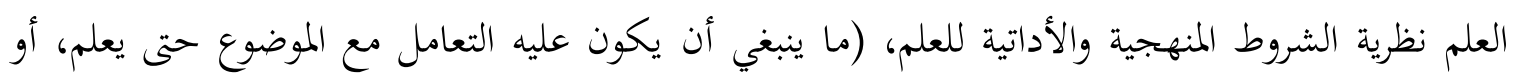

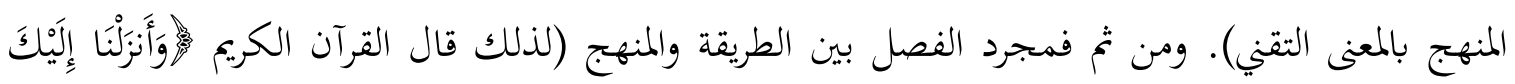

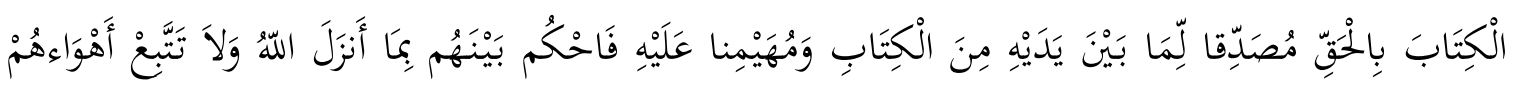

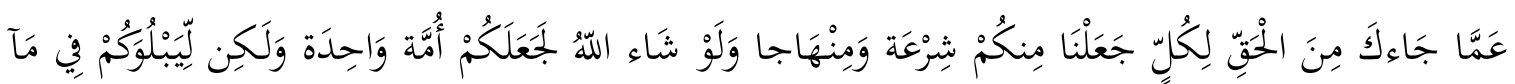

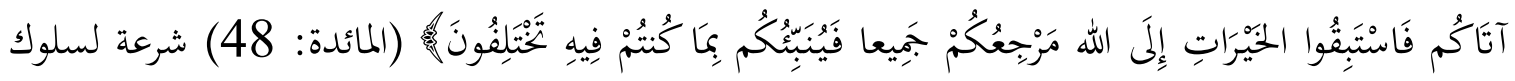

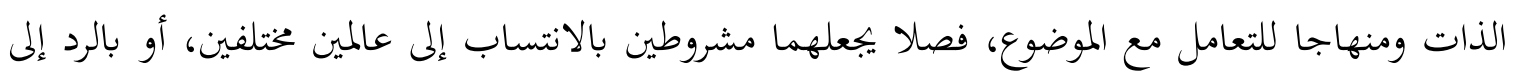

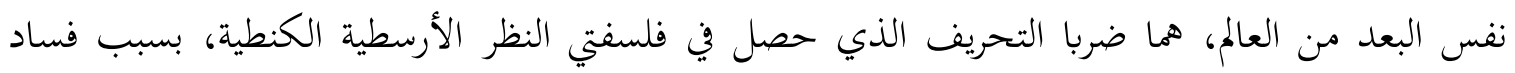

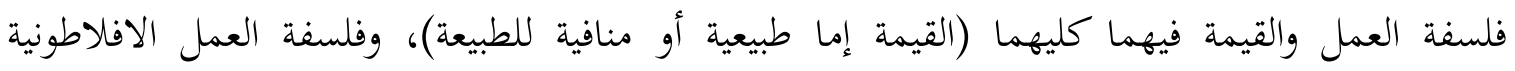
الهيجلية، بسبب فساد فلسفة النظر، والحقيقة فيهما كليهما (الحقيقة إما منافية للواقع أو عين الواقع). 